\title{
UNIVERSIDADE DE SÃO PAULO \\ ESCOLA DE ENFERMAGEM DE RIBEIRÃO PRETO DEPARTAMENTO DE ENFERMAGEM GERAL E ESPECIALIZADA
}

PERFIL DOS PACIENTES COM DIABETES MELLITUS QUE POSSUEM ÚLCERA NO PÉ, ATENDIDOS EM UNIDADE AMBULATORIAL DA CIDADE DE MARÍLIA- SP.

Elizabeth Pillon Scapim

Ribeirão Preto - SP 2004 


\section{ELIZABETH PILLON SCAPIM}

\section{PERFIL DOS PACIENTES COM DIABETES MELLITUS QUE POSSUEM ÚLCERA NO PÉ, ATENDIDOS EM UNIDADE AMBULATORIAL DA CIDADE DE MARÍLIA-SP.}

Dissertação apresentada ao Programa de PósGraduação da Escola de Enfermagem de Ribeirão Preto- Universidade de São Paulo. Área de concentração- Enfermagem Fundamental - para obtenção do Título de Mestre.

Linha de pesquisa: Processo de cuidar do adulto com doenças agudas e crônicodegenerativas.

Orientadora:

Prof $^{a}$ Dr $^{\mathrm{a}}$ Ana Emilia Pace

Ribeirão Preto -SP

2004 


\title{
ELIZABETH PILON SCAPIM
}

\author{
Marília -SP \\ Rua: Dr. Issamu Miura, 81 \\ Bairro: Jardim América
}

CEP: $17.506-470$

Fone: (14)3413-9382

Cel: 9723-4807

Email - bethpisc@ig.com.br

\section{Scapim, Elizabeth Pillon}

Perfil dos pacientes com diabetes mellitus que possuem úlcera no pé, atendidos em unidade ambulatorial da cidade de Marília-SP. Elizabeth Pillon Scapim - Ribeirão Preto: E. P. Scapim, 2004 128p.

Dissertação (Mestrado) - Escola de Enfermagem de Ribeirão Preto/USP - Departamento de Enfermagem Geral e Especializada.

Orientadora: Pace, Ana Emilia.

1.Pé Diabético, 2.Diabetes Mellitus, 3. Úlceras 
Data de Defesa:_14_/_05_/_2004_

\section{Banca Examinadora}

Prof $^{\mathrm{a}}$. Dra ${ }^{\mathrm{a}}$. Maria Helena Caliri Julgamento: Assinatura:

Prof ${ }^{\mathrm{a}}$. Dra ${ }^{\mathrm{a}}$. Maria Tereza Torquato Julgamento: Assinatura:

Prof ${ }^{a}$. Dr ${ }^{\mathrm{a}}$. Ana Emilia Pace Julgamento: Assinatura: 


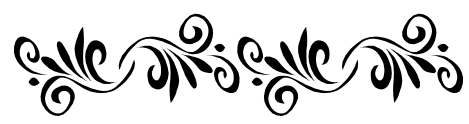

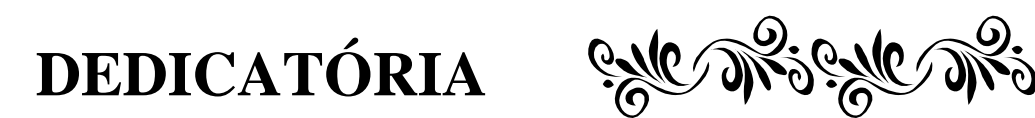


AOS MEUS PAIS Hélio Luiz e Maria Arlete, pelo exemplo de vida amor e compreensão,responsáveis pelo meu desenvolvimento humano por ser o que sou hoje, perdoe as minha ausência .

AO MEU ESPOSO Marcos, pelo carinho, compreensão, companheirismo, grande ajuda e incentivo que me proporcionou por todos estes anos de dificuldades e sacrifícios pelo qual passamos, se não fosse seu incentivo e amor não chegaria até aqui.

AOS MEUS QUERIDOS FILHOS Ramis Vitor, Grazielle e Bruna Laria que acabou de chegar para iluminar nosso lar, me perdoe pelas minhas ausências, mas o sacrifício é necessário para a renovação.

"As pessoas especiais, vieram para fazer nos compreender que o amor é o que faz a diferença na vida. Estas são as pessoas que realmente tornaram a minha vida mais bela"

AS MINHAS IRMÃS Cecília, Ana Maria, Maria Tereza, Lucia, Angela, Márcia, Sandra, Andréia (in memorian), Jackeline e Daniela, pelo incentivo, apoio e amizade nas horas que mais necessitei.

“As pessoas especiais são aquelas que têm a habilidade de dividir suas vidas com os outros.” 


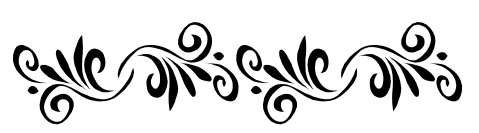

AGRADECIMENTO

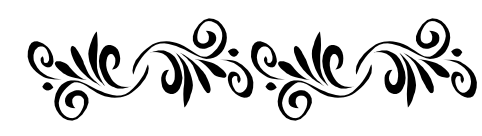




\section{A DEUS ACIMA DE TUDO}

Amo ao Senhor, porque ele ouviu a voz de minha súplica, porque inclinou para mim os seus ouvidos no dia em que o invoquei.

O Senhor é bom e justo, cheio de misericórdia é o nosso Deus.

O Senhor cuida dos corações simples; achava-me na miséria e Ele me salvou.

Na presença do Senhor continuarei o meu caminho na terra dos vivos.(Salmos 114).

Agradeço aos pacientes que participaram desta pesquisa, que Deus ilumine cada um de vocês .

À prof. ${ }^{a}$ Dr ${ }^{a}$ Ana Emilia Pace, minha orientadora, pela sugestão desta temática, atenção, dedicação e amizade no transcorrer destes anos.

À prof. ${ }^{a}$ Dr ${ }^{a}$ Miyeko Hayashida pelo auxílio carinhoso na construção do banco de dados.

À prof. ${ }^{a}$ Dr ${ }^{a}$ Maria Helena Caliri pelas ricas sugestões na qualificação e banca.

À prof. ${ }^{a}$ Dr ${ }^{a}$ Emilia Campos pela participação na qualificação e direcionamento da pesquisa.

À prof. ${ }^{\mathrm{a}}$ Dr ${ }^{\mathrm{a}}$ Maria Lucia Zanetti pelo seu apoio e incentivo na pesquisa.

À prof. ${ }^{a}$ Mestre Fernanda Cerântola Siqueira da Universidade de Marília, que me auxiliou com dedicação no projeto da pesquisa.

À prof. ${ }^{a}$ Dr ${ }^{a}$ Maria Inês Bocardi, da Universidade de Marília, que me apoiou na pesquisa e nas liberações.

À prof. ${ }^{a}$ Dr $^{\mathrm{a}}$ Maria José Sanches Marin, pelas sugestões, auxílio e incêntivo da pesquisa.

Ào prof. ${ }^{0}$ Dr $^{\circ}$ Pedro Marco Karan Barbosa, pelas sugestões, discussões, amizade e incentivo à pesquisa.

À Káttia Ochoa Vigo, pela disponibilidade, sugestões e incentivo dispensados durante a pesquisa. 
À Equipe de Residentes da Vascular do Ambulatório de Especialidades de Marília, Dr. Francisco, Dr.Valdinei, Dr. Carlos e Dr. Antonio Ricardo pelo auxílio e paciência durante minha coleta de dados.

À Equipe de Enfermagem do Ambulatório de Especialidades de Marília, Enf ${ }^{a}$ Shirley, Aux. Enf. Iolanda, Lucy, Ines, Roberto, Rita, Elaine, Sueli, Silvana, Rosalba e as alunas da faculdade de Enfermagem, Júlia e Maíta que com muito carinho me apoiaram e auxiliaram na coleta de dados.

À Faculdade de Medicina de Marília (FAMEMA) - Hospital das Clínicas de Marília, Diretoria Administrativa e Chefia de Enfermagem, que apoiou e concedeu as liberações necessárias.

Às Bibliotecárias Maria Tereza Pillon Ribeiro e Márcia Aparecida Pillon Dalóia que realizaram as correções necessárias das referências da pesquisa.

Às Prof ${ }^{a}$ de Português Maria Derci e Ana Maria Pillon Guimarães que realizaram as correções da pesquisa.

À Prof ${ }^{a}$ Dr $^{a}$ Sandra Cristina Pillon, pelo auxílio, valiosa dedicação, apoio e incentivo nas horas mais difíceis que passei nestes anos, com a sua experiência consegui chegar até aqui, Deus te abençoe por tudo o que fez, e que retribua muito mais, porque você merece.

Àos colegas de serviço da unidade de Urgência e Emergência Adulto do HCI, que me incentivaram nas horas difíceis, com palavras de carinho e conforto, para continuar nesta caminhada.

Às enfermeiras do $\mathbf{H C I}$, que de alguma forma me apoiaram e pela cobertura nas minhas ausências, Enf ${ }^{a}$ Fátima, Ana Lúcia, Selma, Patrícia, Sandra Camilo, Márcia Regina, Soeli, Haler e Enf ${ }^{\mathrm{a}}$ e Mestre Tânia Seabra.

Ao chefe do serviço de enfermagem, prof. $^{\circ}$ Dr $^{\circ}$ Pedro Marco Karan Barbosa, que me apoiou e incentivou durante a realização do mestrado, inclusive autorizando minha saída sem reposição.

As pessoas especiais são aquelas que gostam de estar próximo aos outros e se importam com a felicidade deles. 
Aos profissionais do NTI (Núcleo Técnico de Informática) do $\mathrm{HCl}$, Agnaldo e Edivânia, pela paciência na pesquisa dos dados, pelo apoio e orientações.

À Célia (Secretária) pelo preparo da aula de apresentação da dissertação, pela compreensão e carinho que dispensou.

Às colegas da sala de Leitura Lourdes e Deolinda, pelo apoio, confiança e dedicação que despenderam durante estes anos.

A todos que direta ou indiretamente tornaram a realização deste trabalho possível. 


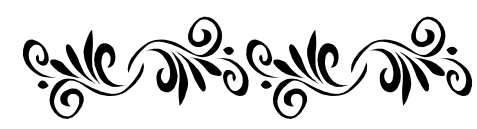




\section{LISTA DE TABELAS}

RESUMO

\section{ABSTRACT \\ RESUMEN \\ APRESENTAÇÃO}

1. INTRODUÇÃO.

1.1 Considerações sobre diabetes mellitus 05

1.2 Pé diabético 05

1.2.1 Neuropatia diabética. 13

1.2.2 Doença Vascular Periférica 15

1.2.3 Alterações Biomecânicas 19

1.2.4 Infecção 21

1.3 Considerações anatômicas do pé 22

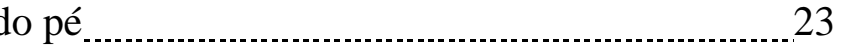

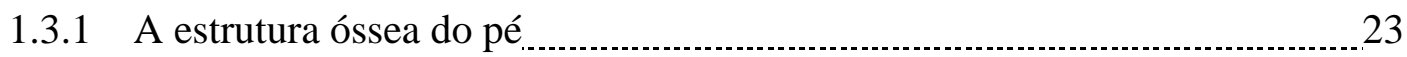

1.3.2 Sistema muscular da perna e do pé

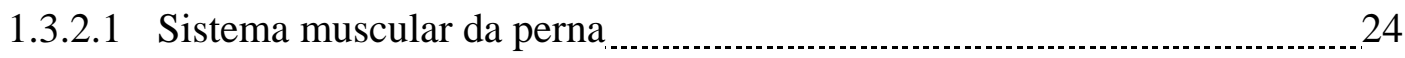

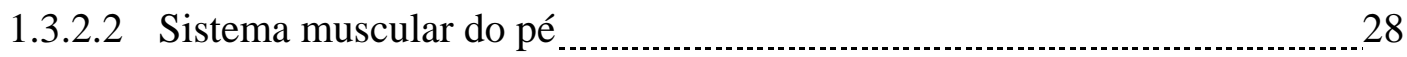

1.3.3 Sistema nervoso do pé

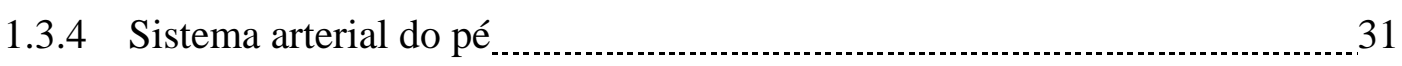

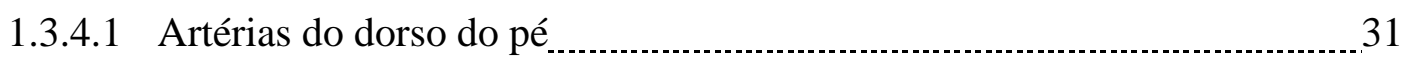

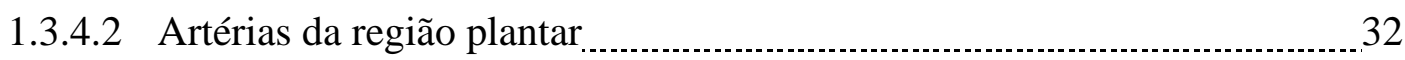

1.3.5 Sistema venoso do pé 32

1.4 Avaliação da função tegumentar

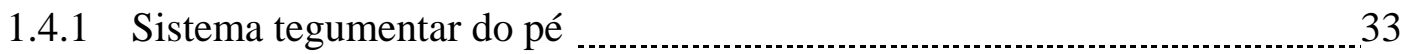

2. JUSTIFICATIVA

3. OBJETIVOS 
3.1 Objetivo geral _............ 44

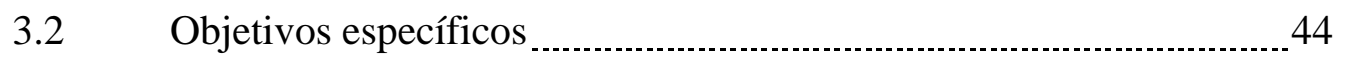

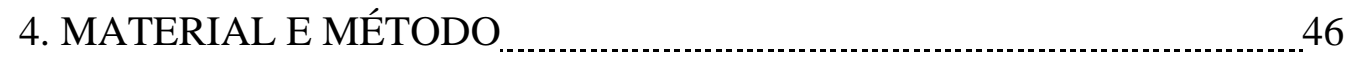

4.1 Delineamento do estudo

46

4.2 Local do estudo

46

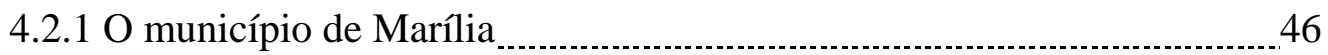

4.3 População base do estudo e amostra .............................................. 49

4.3.1 Critérios de inclusão

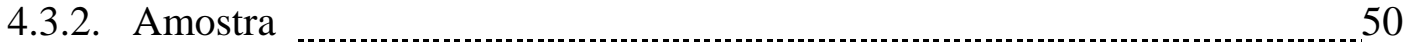

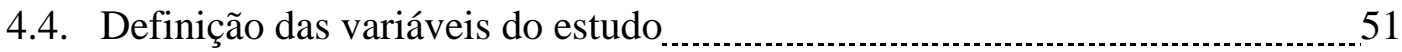

4.4.1. Variáveis sócio-demográficas e estilo de vida _....................................... 51

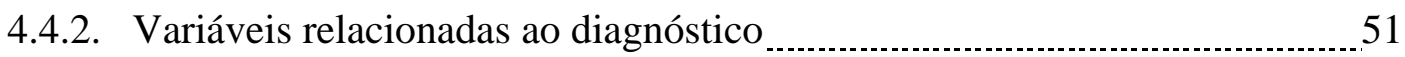

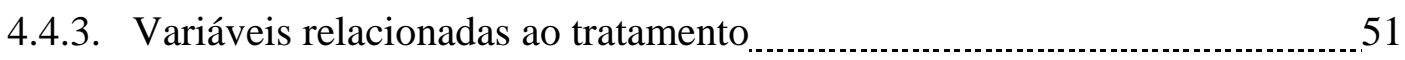

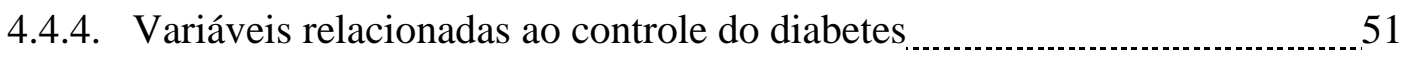

4.4.5. Variáveis relacionadas às complicações do diabetes e doenças

associadas

52

4.4.6. Variáveis relacionadas às condições clínicas dos pés _............................ 53

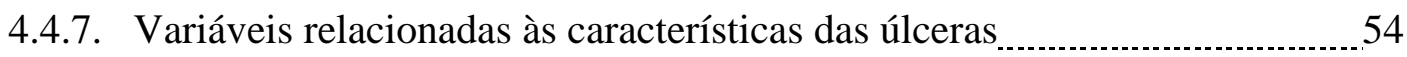

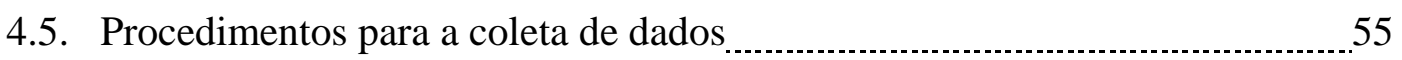

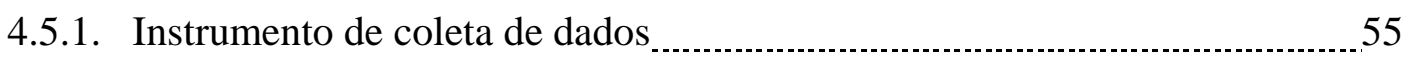

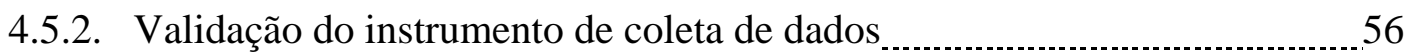

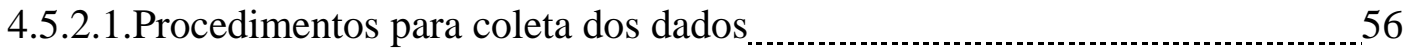

4.6. Processamento dos dados

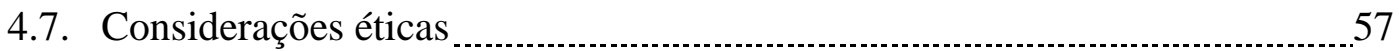




\section{RESULTADO}

5.1. Caracterização dos pacientes com DM e úlcera no pé, segundo as variáveis sócio - demográficas 59

5.1.1. Sexo, idade, escolaridade, estado civil e procedência 59

5.1.2. Tabagismo, etilismo e atividade física 61

5.2. Caracterização dos pacientes com DM e úlcera no pé, segundo as variáveis relacionadas ao diagnóstico, tratamento, condições clínicas dos pés, controle da doença e complicações 65

5.2.1. Diagnóstico e tratamento 65

5.2.2. Controle da doença $\ldots$

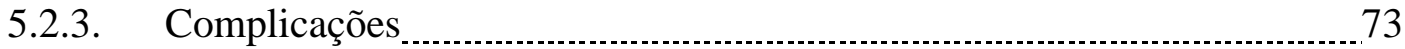

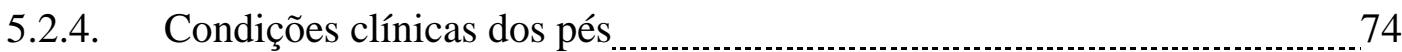

5.3. Caracterização dos pacientes com DM e úlcera no pé, segundo as variáveis relacionadas às características das úlceras 80

6. DISCUSSÃO 87

6.1. Caracterização das pessoas com DM e úlceras, segundo as variáveis sexo, idade

6.2. Caracterização das pessoas com DM e úlceras, segundo as variáveis relacionadas ao diagnóstico, tratamento, condições clínicas dos pés, controle do DM e complicações associadas 90

6.3. Caracterização dos pacientes com DM e úlcera no pé, segundo as variáveis relacionadas às características das úlceras 98 
Apresentação

7.1. Caracterização dos pacientes com DM e úlcera em pé, segundo as variáveis sócio-demográficas e estilo de vida 104

7.2. Caracterização dos pacientes com DM e úlcera em pé, segundo as variáveis relacionadas ao diagnóstico, tratamento, condições clínicas dos pés, controle da doença e complicações 105

7.3. Caracterização dos pacientes com DM e úlceras em pé, segundo as variáveis relacionadas às características das úlceras 106

8. CONSIDERAÇÕES FINAIS 109

9. REFERÊNCIA BIBLIOGRÁFICA 111

ANEXOS 123

Anexo I 123

Anexo II 126

Anexo III 127

Anexo IV 128 
Elizabeth Pillon Scapim

Apresentação

1

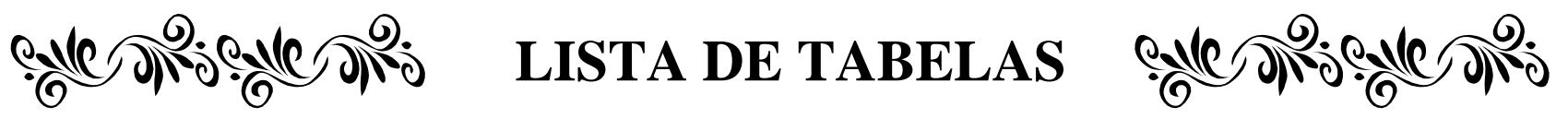


Apresentação

Tabela 1-Distribuição da população diabética atendida no ambulatório de Especialidades do Hospital das Clínicas de Marília, no ano de 2002 segundo faixa etária e sexo.Marília-SP, 2002.

Tabela 2- Distribuição da população diabética com úlceras no pé, atendidas na especialidade de cirurgia vascular do Ambulatório de Especialidades do Hospital das clínicas de Marília, no ano de 2002 segundo faixa etária e sexo . Marília- SP, 2002.

Tabela 3-Parâmetros bioquímicos e critérios de controle metabólico, segundo Consenso Brasileiro de Condutas para o Diabetes Mellitus - SBD, 2001.

Tabela 4-Índice de normalidade da hemoglobina glicosilada, segundo a Associação Latino Americana, 2002 .

Tabela 5 - Distribuição das pessoas com DM e úlcera no pé, segundo idade (anos) e sexo. Marília, 2003.

Tabela 6 - Distribuição dos pacientes com DM e úlcera no pé, segundo o grau de instrução. Marília, 2003.

Tabela 7 - Distribuição das pessoas com DM e úlcera no pé, segundo o estado civil. Marília, 2003.

Tabela 8 - Distribuição das pessoas com DM e úlcera no pé, segundo tabagismo. Marília, 2003.

Tabela 9 - Distribuição das pessoas com DM e úlcera no pé, segundo o tempo de tabagismo. Marília, 2003.

Tabela 10 - Distribuição das pessoas com DM e úlcera no pé, segundo o tempo em que pararam de fumar em anos. Marília, 2003.

Tabela 11 - Distribuição das pessoas com DM e úlcera no pé, segundo o etilismo. Marília, 2003.

Tabela 12 - Distribuição das pessoas com DM e úlcera no pé, segundo o tempo de etilismo. Marília, 2003.

Tabela 13 - Distribuição das pessoas com DM e úlcera no pé, segundo o tipo de bebida ingerida. Marília, 2003. 
Tabela 14 - Distribuição das pessoas com DM e úlcera no pé, segundo a freqüência de uso da bebida. Marília, 2003.

Tabela 15 - Distribuição das pessoas com DM e úlcera no pé, segundo a prática de atividade física. Marília, 2003.

Tabela 16 - Distribuição das pessoas com DM e úlcera no pé, segundo a freqüência da atividade física. Marília, 2003.

Tabela 17 - Distribuição das pessoas com DM e úlcera no pé, segundo o tempo de diagnóstico. Marília, 2003.

Tabela 18 - Distribuição das pessoas com DM e úlcera no pé, segundo o tipo de tratamento medicamentoso e não medicamentoso. Marília, 2003.

Tabela 19 - Distribuição das pessoas com DM e úlcera no pé, segundo o tempo de tratamento do diabetes. Marília, 2003.

Tabela 20 - Distribuição das pessoas com DM e úlcera no pé, segundo o Índice de Pressão arterial, Marília, 2003.

Tabela 21 - Distribuição das pessoas com DM e úlcera no pé, segundo o Índice de Massa Corpórea (IMC) Marília, 2003.

Tabela 22 - Distribuição das pessoas com DM e úlcera no pé, segundo o número de exames de glicemia de jejum, Marília, 2003.

Tabela 23 - Distribuição das pessoas com DM e úlcera no pé, segundo os níveis glicêmicos de jejum, Marília, 2003.

Tabela 24 - Distribuição das pessoas com DM e úlcera no pé, segundo o número de exames de hemoglobina glicosilada por ano, Marília, 2003.

Tabela 25 - Distribuição das pessoas com DM e úlcera no pé, segundo os níveis de hemoglobina glicosilada, Marília, 2003.

Tabela 26 - Distribuição das pessoas com DM e úlcera no pé, segundo o número de exames de colesterol, Marília, 2003.

Tabela 27 - Distribuição das pessoas com DM e úlcera no pé, segundo os níveis de colesterol, Marília, 2003.

Tabela 28 - Distribuição das pessoas com DM e úlcera no pé, segundo número de exames de triglicérides, Marília, 2003. 
Tabela 29- Distribuição das pessoas com DM e úlcera no pé, segundo os níveis de triglicérides, Marília, 2003.

Tabela 30 - Distribuição das pessoas com DM e úlcera no pé, segundo o número de exames de HDL, Marília, 2003.

Tabela 31 - Distribuição das pessoas com DM e úlcera no pé, segundo os níveis de HDL, Marília, 2003.

Tabela 32 - Distribuição das pessoas com DM e úlcera no pé, segundo o número de exames de LDL, Marília, 2003.

Tabela 33 - Distribuição das pessoas com DM e úlcera no pé, segundo os níveis de LDL, Marília, 2003.

Tabela 34 - Distribuição das pessoas com DM e úlcera no pé, segundo as complicações crônicas do DM, registradas nos prontuários. Marília, 2003.

Tabela 35 - Distribuição das pessoas com DM e úlcera no pé, segundo as doenças associadas. Marília, 2003.

Tabela 36 - Distribuição das pessoas com DM e úlcera no pé, segundo a mobilidade física Marília, 2003.

Tabela 37 - Distribuição das pessoas com DM e úlcera no pé, segundo as amputações Marília, 2003.

Tabela 38 - Distribuição das pessoas com DM e úlcera no pé, segundo as úlceras anteriores Marília, 2003.

Tabela 39 - Distribuição das pessoas com DM e úlcera no pé, segundo a avaliação da pele e fâneros do pé diabético, Marília, 2003.

Tabela 40 - Distribuição das pessoas com DM e úlcera no pé, segundo a avaliação do corte de unhas, tipo de calçados e meias. Marília, 2003.

Tabela 41 - Distribuição das pessoas com DM e úlcera no pé, segundo avaliação estrutural do pé, Marília, 2003.

Tabela 42 - Distribuição das pessoas com DM e úlcera no pé, segundo a presença de edema dos pés. Marília, 2003.

Tabela 43. Distribuição das pessoas com DM e úlcera no pé, segundo a avaliação vascular dos pés. Marília, 2003. 
Tabela 44 - Distribuição das pessoas com DM e úlcera no pé, segundo a temperatura dos pés à palpação Marília, 2003.

Tabela 45 - Distribuição das pessoas com DM e úlcera no pé, segundo a avaliação dos pulsos nos pés dos portadores de diabetes Marília, 2003.

Tabela 46 - Distribuição das pessoas com DM e úlcera no pé, segundo a avaliação dos pulsos no pé onde se localiza a úlcera dos portadores de diabetes Marília, 2003.

Tabela 47 - Distribuição dos pacientes portadores de diabetes mellitus com úlcera no pé, segundo a avaliação da sensibilidade da região dorsal e plantar nos pés Marília, 2003.

Tabela 48- Distribuição das pessoas com DM e úlceras nos pés, segundo as causas das úlceras, Marília, 2003.

Tabela 49 - Distribuição das pessoas com DM e úlceras nos pés, segundo o tempo das úlceras, Marília,2003.

Tabela 50 - Distribuição das pessoas com DM e úlceras nos pés, segundo a localização das úlceras, Marília, 2003.

Tabela 51 - Distribuição das pessoas com DM e úlceras nos pés, segundo o tamanho das úlceras, Marília, 2003.

Tabela 52 - Distribuição das pessoas com DM e úlceras nos pés, segundo a coloração do leito das úlceras, Marília, 2003.

Tabela 53 - Distribuição das pessoas com DM e úlceras nos pés, segundo o exsudato das úlceras, Marília, 2003.

Tabela 54 - Distribuição das pessoas com DM e úlceras nos pés, segundo referência de dor nas úlceras Marília, 2003.

Tabela 55 - Distribuição das pessoas com DM e úlceras nos pés, segundo ao odor nas úlceras Marília, 2003.

Tabela 56 - Distribuição das pessoas com DM e úlceras nos pés, segundo o tratamento das úlceras Marília, 2003.

Tabela 57 - Distribuição das pessoas com DM e úlceras nos pés, segundo o estágio das úlceras Marília, 2003. 
Elizabeth Pillon Scapim

1

Apresentação

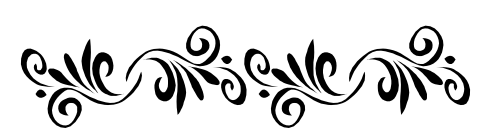

RESUMO

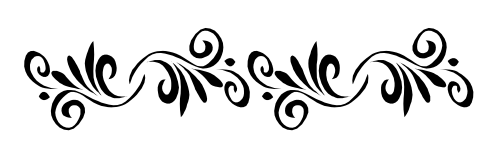


Apresentação

\section{RESUMO}

SCAPIM, P. E. Perfil dos pacientes com diabetes mellitus que possuem úlcera no pé, atendidos em unidade ambulatorial da cidade de Marília-SP. Ribeirão Preto. 2004.128p. Dissertação (Mestrado) - Escola de Enfermagem, Universidade de São Paulo.

Estudo descritivo cujo objetivo foi traçar o perfil dos pacientes com diabetes mellitus (DM) que possuem úlcera no pé, atendidos no Ambulatório de Especialidades Mario Covas de Marília-SP. A amostra foi constituída por 60 pacientes atendidos no período de agosto a setembro de 2003. Para coleta de dados utilizou-se entrevista, consulta ao prontuário e avaliação dos pés. Os resultados mostraram maior freqüência no sexo masculino (51,7\%), destacando a faixa etária de 50 a 70 anos (64,4\%). Em relação ao tipo de diabetes, 95\% eram do tipo 2; o tempo médio referido do diagnóstico foi de 12,6 anos e do tratamento 12,1 anos; $63 \%$ referiram realizar dieta, 56,7\% faziam uso de antidiabético oral e 61,7\% de insulina. Considerando os parâmetros de controle do diabetes, 79,6\% apresentavam mau controle glicêmico e 56,6\% sobrepeso. As complicações crônicas mais freqüentes foram retinopatia (31,7\%) e pé diabético associado à doença vascular periférica ( $31,7 \%)$. Todos apresentavam hipertensão arterial e em 26,6\% estava associada à obstrução arterial crônica. O diagnóstico de obstrução arterial crônica estava presente em 51,7\% dos pacientes. Na avaliação dos pés, 53,3\% deambulavam; 55\% possuíam alteração na marcha; 55\% amputação prévia; 48\% história de úlceras anteriores; 65\% corte de unhas inadequado; 31,7\% dedos em garra; 23,3\% dedos sobrepostos; 18,3\% proeminência do primeiro metatarso; 45\% usavam sapatos e meias inadequados. Na avaliação circulatória identificou-se entre os pacientes, pulsos não palpáveis em $27 \%$ do tibial posterior direito e $23 \%$ do esquerdo; em $26 \%$ do pedioso direito e $21 \%$ do esquerdo; $35 \%$ possuíam edema; $45 \%$ rubor na pendência e empalidecimento à elevação; a sensibilidade tátil pressórica estava ausente em 38,3\% dos pacientes. Quanto as características das úlceras, 36,6\% relataram como causa de maior freqüência bolha infectada e 26,6\% trauma mecânico; a localização mais freqüente foi na região plantar (23,3\%) e nos dedos (21,7\%); o tempo médio das 
úlceras foi de 0,9 anos; dimensões de 1 a $10 \mathrm{~cm}^{2}$ (65\%); 41,7\% das úlceras possuíam leito de cor vermelha; 53,3\% exsudato4 seroso; 38,3\% dor moderada; 58,3\% odor discreto e 46,7\% grau 2 segundo a classificação de Wagner. O tratamento mais referido para as úlceras foi soro fisiológico e óleo de girassol (81,7\% ).Os resultados deste estudo mostraram a gravidade das complicações relacionadas aos pés dos pacientes com diabetes, destacando a história de úlcera e amputação anterior, complicações vasculares e neuropatia como importante fatores de risco para as lesões em pés e trauma extrínseco como principal desencadeante destas lesões, reiterando que intervenções básicas podem contribuir para a sua redução. Apontaram também para a necessidade de elaboração de um protocolo de atendimento; com ênfase no processo educativo junto a pessoa, familiares e profissionais, visando uma maior adesão ao tratamento e controle do DM bem como intensificando medidas preventivas no cuidado aos pés. 
Elizabeth Pillon Scapim

1

Apresentação

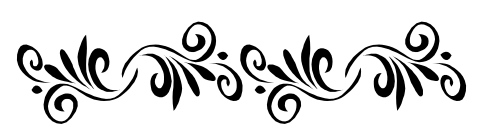

ABSTRACT

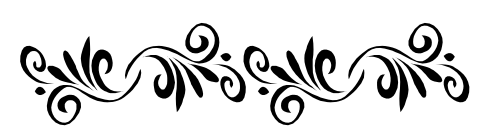


Apresentação

\begin{abstract}
SCAPIM, P.E. Profile of diabetes mellitus patients with foot ulcers, attended at a clinic in Marília-SP, Brazil. Ribeirão Preto. 2004. 128p. Master’s Dissertation University of São Paulo at Ribeirão Preto College of Nursing.
\end{abstract}

This descriptive study aimed to establish the profile of diabetes mellitus (DM) patients with foot ulcers, attended at the Ambulatório de Especialidades Mario Covas in Marília-SP, Brazil. The sample consisted of 60 patients, attended in August and September 2003. Data were collected by means of interviews, patient files and foot evaluation. Research results disclosed higher frequency among men (51.7\%), especially in the age range from 50 to 70 years (64.4\%). 95\% of the patients suffered from type 2 diabetes; average reported diagnosis time was 12.6 years and average reported treatment time 12.1 years. $63.3 \%$ mentioned a diet, $56.7 \%$ took oral antidiabetic drugs and $61.7 \%$ took insuline. In view of diabetes control parameters, $79.6 \%$ of the patients demonstrated bad glycemic control and 56.6\% were overweight. The most frequent chronic complications were retinopathy (31.7\%) and diabetic foot associated with peripheric vascular disease (31.7\%). All patients demonstrated arterial hypertension, associated with chronic arterial obstruction in $26.6 \%$ of the cases. The chronic arterial obstruction diagnosis applied to $51.7 \%$ of the patients. With respect to foot evaluation, 53.3\% of all patients displayed instability; 55\% claudication; 55\% previous amputation; 48\% ulcer antecedents; $65 \%$ inappropriate nail cutting; $31.7 \%$ claw toes; $23.3 \%$ hammer toes; $18.3 \%$ prominence of the metatarsus and $45 \%$ used inadequate shoes and socks. During circulatory evaluation, pulse could not be palpated in $27 \%$ of the right posterior tibial and $23 \%$ of the left one; in $26.6 \%$ of the right pedal and $21 \%$ of the left one; $35 \%$ of the patients had edema; $45 \%$ dependent redness and blanching on elevation; tactile sensitivity to pressure was absent in $38.3 \%$ of the patients. With respect to ulcer characteristics, $36.6 \%$ mentioned an infected blister as the most frequent cause and $26.6 \%$ a mechanical trauma; the most frequent locations were the plantar (23.3\%) and toe (21.7\%) region; average ulceration time was 0.9 years, dimensions ranged from 1 to $10 \mathrm{~cm}^{2} ; 41.7 \%$ of the ulcers involved redness, $53.3 \%$ serous discharge; 
38.3\% moderate pain; 58.3\% discrete smell and 46.7\% Wagner classification level 2. The most frequently mentioned treatment for ulcers was physiological serum and sunflower oil (81.7\%). Study results displayed the seriousness of complications related to diabetic foot, highlighting ulcer antecedents and previous amputation, vascular complications and neuropathy as important risk factors for foot injuries and extrinsic trauma as the main factor leading to this kind of injury, reiterating that basic interventions can contribute to its reduction. Results also indicated the need to elaborate a care protocol, emphasizing the education of patients, family members and professionals with a view to greater treatment adhesion and control of DM, as well as intensifying preventive measures in foot care. 
Elizabeth Pillon Scapim

1

Apresentação

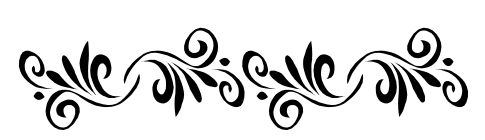

RESUMEN

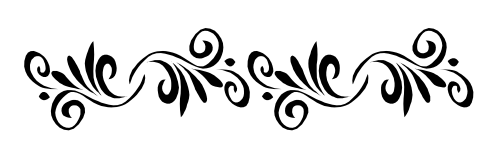


Apresentação

\section{RESUMEN}

SCAPIM, P.E. Perfil de pacientes con diabetes mellitus que tienen úlcera de pie, atendidos en unidad clínica de Marília-SP, Brasil. Ribeirão Preto. 2004128 dissertación (Maestría) - Escuela de Enfermería, Universidad de SãoPaulo.

La finalidad de este estudio descriptivo fue la de delinear el perfil de los pacientes con diabetes mellitus (DM) que tienen úlcera de pie, atendidos en la Clínica de Especialidades Mario Covas de Marília-SP, Brasil. La muestra fue constituida por 60 pacientes, atendidos entra agosto y septiembre de 2003. Para la colección de datos, utilizamos entrevista, consulta a las fichas de pacientes y evaluación de los pies. Los resultados mostraron mayor frecuencia en el sexo masculino (51,7\%), resaltando el grupo con edad entre 50 y 70 años (64,4\%). Con respecto al tipo de diabetes, 95\% de los pacientes eran del tipo 2; el tiempo medio del diagnóstico fue 12,6 años y del tratamiento fue 12,1 años; $63,3 \%$ de los pacientes mencionaron dieta, 56,6\% usaban antidiabético oral y 61,7\% usaban insulina. Considerando los parámetros de control para diabetes, 79,6\% presentaban control glicémico incorrecto y 56,6\% sobrepeso. Las complicaciones crónicas más frecuentes fueron retinopatía $(31,4 \%)$ y pie diabético asociado a enfermedad vascular periférica (31,7\%). Todos los pacientes demostraron hipertensión arterial y en 26,6\%, estaba asociada a obstrucción arterial crónica. El diagnóstico de obstrucción arterial crónica estaba presente en 51,75\% de los pacientes. En la evaluación de los pies, 53,3\% manifestaban inestabilidad; 55\% marcha anormal, 55\% amputación previa, 48\% antecedentes de úlceras; 65\% mal cortado de las uñas; $31,7 \%$ dedo en garra; $23,3 \%$ dedo en martillo; $18,3 \%$ prominencia del primer metatarso; 45\% utilizaban zapatos y calcetines inadecuados. En la evaluación circulatoria, fueron identificados entre los pacientes pulsos no palpables en $27 \%$ del tibial posterior derecho y 23\% del izquierdo; en 26,6\% del pedio derecho y 21\% del izquierdo; 35\% poseían edema; 45\% rubor de pendencia y blanqueamiento en elevación; no ocurría sensibilidad táctil a la presión en 38,8\% de los pacientes. Con respecto a las características de las úlceras, 36,6\% mencionaron como causa más frecuente ampolla infectada, 26,6\% trauma mecánico; la localización más frecuente fue en la región plantar $(23,3 \%)$ y en los 
dedos (21,7\%); el tiempo medio de las úlceras fue 0,9 años; dimensiones entre 1 y 10 $\mathrm{cm}^{2}$ (65\%); 41,7\% de las úlceras poseían fondo rojo; 53,3\% líquido seroso; 38,3\% dolor moderado; 58,3\% olor discreto y 46,7\% grado 2 según la clasificación de Wagner. El tratamiento más relatado para las úlceras fue soro fisiológico y aceite de girasol (81,7\%). Los resultados de este estudio demostraron la gravedad de las complicaciones relacionadas a pie diabético, destacando antecedentes de úlcera y amputación previa, complicaciones vasculares y neuropatía como importantes factores de riesgo para las lesiones del pie y trauma extrínseco como principal desencadenante de estas lesiones, reiterando que intervenciones básicas pueden contribuir a su reducción. También indicaron la necesidad de elaborar un protocolo de atención, realzando el proceso educativo ante los pacientes, familiares y profesionales con vistas a mayor adhesión al tratamiento y control del DM y también intensificando medidas preventivas en el cuidado del pie. 


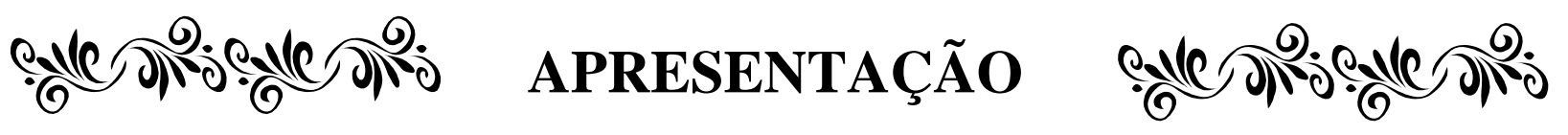




\section{$\mathrm{E}$}

ste estudo é fruto das minhas vivências e reflexões quanto à questão da saúde dos pacientes portadores de diabetes mellitus com complicações nos pés.

Concluí o curso de graduação em Enfermagem e Obstetrícia em dezembro de 1986 pela Escola de Enfermagem da Fundação Municipal de Ensino Superior de Marília (FAMEMA). Durante a graduação, o tema diabetes mellitus despertou-me muito a atenção pelo grande número de pessoas que atendíamos com esse diagnóstico.

Atuando como enfermeira, inquietavam-me muito as complicações do diabetes já estabelecidas, muitas vezes com danos e comprometimentos físicos e psicológicos, devido a poucas informações, baixa adesão ao tratamento e a não aceitação da patologia.

No decorrer da carreira profissional, administrei aulas para o Ensino Técnico de Enfermagem e as inquietações aumentavam quando entrava em contato com pacientes portadores de diabetes mellitus com complicações crônicas, em particular as lesões nos pés e amputações, as quais podem ser prevenidas por meio de intervenções básicas e educativas.

Posteriormente, atuando como docente junto à Graduação de Enfermagem e na área de conhecimento, intensifiquei as observações e orientações aos pacientes portadores de diabetes mellitus com úlceras nos pés. Reconheci que nem todas as instituições proporcionam tratamento específico para esses pacientes. Geralmente são atendidos no ambulatório de especialidade vascular, quando possuem um comprometimento, e não existe um controle do nível dos exames, principalmente da glicemia.Observei também que a equipe multidisciplinar não estava completa, conforme a literatura recomendada, ou seja, um endocrinologista, um vascular, um enfermeiro, um psicólogo, um nutricionista e às vezes até um ortopedista. Apesar dessa equipe estar incompleta, iniciei o trabalho junto a esses pacientes em janeiro de 2000, desenvolvendo ações educativas e cuidados com as úlceras, visando à prevenção e/ou minimização das complicações em extremidades de membros inferiores.

Inicialmente avaliei o perfil da população diabética atendida no ambulatório do Hospital das Clínicas de Marília com suas variáveis sócio- econômicas e estilo de vida, como sexo, idade, escolaridade, estado civil, ocupação, procedência, tabagismo, 
Apresentação

etilismo e atividade física, tempo do diagnóstico, tipo de diabetes, tempo e tipo de tratamento; complicações relacionadas ao diabetes, o controle metabólico, as características das úlceras, (a causa, o tempo, a localização, o tamanho, o tratamento realizado, bem como seu estágio), foi feita ainda avaliação dos membros inferiores, como alterações da marcha, mobilidade, úlceras anteriores, higienização do pés, edema, temperatura, deformidades nos pés, nos dedos e nas unhas, o corte das unhas, adequação ou não do tipo de meia e sapato usados, dos pulsos e da sensibilidade tátil pressórica. Conhecendo-se o perfil da população em foco, a realização de projetos para a melhoria do atendimento e da assistência de enfermagem aos portadores de diabetes mellitus e com úlceras nos pés será, certamente, melhor viabilizada. 


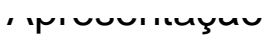

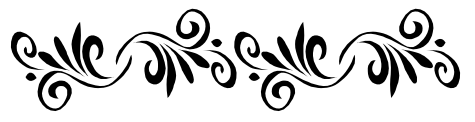

INTRODUÇÃO

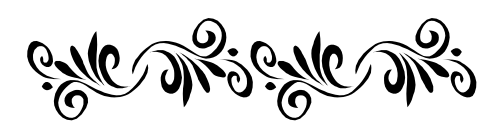




\subsection{Considerações sobre Diabetes Mellitus}

American Diabetes Association-ADA, (2001) define o Diabetes Mellitus
como um grupo de doenças metabólicas caracterizadas por hiperglicemia,
resultante de defeitos na secreção de insulina, na ação da insulina ou em ambos. Também considera que a hiperglicemia, a longo prazo, leva à falência de vários órgãos como os olhos, rins, nervos, coração e vasos sangüíneos.

Diversas tentativas de classificação do Diabetes Mellitus têm sido propostas, baseadas no peso corpóreo, na idade, etiologia, evolução e no tratamento indicado (OMS, 1994).

Os termos diabetes mellitus insulino-dependente e diabetes mellitus nãoinsulino-dependente e suas siglas não são mais usados, devido à confusão que realizavam, classificando todos os indivíduos que recebiam insulina, como tendo diabetes mellitus insulino-dependente. Os termos usados agora são diabetes tipo1 e diabetes tipo 2 (Davidson, 2001).

Devido ao avanço tecnológico e novos conhecimentos sobre a patogenia e a etiologia das várias categorias do diabetes, tanto o Expert Committee on the Diagnosis and Classification e Association of Diabetes (constituído pela American Diabetes Association) como a WHO propuseram nova classificação do diabetes e dos distúrbios, que se apresenta abaixo (Committee Report, 2001):

I. Diabetes tipo 1

II. Diabetes tipo 2

III. Outros tipos específicos

a. Defeitos genéticos da célula

b. Defeitos genéticos da ação da insulina

c. Doenças do pâncreas exócrino

d. Endocrinopatias 
e. Induzido por drogas ou substâncias químicas

f. Infecções

g. Formas incomuns de diabetes imuno imediato

h. Outras síndromes genéticas associadas ao diabetes

IV. Diabetes mellitus gestacional

O diabetes tipo 1 é um processo patológico em particular, caracterizado pela destruição imunológica das células beta de indivíduos geneticamente suscetíveis. Desenvolve-se na infância, manifestando-se na puberdade e adulto jovem e o paciente necessita de insulina para sua sobrevida; pode aparecer também a qualquer idade. $\mathrm{O}$ início do quadro clínico é abrupto, com tendência a cetoacidose e há absoluta dependência de insulina exógena. Corresponde a cerca de 5\% do total de casos de Diabetes Mellitus (OMS, 1994; Sociedade Brasileira de Diabetes, 2000).

O diabetes tipo 2 é uma condição em que os indivíduos não dependem da administração de insulina exógena para a sua sobrevivência. Varia desde a resistência da insulina com deficiência a um defeito secretório, com ou sem resistência de insulina; manifesta-se freqüentemente na maturidade, tem evolução lenta e os indivíduos geralmente são obesos. A maioria dos pacientes pode ser tratado somente com dieta e antidiabéticos orais. Porém, em condições de estresse e com o decorrer dos anos, a administração de insulina pode ser necessária para se obter bom controle metabólico. No início, pode apresentar-se assintomático, permanecendo assim por muitos anos. Corresponde a cerca de 90\% dos casos de Diabetes Mellitus (Sociedade Brasileira de Diabetes, 1997; Sociedade Brasileira de Diabetes, 2000; Sociedade Brasileira de Diabetes 2001; Associação Americana de Diabetes, 2001).

Sabe-se que o diabetes mellitus é uma das principais doenças crônicas da atualidade sendo altos os custos para seu controle e tratamento de suas complicações. Tem afetado a qualidade de vida e diminuído a vida produtiva, decorrente da morte precoce (Brasil, 1993; OMS, 1994; Sociedade Brasileira de Diabetes, 1997; Sociedade Brasileira de Diabetes, 2000), devido a sua alta prevalência e elevada taxa de mortalidade (Chacra, et al, 1996). 
A prevalência do diabetes mellitus, na maioria dos países, varia de $2 \%$ a $5 \%$ da população adulta (Brasil, 1993; Foss, 2000). Nos Estados Unidos, afeta aproximadamente 6\% da população (Davidson, 2001).

No Brasil, a taxa de prevalência do diabetes mellitus é de 7,6\%, verificada por meio de um estudo multicêntrico, realizado em nove capitais brasileiras no período de 1986 a 1988, numa população com idade entre 30 e 69 anos, confirmando a necessidade de apoio e programas de saúde voltados para essa patologia (Brasil, 1993; Ministério da Saúde, 1996; Franco, 1998).

O diabetes mellitus vem se sobressaindo, nas últimas décadas, entre as doenças crônicas pelos índices elevados de morbidade e mortalidade em decorrência de vários fatores, como industrialização, maior taxa de urbanização, sedentarismo, aumento da expectativa de vida, obesidade e dietas hipercalóricas (Franco, 1988; Brasil, 1993; Franco, 1998; Sociedade Brasileira de Diabetes, 1997, Lessa, 1996).

Torquato et al (2003), relatam em um estudo na cidade de Ribeirão Preto, sobre diabetes mellitus a prevalência foi de 12,1 \%, comparado com o que tem sido relatado em outros países e confirmando assim os fatores que contribuíram para isto, como a industrialização, urbanização e outros.

Segundo OMS (1994) os maiores salários e o tipo de vida, que tomaram lugar nos países em desenvolvimento e nos recentemente industrializados, levaram a aumentos significativos na incidência e prevalência do diabetes mellitus tipo 2. E ainda enfatiza, que muitas populações são susceptíveis a contrair diabetes, em conseqüência da modernização e ocidentalização dos hábitos de vida, a prevalência da enfermidade tem alcançado níveis muito altos.

Embora o diabetes mellitus esteja presente em quase todas as populações do mundo, a incidência e prevalência do tipo 1 e tipo 2, assim como a distribuição relativa dos dois tipos principais desta enfermidade, apresentam grandes diferenças entre os países e entre os grupos étnicos dentro dos países (OMS, 1994).

A população brasileira é bastante afetada pelo diabetes mellitus, que ocasiona grande número de mortes prematuras e invalidez precoce com a diminuição da expectativa e da qualidade de vida, bem como da força de trabalho (Foss, 2000).

Como, por definição, o diabetes se caracteriza pelas elevadas concentrações de glicose, o impacto que essa patologia exerce sobre a saúde dos acometidos, como 
também sobre o sistema de saúde pública dos países industrializados, reside quase exclusivamente nas complicações que causa (Davidson, 2001). As complicações do diabetes podem se desenvolver em qualquer pessoa com diabetes tipo 1 e 2 e não apenas nos que tomam insulina.

As complicações agudas e crônicas do diabetes mal controlado, segundo Davidson (2001), são:

Agudas: cetoacidose diabética, coma hiperosmolar não-cetótico, hipoglicemia e coma hipoglicêmico

Crônicas: macrovasculopatia (angina, infarto, AVC), microangiopatia (retinopatia diabética e nefropatia diabética), neuropatia diabética (sistema nervoso periférico).

A morbidade associada ao diabetes de longa duração, independente do tipo, resulta de várias complicações grave .

Microangiopatia é o acometimento de pequenos vasos, ocorrendo assim lesões microvasculares em todo o organismo.Verifica-se um espessamento difuso das membranas basais, sendo mais evidente nos capilares da pele, músculos esqueléticos, retina, glomérulos e medula renal e também nos nervos periféricos, tendo como manifestações a retinopatia diabética e a nefropatia diabética (Davidson, 2001).

A microangiopatia tem um grande papel na patogênese da ulceração, por ocorrer espessamento da membrana basal e edema endotelial nos capilares, apesar de não causar a obstrução, deve-se acrescentar que edemas leves, devido a traumas, trombose séptica ou infecção podem resultar em uma oclusão total das artérias distais, levando à gangrena dos dedos (Consenso Internacional do Pé Diabético, 2001).

Macrovasculopatia é o acometimento de grandes vasos ou aterosclerótica, tendo como manifestações clínicas angina e infarto do miocárdio, acidente cerebrovascular e doenças vasculares periféricas (Davidson, 2001).

Neuropatia é o envolvimento do sistema nervoso periférico e do autonômico, cujas manifestações clínicas podem induzir vários problemas. 
A maior parte dos estudos experimentais e clínicos disponíveis sugere que as complicações são conseqüências de distúrbios metabólicos, principalmente da hiperglicemia (Reiber, 1998).

Estudos de mortalidade têm apontado o diabetes como importante causa de óbito por doença crônica não transmissível em nossa população e no mundo todo, sendo a macroangiopatia e a nefropatia as causas principais de morte entre os diabéticos (Laurenti, 1982; Oliveira, 1992; OMS, 1994).

Laurenti et al (1982), avaliando a mortalidade por diabetes mellitus no Estado de São Paulo, analisam os óbitos de pessoas de 15 a 74 anos num período de um ano e constatam que o diabetes mellitus tinha sido a causa básica de óbitos em 2,11\%, sendo que, como causa múltipla, esteve presente em 10,8\% dos casos. As causas múltiplas compreendem doença isquêmica do coração, o diabetes mellitus, doença cerebrovascular e as neoplasias malignas. Também comparam os dados obtidos com os de outros países desenvolvidos e concluem que essa taxa pode ser considerada alta.

Segundo os indicadores de saúde dos municípios da Divisão Regional de Saúde (DIR) - XIV -Marília 1993/1996, as causas de mortalidade por faixa etária, em 1996, foram, em primeiro lugar, as doenças cérebrovasculares, nas idades de 20 a 49 anos com taxa de 6,4\% e nas idades de 50 anos ou mais com taxa de 39,4\%; em segundo lugar, o diabetes mellitus com taxas de 1,5\% e 10,6\% nas mesmas faixas etárias (Marília, 1997).

Não há dúvida de que o diabetes mellitus continuará sendo uma ameaça para a saúde pública nos anos subseqüentes. Os dados demográficos e epidemiológicos indicam que,se não houver uma intervenção eficaz, o índice de diabetes aumentará em todo o mundo (King, 1989).

As complicações crônicas oftalmológicas e neurológicas são causas freqüentes de morbidade, piorando assim a qualidade de vida dos diabéticos, levando-os a graus diferentes de incapacidade e invalidez, como a perda da visão e amputações não traumáticas dos membros inferiores (Associação Americana de Diabetes, 2001).

No estudo de Foss (1991) com dois grupos de pacientes portadores de diabetes tipo1 e tipo 2, insulinodependentes, a prevalência das complicações crônicas no tipo 1 foi de $10 \%$ para macroangiopatia; de $21 \%$ para retinopatia e nefropatia, e de $32 \%$ para neuropatia. No grupo estudado de diabetes tipo 2, os pacientes estavam na faixa etária de 25 a 84 anos, com duração da patologia entre 1 a 43 anos. O controle metabólico do 
Introdução

grupo foi considerado bom em 19,4\%; regular em 48,4\% e mau em 32,2\%. A complicação mais freqüente foi a neuropatia, presente em 50,9\% dos casos.

Foss (1991), em estudo com 112 pacientes da cidade de Ribeirão Preto, portadores de diabetes tipo 1, na faixa etária de 11 a 23 anos, com duração da patologia de 6 a 7 anos, observou como complicação crônica mais freqüente a neuropatia diabética. O referido estudo mostrou também que o aumento da prevalência das complicações é progressivo em relação à duração da patologia e que a prevalência de complicações apresenta tendência sempre maior no grupo de controle inadequado.

Estudos mostram que existe uma relação entre a duração da patologia e o surgimento de complicações microvasculares e também entre o controle inadequado do diabetes e a maior prevalência de complicações crônicas (Foss, 1991; Filho, 1998; Associação Americana de Diabetes, 2001;Sumpio, 2000).

O estudo de Bauer (2000) reitera que o bom controle glicêmico de pacientes diabéticos do tipo 1 ou 2 é determinante de melhor evolução a longo prazo, relacionado às complicações vasculares ou neurológicas.

Como o custo social para o tratamento das complicações do diabético é altíssimo, torna- se necessário viabilizar na rede pública as medidas profiláticas para evitar a ocorrência desta doença e o desenvolvimento de suas complicações. Na realidade não se dispõe de medidas preventivas para o diabetes tipo 1, mas para o tipo 2 existem medidas que podem ser utilizadas para sua prevenção ou para retardar seu aparecimento (Oliveira, 1996).

Lessa (1996) aponta que as complicações mais freqüentes do diabetes são as doenças cardiovasculares, comas e gangrena, o que reflete a precária assistência primária.

O diabetes mellitus tem sido uma das principais causas de hospitalização no Brasil, o que significa altos custos financeiros. Suas complicações crônicas são causas freqüentes de invalidez precoce (Ministério da Saúde, 1993 ; Cunha, 1995).

Segundo Oliveira (1996), épocas atrás, o diabético morria precocemente de cetoacidose e infecções. A descoberta, da insulina por (Basting e Best, em 1922) e dos antibióticos e dos antidiabéticos orais mudaram radicalmente a expectativa de vida e a causa de morte dos diabéticos. No presente, preocupam as complicações tardias da 
Introdução

doença especialmente as cardiovasculares e renais, pois a maior longevidade da população aumentou ainda mais a prevalência das complicações do diabetes mellitus.

A freqüência de complicações macro e microvasculares cresce com o envelhecimento e com a duração do diabetes mellitus. Nos idosos diabéticos, o risco para o infarto do miocárdio, AVC e insuficiência renal tem aumentado comparando-se aos idosos não-diabéticos. Também aumenta a prevalência de lesões vasculares e neuropatia nos diabéticos idosos com controle glicêmico inadequado (Naliato, 1998).

A aterosclerose periférica é a principal doença causadora de amputações de membros inferiores e o número de pacientes tem aumentado devido ao aumento da expectativa de vida das populações. A alta incidência de diabetes nesse tipo de população é uma constante, variando de 35 a 70\% (Ramaccioti apud Maffei, 1995).

No sistema vascular dos diabéticos, os vasos de todos os calibres são afetados pela aterosclerose acelerada, desde a aorta até as arteríolas e capilares, ocorrendo o infarto do miocárdio, causa mais comum de morte em diabéticos. Cerca da metade dos pacientes diabéticos apresentam níveis sanguíneos elevados de lipídeos, que predispõem à aterosclerose. As doenças cardiovasculares representam a maior causa de morbidade e mortalidade entre indivíduos diabéticos, depois da neuropatia diabética (Chacra,1996).

A gangrena dos membros inferiores, em decorrência da doença vascular avançada, é mais freqüente nos diabéticos do que na população em geral. (Reiber,1998).

As amputações não traumáticas são realizadas, na proporção de metade ou mais, em diabéticos e a incidência anual de gangrena é de 1 por 200 diabéticos (Maffei, 1995; Abbott,1998; Mayfield,1998).

Uma pesquisa americana realizada em seis estados, no período de 1976 a 1978, indicou que 45\% das amputações de membros inferiores são realizadas em pacientes diabéticos (a média foi de 59,7 de amputações para cada 10.000 indivíduos diabéticos). O índice de amputações aumenta com a idade e é mais alto no sexo masculino (OMS, 1994; Maffei,1995; Naliato, 1998; Spilchler, 1998; Davidson, 2001).

A pessoa diabética tem 15 vezes mais risco de amputações de membros inferiores do que o indivíduo não diabético (OMS, 1994; Maffei, 1995; Pedrosa, 1998; Naliato, 1998; Spilchler, 1998; Davidson, 2001).

Os diabéticos têm a mesma incidência de oclusão arterioesclerótica na região femoropoplítea que os não diabéticos, mas a incidência de lesões arteriais distais é 
maior nos diabéticos. Dos pacientes diabéticos, 65\% são submetidos a amputações primárias, portanto sem tentativa de reconstrução arterial, e somente 35\% com algum tipo de reconstrução (Maffei, 1995).

Estudo envolvendo 176 amputações, num período de 20 anos, relata a mortalidade operatória 2,3\% vezes maior no grupo diabético comparado com o grupo não diabético (Maffei, 1995). Portanto, no período de três anos após uma amputação dos membros inferiores, a porcentagem de sobrevida é de $50 \%$ e, num período de 10 anos, o índice de mortalidade é de 39\% a 68\% (Zavala \& Braver, 2000; Bild, 1989).

Os dados apresentados acima apontam para a necessidade de ampliar projetos que visam à prevenção das complicações em extremidades de membros inferiores de pessoas com DM.

O enfermeiro, enquanto membro da equipe multidisciplinar, deve acompanhar o paciente com DM, visando promover a aquisição de habilidades para o auto cuidado e assim prevenir as complicações que podem ocorrer em conseqüência ao mau controle da doença.

Dentre as intervenções que deverá desenvolver, destacam-se as relacionadas com a prevenção das complicações em extremidades de membros inferiores, as quais constituem o foco do presente estudo e possuem um significado importante no quadro da morbimortalidade entre as pessoas com DM; portanto, a seguir, será apresentado um tópico destacando a entidade denominada pé diabético.

A avaliação dos pés destes pacientes bem como o planejamento de cuidados para esses são de extrema importância. Os pacientes diabéticos apresentam alguns fatores que predispõem e que contribuem para o aumento de risco de infecções nos pés, como a neuropatia, doença vascular periférica e imunocomprometimento. A seqüência dessas alterações proporciona danos nos pés do diabético, como pele seca, fissura interdigitais, formação de calo e até mesmo úlceras. Ainda pode haver diminuição da sensibilidade nos pés, fato que poderá promover danos por insensibilidade térmica, química ou traumática (Laing, 1998).

Como a hospitalização prolongada, a reabilitação e a grande necessidade de cuidados domiciliares e de assistência tornam onerosas as complicações do pé diabético, o trabalho preventivo, que é de custo relativamente baixo, apresenta vantagens diante 
dos elevados custos das amputações e do tratamento das úlceras, com relação à pessoa e à sociedade (Consenso Internacional do Pé Diabético, 2001).

Nos EUA, o gasto para o tratamento de uma úlcera é de US\$ 7.000 e o de uma amputação varia de US\$ 43.000 a US\$ 65.000 (Macedo \& Pedrosa, 2001).

Mediante a complexidade das complicações em pés das pessoas com diabetes, realizou-se o presente estudo entre os pacientes com úlceras em pés, buscando compreender os fatores etiológicos, bem como as condições para o seu desenvolvimento.

A seguir será apresentada uma revisão da literatura sobre "pé diabético", incluindo fatores etiológicos e aspectos anatomo-fisiológicos do pé.

\subsection{PÉ DIABÉTICO}

O pé diabético é definido pelo conjunto de lesões nos pés dos pacientes diabéticos, as quais ocorrem devido a anormalidades neurológicas em $90 \%$ dos casos, doença vascular periférica, alterações biomecânicas que levam a deformidades, podendo ser acometidos por infecção ou destruição dos tecidos profundos (Consenso Internacional do Pé Diabético, 2001; Sociedade Brasileira de Diabetes, 1997; Pedrosa; 1998). Desta forma qualquer trauma no pé do paciente diabético poderá rapidamente evoluir para uma úlcera, infecção, gangrena, perda de extremidades e, às vezes, da própria vida.

Como se pode perceber, as lesões nos pés, conhecidas como pé diabético, estão entre as mais graves. As úlceras do pé diabético ocorrem mais comumente devido à neuropatia periférica e à doença vascular periférica e sua prevalência é de 1,7 - 3,3\% a 5 - 10\% entre indivíduos portadores de diabetes mellitus tanto do tipo 1 como do tipo 2 , compreendendo uma faixa etária mais idosa (Pedrosa, 1998).

Frykberg (2000) afirma que a complicação mais comum do diabetes nos membros inferiores é a úlcera do pé diabético. Estima-se que 15\% de pacientes com diabetes desenvolverão úlceras nos membros inferiores no curso de sua doença. 
McCulloch (2000) informa que as úlceras no pé diabético são a maior causa de mortalidade e morbidade, sendo responsáveis por, aproximadamente, 2/3 de todas as amputações não traumáticas realizadas nos EUA.

Estudos realizados por Mayall (1992) mostram que o pé diabético aparece mais na idade adulta. Em apenas 7,8\% ocorre antes dos 50 anos em 68,8\%, entre os 51 e os 70 anos e em 23,7, acima dos 70 anos, sendo a incidência das lesões idêntica em ambos os sexos.

Uma taxa de 14 a 20\% dos pacientes com úlcera nos pés subseqüentemente requer amputação. As ulcerações nos pés são precursoras de, aproximadamente, 85\% das amputações dos membros inferiores em pessoas com diabetes (Frykberg, 2000).

No pé diabético, a neuropatia, a microangiopatia e a macroangiopatia, juntamente com as infecções, deixam expostas a epiderme e a derme, contribuindo para que ocorra a lesão.

Bernardes et al. (1993), realizando a análise dos pés diabéticos, obtiveram bons resultados com o controle do diabetes, orientações para o uso de calçados adequados, a higiene dos pés, exercícios para ativação da circulação e curativos especiais nas lesões.O tratamento cirúrgico desses pacientes foi realizado quando necessário, sendo o desbridamento cirúrgico mais utilizado do que a amputação.

As lesões do pé diabético ocorrem da combinação de dois ou mais fatores de risco, as neuropatias e as angiopatias, que podem estar juntos ou separados, alterando o quadro de simples a bastante complexo (Consenso Internacional do Pé Diabético, 2001).

Reiber et al (1998) referem que as úlceras no pé são erosões cutâneas caracterizadas pela perda do epitélio, que invadem a derme, atingindo os tecidos profundos. Essas úlceras resultam de vários fatores etiológicos e podem agravar-se pela inabilidade de reparação tecidual de maneira oportuna e ordenada.

Segundo Frykberg (2000), os fatores de risco identificados para lesão do pé diabético são a neuropatia diabética, a doença vascular, limitação da mobilidade das articulações, deformidades no pé, pressão anormal nos pés, traumas pequenos, história de ulcerações ou amputações.O risco para o surgimento destas complicações crônicas aumenta quanto maior for a duração da hiperglicemia ao longo dos anos da doença (Simons, 1994; Grossi, 1998). 
Para formação de úlcera em pé do paciente com DM é importante lembrar-se da equação: pressão = força / área. O pé insensível pode ser lesado por forças externas, ou seja, a pressão constante por horas pode causar necrose isquêmica (como o uso de sapatos novos), pressão alta em um ponto, por curto período, causa danos mecânicos diretos (como pisar num prego) e o stress moderado e repetitivo, que pode levar à autólise moderada (Laing,1998; Rodrigues, 1998).

A úlcera neurotrófica plantar representa a complicação final das alterações patológicas causadas pela neuropatia após a formação de calosidades plantares que fissuram e formam úlceras. Somado a estes fatores, as condições da pele nos espaços interdigitais podem predispor à colonização bacteriana, tornando a infecção a maior causa de morbidade (Reiber, 1998).

Nas úlceras plantares, os calos formam-se devido ao estresse mecânico repetitivo, desenvolvendo a úlcera, muitas vezes precedida de uma hemorragia subcutânea (Consenso Internacional do Pé Diabético, 2001).

Kozak (1996) refere que a infecção no pé do paciente diabético é mais suscetível que nos não diabéticos, visto que a oxigenação precária no pé isquêmico provoca uma resposta imune vigorosa. Isso também ocorre devido ao estado hiperglicêmico que afeta o mecanismo de defesa do corpo, prejudicando a resposta dos glóbulos brancos e dos neutrófilos, em particular.

Pedrosa (1998) afirma que a infecção não leva diretamente à ulceração, mas é um fator importante na complicação, aumentando o risco de amputação.

A seguir destacaremos os principais fatores envolvidos na etiologia das lesões no pé da pessoa com diabetes.

\subsubsection{Neuropatia Diabética}

McCulloch 2000 afirma que a prevalência da neuropatia diabética em pacientes com diabetes tipo 2 é de 30\% e mais de 50\% em pacientes acima de 60 anos.

A neuropatia diabética é o fator de risco mais comum para o desenvolvimento de úlceras nos pacientes portadores de diabetes mellitus. É definida como a lesão das fibras nervosas somática e autônoma. A patogênese da neuropatia é atribuída à maior 
Introdução

atividade da via do poliol no tecido nervoso (Kozak \& Giurini, 1996; Grossi, 1998; Sumpio, 2000; Davidson, 2001).

Embora não seja conhecido o mecanismo exato, o mau controle metabólico do diabetes, como a hiperglicemia de longa duração, está relacionado com a lesão neural do paciente. Ocorrem também alterações microcirculatorias nos nervos periféricos, podendo afetar a nutrição e a reparação destes, decorrendo então a isquemia neuronal por espessamento das paredes vasculares e obstrução do fluxo sanguíneo (Kozak \& Giurini, 1996; Davidson, 2001).

Bryant (1992) refere que as causas da neuropatia periférica são multifatoriais, sendo que as condições mais envolvidas são a hiperglicemia e a isquemia que atingem os nervos periféricos.

Na neuropatia periférica, a lesão neurológica é extensa, comprometendo todo o sistema nervoso periférico nos seus componentes sensitivo-motor e autonômico (Laing, 1998; Consenso Internacional do Pé Diabético, 2001).

Segundo O Consenso Internacional sobre Pé Diabético (Secretaria de Estado de Saúde-DF, 2001), na neuropatia sensitiva ocorre perda da sensibilidade dolorosa, de percepção da pressão, de temperatura e de propriocepção. Com a perda dessa última, os estímulos para percepção de ferimentos ou traumas ficam diminuídos ou ausentes, resultando assim em ulcerações. A perda da sensação proprioceptiva leva à perda do reflexo do tendão de Aquiles.

Devido à perda da sensibilidade protetora, o trauma repetitivo causado pela caminhada pode não ser percebido e, como resposta fisiológica natural, ocorre a formação de calos que agem como corpo estranho à superfície da pele e causam a elevação da pressão local. As úlceras, portanto, resultam de fatores extrínsecos ao pé insensível, como um trauma externo associado a fatores intrínsecos, como a pressão plantar aumentada (Sumpio, 2000; Frykberg, 2000; Consenso Internacional do Pé Diabético, 2001).

As alterações sensoriais da neuropatia nos pés também põem em risco o paciente que pode ferir os pés com objetos externos ou no interior dos calçados, queimar-se e não sentir dor, levando a ulcerações nestas regiões de difícil cicatrização (Frykberg, 2000; Bryant, 1992). 
Introdução

Na neuropatia motora associada à desmielinização, acredita-se que ocorra atrofia e enfraquecimento dos músculos intrínsecos do pé, causando desequilíbrio entre os tendões flexores e extensores, fato que leva ao pé cavus ou acentua a curvatura do pé. Assim, ocorrem deformidades na flexão dos dedos, favorecendo-se a formação de dedos em garra e martelo, resultado do domínio dos músculos flexores sobre os extensores. As deformidades são conseqüências que atingem as áreas que sofrem maior pressão, como as cabeças dos metatarsos e dos dedos. As deformidades também podem causar áreas de pressão constante que levam a úlceras neuropáticas ou neurotróficas. (Sumpio, 2000).

Segundo Sumpio (2000), na neuropatia autonômica ocorre a redução e/ou ausência total da secreção sudorípara (anidrose), provocando o ressecamento da pele e causando rachaduras e fissuras. Além disso, há aumento do fluxo sanguíneo, causado pelos shunts artério-venosos, que resultará em um pé quente, quando em pendência, e descorado, quando elevado, podendo ocorrer edema e distensão das veias dorsais.

Com a redução ou ausência de secreção sudorípara, a pele dos pés torna-se seca, favorecendo as fissuras, rachaduras e úlceras que se tornam susceptíveis a infecções oportunistas. As unhas encravadas também se infectam com freqüência por micoses e agentes piogênicos, iniciando assim a ulceração (Rodrigues, et al. 1998; Frykberg, 2000).

Nas afecções osteoarticulares, o que se destaca é o pé de Charcot que atinge todos os estágios, desde osteítes, osteomielites, osteoartroses e osteoartrites até reabsorção externa dos ossos do pé (Rodrigues, et al, 1998).

A polineuropatia, associada a vasculopatia e alterações metabólicas, pode acometer a estrutura muscular e óssea dos pés e pernas, causando fraturas patológicas "artropatia de charcot" (Bowker \& Pfeifer, 2002). A denervação simpática dos membros inferiores pode contribuir para o aumento do fluxo sangüíneo nos pés, levando à absorção óssea, ocorrendo assim a fragmentação dos ossos, que levará à queda da arquitetura plantar normal do pé, denominada de pé de Charcot (Frykberg, 2000).

A neuropatia autonômica, então, compromete o sistema nervoso autônomo e provoca disfunções em quase todos os órgãos provocando manifestações clínicas como hipotensão, taquicardias, infarto do miocárdio, além da anidrose de membros inferiores, decorrente da inativação das glândulas sudoríparas, levando ao ressecamento 
da pele dos pés que contribui para as fissuras e rachaduras dos pés, facilitando aos processos infecciosos.

Os sinais e sintomas somáticos de lesão neural manifestam-se por fenômenos sensoriais: parestesias, dores, hipoestesia, analgesias nas extremidades dos membros inferiores, fenômenos motores decorrentes de perdas de força e atrofia muscular. As lesões de fibras nervosas grossas causam perda de sensibilidade vibratória e proprioceptiva enquanto a desmielinização de fibras finas causa a perda da sensibilidade tátil, térmica e dolorosa. (Foss, 2000; Robbins, 2000; Sociedade Brasileira de Diabetes, 1997).

O acometimento patológico do sistema nervoso no diabético é bastante grave.Os diabéticos são também prejudicados pela maior suscetibilidade às infecções da pele e ao desenvolvimento de outras infecções. A prevalência da neuropatia é acima de $50 \%$, sendo a complicação crônica mais freqüente observada entre os diabéticos. As amputações de membros inferiores de pacientes diabéticos estão geralmente relacionadas à presença de neuropatia e constituem um sério problema de saúde pública (OMS, 1994).

São sinais e sintomas das alterações do pé com comprometimento vascular, a claudicação intermitente, pé frio, dor noturna, dor ao repouso, alívio em posição antálgica, ausência de pulsos, palidez à elevação, atrofia dos tecido subcutâneo gorduroso, rubor condicionado e retorno no enchimento venoso após elevação, pele com aspecto brilhante, perda dos pêlos nos pés e dedos, artelhos estreitados e com infecção fúngica freqüente, gangrena, síndrome do dedo azul e oclusão vascular aguda.

A neuropatia no pé e na perna do paciente com DM causa perda dos reflexos tendinosos profundos, queda do pé e alterações em sua forma devido à atrofia da musculatura (Rodrigues, 1998)

Como já se sabe a diminuição do fornecimento de sangue aos tecidos, devida ao processo oclusivo, e a perda de sensibilidade (na neuropatia há susceptibilidade a infecções e a deficiência da cicatrização da pele nos membros inferiores) levam à ocorrência de perda da integridade cutânea e à conseqüente ulceração. 
Introdução

\section{Doença Vascular Periférica}

A doença vascular periférica nos membros inferiores é um dos mais importantes fatores associados às amputações. Contribui com a ulceração dos membros e com a gangrena e prejudica a cicatrização das úlceras.A isquemia também diminui a habilidade de combater a infecção por prejudicar a oxigenação e a nutrição, assim como a chegada de antibióticos às áreas infectadas (Reiber, 1998).

A doença vascular periférica ligada aos processos ulcerativos é quatro vezes mais comum em diabéticos e ocorre precocemente em ambos os sexos. Sua gravidade está também diretamente relacionada ao inadequado controle glicêmico, duração da doença, idade, tabagismo, hipertensão, hiperlipidemia e obesidade (Levin, 1995).

Segundo Pedrosa, (1998) a doença vascular periférica, junto com traumas leves ou danos comuns, podem resultar em úlceras dolorosas e isquêmicas.O autor acrescenta ainda que a doença vascular periférica e a neuropatia estão presentes geralmente no mesmo paciente e que a redução do fluxo sangüíneo na pele, devido à doença macrovascular, deixa-a mais sensível à oclusão durante períodos de elevada pressão biomecânica nela. Considera-se improvável a contribuição direta da doença microvascular no processo de ulceração ou de cicatrização atribuindo-as a um provável dano funcional. A macroangiopatia é mais observada nas artérias poplíteas e tibiais.

Segundo Khettry (1996), a doença macrovascular nos portadores de diabetes consiste na arteriosclerose que são lesões resultantes de espessamento e perda da elasticidade da parede arterial, a alteração mais comum das grandes artérias. Existem também outras duas alterações que são a esclerose de Monckeberg, que se caracteriza pela calcificação da camada média das artérias musculares e a fibrose difusa da íntima, que constitui um processo normal do envelhecimento. A aterosclerose nos portadores de diabetes aparece poucos anos após as manifestações clínicas da doença. São lesões mais extensas e maiores, com o depósito na camada interna das artérias de lipídios, colesterol e cálcio.

Levin (1995) e Reiber (1998) referem que processos oclusivos macrovasculares mais graves decorrentes da formação de trombos de origem aterosclerótica, trombos secundários à infecção e êmbolos de colesterol deslocados de placas ateromatosas, sendo caracterizados por cianose, súbita crise de dor e coloração arroxeada da área 
envolvida. Nos portadores de diabetes, a doença oclusiva macrovascular caracteriza-se pela aterosclerose das artérias tibiais anteriores e posteriores e fibulares, entre o joelho e o tornozelo.

Khettry (1996) afirma que a microangiopatia (ou doença dos pequenos vasos) consiste em alterações nas pequenas artérias nas arteríolas e nos capilares, que são acometidos gravemente . As lesões nestes vasos acabam em estreitamento e oclusão da luz vascular, o que resulta em pequenas áreas de gangrena, como nos artelhos.A lesão arteriolar consiste em espessamento da parede vascular com depósito de material ácido periódico-Schiff (PAS) positivo com a hipertrofia e proliferação da íntima e do endotélio.O material (PAS) confere homogeneidade e hialinização à parede das arteríolas, resultando no desaparecimento dos detalhes estruturais. A luz destes vasos fica extremamente estreita.

Pesquisadores salientam que, embora exista espessamento da membrana basal nos capilares, não existe lesão oclusiva na microcirculação dos diabéticos, como se pensava antes, pois a doença vascular geralmente termina no tornozelo, poupando de forma relativa as artérias pediosas.Acrescentam ainda que, se houver necessidade, a reconstrução arterial distal é possível e com sucesso, o que restaura a perfusão normal e reduz o número de amputações. Portanto, o pé com boa perfusão é menos suscetível a ulcerações e necrose por pressão repetitiva e infecções (Khettry, 1996; Reiber, 1998).

Pedrosa et al. (1998) e Browker \& Pfeifer (2002) comentam que a macrovasculopatia distal, geralmente nos dois membros, leva a uma diminuição do fluxo arterial e é agravada pelo fumo e dislipidemia.Havendo trauma, existe a formação de úlcera isquêmica ou neuroisquêmica, dolorosa ou indolor, dependendo da associação da neuropatia.

Entre os sinais de insuficiência vascular observados nos membros inferiores, a claudicação no andar é o primeiro sintoma, seguido por aparência brilhante da pele, rubor com a pendência do membro e empalidecimento com elevação do membro (Mulder, 2000). Para proceder a essa avaliação deve-se elevar os membros inferiores do paciente por 20 segundos e, em seguida, os membros inferiores devem ser colocados em declive por um igual tempo. (McCulloch,2000). Também ocorre perda dos pêlos, cianose, atrofia de tecido gorduroso subcutâneo, enchimento capilar maior que 15, atrofia de tecido gorduroso subcutâneo, pés frios, presença de dor noturna ou alívio 
durante o repouso com pendência das pernas. A palpação dos pulsos nas artérias tibial posterior e pediosa dorsal deve ser avaliada, mas a presença dos pulsos não elimina a possibilidade de doença vascular. Na ausência destes pulsos referidos acima, deve-se verificar os pulsos das artérias poplítea e femoral (Mulder, 2000; McCulloch, 2000).

\section{Alterações Biomecânicas}

Como há necessidade de conhecer as alterações ocorridas no pé, devidas à neuropatia e à má distribuição do peso do corpo sobre os pés durante a marcha e a má acomodação desses nos sapatos, serão descritas e analisadas então as deformidades encontradas nos pacientes portadores de diabetes mellitus e com pé diabéticos esperando contribuir para sua prevenção.

O mecanismo normal da locomoção é atribuído à harmonia existente entre os músculos, tendões, ligamento e o esqueleto. Com a presença da neuropatia, da doença vascular periférica e das forças empregadas para a realização da marcha, podem ocorrer danos na pele, visto que a ausência de elasticidade e a resistência dos tecidos causados pela isquemia levam à morte dos tecidos. A falha da perfusão no sistema circulatório dificulta a chegada de substâncias de reconstrução tecidual, complicando ainda mais o problema.A morfologia corporal influencia as forças geradas nas extremidades inferiores. Quanto maior for o peso do corpo, maior será a pressão sobre uma certa área superficial (Habershaw \& Chzran, 1996; Sumpio, 2000).

$\mathrm{O}$ atrito constante e rápido contra a pele forma vesículas (bolhas) como a bolha causada no calcanhar pelo sapato novo. O atrito menos constante e lento causa calosidade e calos, como o calo no artelho pequeno causado por calçados apertados e a calosidade uniforme da sola do pé nas pessoas obesas ou que usam calçados com salto. A pele sobre a joanete, com o uso de sapato apertado, necrosará devido à pressão. A pressão direta contra um tecido acima dos limites de tolerância acarreta hiperemia localizada, edema e destruição tecidual se a pressão não for eliminada. O alívio periódico permite a recuperação do tecido e o eventual endurecimento ou ceratinização da pele, com formação de calosidades e calos (Habershaw \& Chzran, 1996). 
A formação de calosidade de localização profunda, abaixo da cabeça do segundo ou terceiro metatarso em uma pessoa com um arco acentuado, é causada pelas forças de cisalhamento, que é definido como o resultado de forças aplicadas que causam o deslizamento de partes de um corpo em relação a umas e outras numa direção paralela ao seu plano de contato. A deformidade tipo hálux valgo é um problema análogo a este citado (Sumpio, 2000).

O déficit sensorial é acompanhado também pela alteração motora, como a atrofia muscular acompanhada por fraqueza.Os artelhos levantados, as cabeças dos metatarsos com proeminência plantar, o desgaste do músculo intrínseco, a deformidade do pé eqüino e a posição em varo do antepé, são deformidades observadas no tipo de pé cavo varo, os quais se caracterizam por rigidez, ausência de movimentos, baixa tolerância ao choque, incapacidade de se adaptar às irregularidades no terreno e alinhamento proximal inadequado (Habershaw \& Chzran, 1996).

Os músculos intrínsecos do pé funcionam como estabilizadores das articulações metatarsofalangeanas, estabilizando as falanges contra as cabeças dos metatarsos, antes dos movimentos de elevação do pé. A atrofia produz deformidades como a perda da estabilidade nas referidas articulações. Observa-se, então, flexão do pé no tornozelo, extensão das falanges proximais às articulações metatarsofalangeanas e flexão das articulações interfalangeanas proximais ao pé. O músculo longo do hálux é afetado precocemente e sua fraqueza traduz-se na deformidade tipo martelo, por predominar a tração exercida pelo longo flexor (Habershaw \& Chzran, 1996).

\section{Infecção}

A infecção e defeitos na função dos leucócitos têm sido associados à susceptibilidade de infecções nos pacientes diabéticos. A fagocitose dos leucócitos, com a morte intracelular de bactérias, é significativamente reduzida em pacientes diabéticos com controle inadequado da glicemia. A correção da hiperglicemia melhora a taxa de microbicida.Portanto em paciente com pobre tolerância à infecção, o controle do diabetes è afetado desfavoravelmente, e o não controle do diabetes afeta desfavoravelmente a resposta à infecção. As bactérias mais comuns encontradas nas 
culturas são os aeróbicos coccos gram-positivo Também podem ser encontrado nas culturas os patógenos gram-negativos (Frykberg, 1998).

O pé com sensibilidade comprometida em graus variáveis, com perfusão sangüínea reduzida, calçado inadequado e com alterações funcionais e estruturais graves, torna-se segmento de alto risco de colonização bacteriana, de infecção e seus efeitos (Young \& Young 1994).

Cristensen et al (1991) referem que a infecção, celulite e a osteomielite são condições muito comuns em úlceras neuropáticas de pacientes diabéticos. Para os pesquisadores, os antibióticos sistêmicos, orais ou endovenosos, são indicados quando houver sinais de celulite ou osteomielite.O desbridamento ósseo também deve ser considerado em caso de osteomielite.

Segue-se a descrição da anatomia do pé, ponto central e alvo do trabalho a ser desenvolvido.

\subsection{CONSIDERAÇÕES ANATÔMICAS DO PÉ}

O pé é a parte do membro inferior, abaixo da articulação do tornozelo e tem como função a sustentação e a locomoção do corpo (Moore, 1994). È ainda a estrutura essencial de suporte e locomoção do corpo humano, constituído por delicadas estruturas harmoniosamente balanceadas, com 26 ossos, 46 músculos, tendões, nervos e uma vasta rede vascular arterial, venosa e linfática (Bernardes, et al. 1993).

\subsubsection{A Estrutura Óssea do Pé}

Segundo Moore (1994), o esqueleto do pé é constituído do tarso, metatarso e falanges. O tarso consiste de sete ossos interligados - tálus, calcâneo, cubóide, navicular e três cuneiformes-, sendo que apenas o tálus se articula com os ossos da perna. Ele repousa sobre os dois terços anteriores do calcâneo e articula-se com a tíbia, fíbula e osso navicular. Sua face superior, em forma de sela, sustenta o peso do corpo, que chega através da tíbia. 
O calcâneo, um bloco ósseo retangular, é o maior e mais forte osso do pé. O navicular é um osso achatado, em forma de barco, situado entre o tálus e os três ossos cuneiformes. O cubóide, em forma de cubo, é o mais lateral, distal ao tarso. Os ossos cuneiformes, denominados medial, intermédio e lateral, articulam-se com o osso navicular, atrás e anteriormente com o metatársico correspondente (Dangelo e Fattini, 1983; Moore, 1994).

Moore (1994) descreve ainda que o metatarso consiste em cinco ossos, numerados a partir da face medial do pé, sendo que cada osso é dividido em base (proximal), corpo e cabeça ou diáfise (distal). O segundo metatársico é o mais longo e as cabeças desses ossos sustentam parte do peso do corpo. Os ossos sesamóides do primeiro dedo (hálux) sustentam o peso do corpo, durante a última fase do processo de marcha.

Quanto às 14 falanges, observa-se que o primeiro dedo (hálux) tem duas falanges fortes (proximal e distal), os outros dedos possuem três falanges cada um (proximal, média e distal), sendo que cada falange consiste em base (proximal), corpo ou diáfise e a cabeça (distal). As falanges distal e média do dedo mínimo do pé são fundidas (O’Rahilly, 1985).

\subsubsection{Sistema Muscular da perna e do pé}

\subsubsection{Sistema muscular da perna}

Os quatro músculos do compartimento anterior da perna agem sobre a articulação do tornozelo e articulações intertársicas, resultando em movimentos do pé. São extensores, ou seja, realizam a dorsiflexão, os músculos tibial anterior, extensor longo do hálux, extensor longo dos dedos e fibular terceiro. Eles estão relacionados com a dorsiflexão da articulação do tornozelo e extensão dos dedos do pé (Dangelo e Fattini; O’Rahilly, 1985; 1983; Moore, 1994).

Dangelo e Fattini (1983) descrevem que os músculos do compartimento anteriores da perna possuem uma inervação comum que é realizada pelo nervo fibular profundo. 
Moore (1994) relata que o músculo tibial anterior situa-se na face lateral da tíbia, onde é facilmente palpado, e ainda diz que, se este músculo for paralisado pela lesão do nervo fibular comum ou de seu ramo, o nervo fibular profundo, o pé cai (pende em flexão plantar quando é levantado do chão).O mesmo autor refere que o músculo extensor longo do hálux situa-se na região interna entre os músculos tibial anterior e extensor longo dos dedos e sua inserção acontece na face dorsal da falange distal do hálux. As suas ações são estender o hálux e realizar a dorsiflexão do mesmo.

O músculo extensor longo dos dedos situa-se lateralmente ao músculo tibial anterior e uma bainha sinovial comum circunda seus quatro tendões, que se separam sobre o dorso do pé, seguindo até sua fixação nas partes distais. Cada tendão forma uma expansão extensora membranosa sobre o dorso da falange proximal, que se dividem em duas faixas laterais, e uma faixa central, que se insere na base da falange média, e as laterais se dividem para se inserir em na base da falange distal. Ele estende os quatro dedos laterais e dorsiflete o pé (Dangelo e Fattini, 1983; Moore, 1994).

Segundo Dangelo e Fattini (1983), o músculo fibular terceiro não tem ação independente, é pequeno e variável, constituindo uma porção separada do músculo extensor longo dos dedos. Tais músculos se unem em suas fixações proximais; na parte distal, o tendão do fibular terceiro não se fixa a um dedo, ele dorsiflete o pé e auxilia na sua eversão.

O’ Rahilly (1985) descreve o compartimento lateral da perna que contém os músculos fibular longo e curto, cuja função é fazer a flexão plantar e inverter o pé.O músculo fibular longo tem sua origem na parte mais alta do corpo da fíbula, estendendose até a região plantar. Sua inserção proximal ocorre na cabeça e parte superior da face lateral da fíbula e a inserção distal, na base do primeiro metatársico e osso cuneiforme medial. Quando a pessoa permanece apoiada em apenas um pé, esse músculo ajuda a manter o equilíbrio da perna sobre o pé (O’Rahilly, 1985; Moore, 1994).O músculo fibular curto tem sua fixação na parte proximal e está a dois terços inferiores da face lateral da fíbula e sua fixação distal ocorre na face dorsal da tuberosidade e na face lateral do quinto metatársico. (O’Rahilly, 1985; Moore, 1994).

Moore (1994) descreve o compartimento posterior da perna que se situa atrás da tíbia.Os músculos da panturrilha são divididos em dois grupos - o superficial e o profundo. O grupo superficial de músculos forma uma massa potente na panturrilha, 
cuja função é fazer a flexão plantar do pé. Característica humana, esse músculo de grande volume e força mantém o homem ereto, sustenta e desloca o peso do corpo.

Segundo Moore, três músculos constituem o grupo superficial - o gastrocnêmico, o sóleo e o plantar-, sendo que o gastrocnêmico e o sóleo formam um músculo tripartido, chamado músculo tríceps da perna, que molda a panturrilha. Eles atuam juntos na flexão plantar, na articulação do tornozelo, elevam o calcanhar contra o peso do corpo, como na dança.

O músculo gastrocnêmico é fusiforme com duas origens. Possui duas cabeças que nascem dos côndilos do fêmur e terminam em uma aponeurose comum unindo-se com o tendão subjacente do músculo sóleo para formar o tendão calcâneo (de Aquiles). A inervação deste músculo é realizada pelo nervo tibial. Sua contração produz rápido movimento durante a corrida e o salto, também ajuda a equilibrar as pernas e está ativo durante a postura ereta, mesmo em posição de relaxamento, tem como função a flexão plantar que eleva o calcanhar durante a marcha e flete a articulação do joelho (O’Rahilly, 1985; Moore, 1994).

O músculo sóleo é largo, plano, carnoso, semelhante a várias penas e localiza-se mais profundamente ao músculo gastrocnêmico. Sua inserção proximal em forma de ferradura ocorre na tíbia e na fíbula. Ele atua junto ao músculo gastrocnêmico na flexão plantar do tornozelo como acontece na marcha e na dança. Também mantém a postura, garantindo o equilíbrio da perna sobre o pé, impedindo que o corpo caia para a frente na posição ereta. É suprido pelo nervo tibial (O’Rahilly, 1985; Moore, 1994). A secção do nervo tibial provoca perda de sensibilidade na sola do pé. A flexão plantar pode ser perdida, deixando um modo de andar arrastando os pés. A inversão pode ser prejudicada, porque o nervo tibial supre os músculo gastrocnêmico, plantar, sóleo, flexor longo dos dedos, flexor longo do hálux, o tibial posterior e também a pele do calcanhar e da sola do pé.

Moore (1994) descreve o músculo plantar como pequeno, tamanho e extensão variável, de ventre carnoso e de tendão delgado, que segue obliquamente entre os músculos gastrocnêmico e sóleo.Sua origem encontra-se na extremidade inferior da linha supracondilar lateral do fêmur e ligamento poplíteo oblíquo. É suprido pelo nervo tibial e auxilia o músculo gastrocnêmico na flexão plantar e na flexão da articulação do joelho.Há também quatro músculos que constituem a camada profunda de músculos da 
face posterior da perna: o poplíteo, o flexor longo dos dedos, o flexor longo do hálux e o tibial posterior. O músculo poplíteo atua sobre a articulação do joelho, enquanto os outros atuam sobre as articulações do tornozelo e do pé. Todos os músculos deste grupo são inervados pelo nervo tibial.

O músculo poplíteo, como descrevem Dangelo e Fattini(1983) e Moore (1994), é um músculo triangular, plano e delgado e forma o assoalho da parte inferior da fossa poplítea. Tem sua origem dentro da cápsula fibrosa da articulação do joelho, face lateral do côndilo do fêmur e menisco lateral.Sua inserção proximal do tendão do músculo poplíteo situa-se no interior da cápsula da articulação do joelho e a inserção distal, na face posterior da tíbia, fica acima da linha do sóleo. Sua principal ação é destrancar o joelho e além disto realiza uma fraca flexão do mesmo.

O músculo flexor longo do hálux, como o nome já diz, é longo e potente flexor do hálux, sendo o maior deles. Origina-se na face posterior da fíbula e parte inferior da membrana interóssea, insere- se na base da falange distal do hálux e tem como função fletir o hálux em todas as articulações. Atua na flexão plantar, sustenta o arco longitudinal do pé e é um potente músculo da impulsão durante a marcha, corrida e salto. Também é importante para manter a perna na posição normal do pé (Dangelo e Fattini, 1983; Moore, 1994).

O músculo flexor longo dos flete os quatro dedos laterais. É menor que o flexor longo do hálux embora movimente quatro dedos.Tem sua origem na face posterior da tíbia, abaixo do músculo sóleo. Suas inserções ocorrem nas bases das falanges distais dos quatro dedos laterais, além de fletir os quatro dedos laterais, e atua na flexão plantar e ainda sustenta o arco longitudinal do pé (Seeley, 1991; Moore, 1994).

O músculo tibial posterior é um grande músculo fusiforme sendo o mais profundo deles. Localiza-se entre o flexor longo dos dedos e o flexor longo do hálux, tendo sua origem na membrana interóssea, na face posterior da tíbia abaixo da linha do músculo sóleo e face posterior da fíbula. Sua inserção ocorre na tuberosidade dos ossos navicular, cuneiforme e cubóide e bases do segundo, terceiro e quarto metatársicos. Sua ação é atuar na flexão plantar e na inversão do pé (Seeley, 1991; Moore, 1994). 
Introdução

\subsubsection{Sistema Múscular do Pé}

O dorso do pé é constituído de dois músculos: o extensor curto dos dedos e o extensor curto do hálux que, juntos, formam uma massa carnosa na parte lateral do dorso do pé. Estes músculos estão inseridos proximamente na parte anterior da face dorsal do calcâneo e anterior e medial ao maléolo lateral. Sua inserção distal ocorre no meio de quatro tendões. Sua inervação é realizada pelo nervo fibular profundo, e tem a ação, de estender os dedos (do segundo ao quarto) e o hálux nas articulações metarsofalangianas. (O’Rahilly, 1985; Moore, 1994).

Segundo a descrição de Moore (1994), a região plantar do pé é constituída de quatro camadas de músculos que são especializados na manutenção dos arcos do pé e possibilitam a uma pessoa ficar ereta sobre um solo irregular. Eles possuem funções posturais.

A primeira camada de músculos plantares contém três músculos curtos : os abdutores do hálux e do dedo mínimo e o flexor curto dos dedos. Esses músculos constituem um grupo funcional que atua como uma mola elástica para sustentar os arcos do pé e manter a sua concavidade (O’Rahilly, 1985; Moore, 1994).

O músculo abdutor do hálux, segundo O’Rahilly (1985) e Moore (1994), tem sua inserção na face medial da base da falange proximal do hálux e sua ação é abduzir e fletir o hálux. O músculo flexor curto dos dedos localiza-se entre os músculos abdutor do hálux e abdutor do dedo mínimo, ele insere em ambos os lados das falanges média dos quatro dedos laterais e tem como ação fletir esses quatro dedos laterais. O músculo abdutor do dedo mínimo tem sua inserção na face lateral da base da falange proximal do quinto dedo e sua ação é abduzir e fletir o quinto dedo.

Segundo os mesmos autores, a segunda camada de músculos plantares, situada mais profundamente que a primeira camada, consiste nos músculos, quadrado plantar e lumbricais. O músculo quadrado plantar, conhecido como flexor acessório, une-se ao tendão do músculo flexor longo dos dedos no calcâneo e forma uma lâmina muscular carnosa na metade posterior do pé. Sua inserção localiza-se na borda posterolateral do tendão do músculo flexor longo dos dedos e sua ação é auxiliar o músculo flexor longo dos dedos na flexão dos quatro dedos laterais. Existem quatro músculos lumbricais pequenos e vermiformes, inseridos nas faces mediais das bases das falanges proximais dos quatro dedos laterais e expansões extensoras dos tendões do músculo flexor longo 
dos dedos, cuja ação é fletir as falanges proximais e estender as falanges média e distal dos quatro dedos laterais.

A terceira camada de músculos plantares é composta de três músculos: os músculos curtos do hálux, o músculo adutor do hálux e o músculo flexor curto do dedo mínimo (Moore, 1994; Hall-Craggs, 1995).

O músculo flexor curto do hálux possui duas cabeças que recobrem a face plantar do primeiro metatarso, inserido em ambas as faces da base da falange proximal do hálux e sua ação é fletir a falange proximal do hálux. Um osso sesamóide adere a cada um de seus tendões, com a função de proteger os tendões da pressão exercida pela cabeça do primeiro metatársico durante a posição ereta e a marcha (Moore, 1994; HallCraggs, 1995).

O músculo adutor do hálux possui duas cabeças que se inserem a face lateral da base da falange proximal do hálux. Tem como ação aduzir o hálux e auxiliar na manutenção do arco transverso da base do pé. O músculo flexor curto do dedo mínimo tem sua origem no quinto metatársico. Sua inserção é na base da falange proximal do quinto dedo e tem como função fletir a falange proximal do mesmo, auxiliando assim sua flexão (Moore, 1994; Hall-Craggs, 1995).

A quarta camada de músculos plantares é constituída pelos músculos interósseos e os tendões dos músculos fibular longo e tibial posterior que cruzam a região plantar para atingir suas inervações distais. Os músculos interósseos são compostos por três músculos plantares e quatro interósseos dorsais, que ocupam os espaços intermetatársicos. Os músculos interósseos dorsais originam-se por duas cabeças. Os músculos interósseos plantares têm sua origem nas bases e faces mediais dos metatársicos 3-5, com inserções nas faces mediais das bases das falanges proximais do $3^{\circ}$ ao $5^{\circ}$ dedos.Suas funções são aduzir os dedos $\left(2^{\circ} \mathrm{e} 4^{\circ}\right)$ e fletir as articulações metatarso falangianas. Os músculos interósseos dorsais têm origem nas faces adjacentes dos ossos metatársicos $1-5$, com inserção na primeira face medial da falange proximal do segundo dedo, segunda e quarta faces laterais dos $2^{\circ}$ e $4^{\circ}$ dedos e têm as mesmas funções do anterior. O músculos interósseos mantêm a integridade da parte anterior do pé por meio da aproximação dos ossos durante a sustentação de peso e também fletem os dedos nas articulações metarsofalangianas (Moore, 1994; Hall-Craggs, 1995). 
Introdução

\subsubsection{Sistema Nervoso do Pé}

Segundo Dangelo e Fattini, (1983), o nervo tibial divide-se em nervos plantar medial e lateral, que suprem os músculos intrínsecos do pé (exceto pelo extensor curto dos dedos, suprido pelo nervo fibular profundo)e também a pele do pé.

O nervo plantar medial, o maior dos dois ramos terminais do nervo tibial, passa profundamente ao músculo abdutor do hálux e segue anteriormente entre estes músculos e o flexor curto dos dedos, na face lateral da artéria plantar medial. Termina próximo às bases dos ossos metatársicos, com a divisão em três ramos sensitivos (que enviam ramos cutâneos para os três e meio dedos mediais) e ramos motores para os músculos abdutor do hálux, flexor curto dos dedos, flexor curto do hálux, e o músculo lumbrical mais medial (Dangelo e Fattini, 1983; O’Rahilly, 1985 Moore, 1994).

O nervo plantar lateral, o menor dos dois ramos terminais do nervo tibial, origina-se profundamente no retináculo dos músculos flexores e no músculo abdutor do hálux e segue em sentido anterolateral, medialmente à artéria plantar lateral e entre a primeira e segunda camadas de músculos plantares. O nervo plantar lateral termina dividindo-se em ramos superficial e profundo. O ramo superficial divide-se em dois nervos digitais que enviam ramos cutâneos para o quinto dedo e metade do quarto. Os ramos superficiais e profundos do nervo plantar lateral enviam ramos motores para os músculos da região plantar que não são supridos pelo nervo plantar medial (Dangelo e Fattini, 1983; O’Rahilly, 1985 Moore, 1994).

O nervo sural forma-se na fossa poplítea e desce entre as duas cabeças do músculo gastrocnêmico, passa pela fáscia profunda, ao redor da porção média da face posterior da perna, onde se une ao ramo comunicante fibular do nervo fibular comum. Ele supre a pele na parte lateral e posterior do terço inferior da perna, insere-se no pé atrás do maléolo lateral e supre a pele ao longo da borda lateral do pé e na face lateral do quinto dedo (Dangelo e Fattini, 1983; O’Rahilly, 1985 Moore, 1994).

O nervo safeno é o maior ramo cutâneo do nervo femoral. Além de suprir a pele e a fáscia das faces anterior e medial da perna, segue para o dorso do pé, anteriormente ao maléolo medial. Ele supre a pele ao longo da face medial do pé até a cabeça do primeiro metatársico (Dangelo e Fattini, 1983; O’ Rahilly, 1985 moore, 1994). 
Introdução

\subsubsection{Sistema Artérial do Pé}

Segundo Moore (1994), as artérias do pé são os ramos terminais das artérias tibiais anterior e posterior.

\subsubsection{Artérias do Dorso do Pé}

A chamada artéria dorsal do pé é a continuação direta da artéria tibial anterior distalmente à articulação do tornozelo. Origina-se entre os maléolos e segue em sentido anteromedial, profundamente ao retináculo inferior dos músculos extensores, até a extremidade posterior do primeiro espaço interósseo. Divide-se assim em artéria plantar profunda e artéria arqueada A primeira segue até a região plantar (O’Rahilly, 1985; MOORE, 1994).

Segundo O’Rahilly (1985), a artéria dorsal do pé é clinicamente importante para avaliar a circulação periférica. Seus pulsos devem ser avaliados e podem ser sentidos entre os tendões do extensor longo dos dedos.

A artéria plantar profunda segue profundamente através do primeiro espaço interósseo para se unir à artéria plantar lateral e formar o arco plantar profundo (Moore,1994).

A artéria arqueada segue lateralmente através das bases dos ossos metatársicos, profundamente aos tendões dos músculos extensores, de onde saem a segunda, terceira e quarta artérias metatársicas dorsais. Essa artérias acompanham as falanges e cada uma se divide em duas artérias digitais dorsais para as faces laterais de dedos adjacentes (Dangelo e Fattini, 1983; O’Rahilly, 1985; Moore,1994). 
Introdução

\subsubsection{Artérias da Região Plantar}

Segundo Dangelo e Fattini (1983), essas artérias, ramos da artéria tibial posterior, dividem-se profundamente para formar as artérias medial e lateral que correm paralelamente aos nervos homônimos.

A artéria plantar medial é a menor dos dois ramos terminais da artéria tibial posterior. Origina-se profundamente no retináculo dos músculos flexores entre o maléolo medial e a proeminência do calcanhar e segue no sentido distal entre os músculos abdutor do hálux e flexor curto dos dedos. A artéria plantar medial envia ramos para a face medial do hálux e emite ramos musculares, cutâneos e articulares em seu trajeto (Dangelo e Fattini, 1983; Moore,1994).

A artéria plantar lateral é o maior dos ramos terminais da artéria tibial posterior. Ela tem sua origem junto ao retináculo dos músculos flexores e corre obliquamente pela região plantar sobre a face lateral do nervo plantar lateral, entre os músculos flexor curto dos dedos e quadrado plantar, também emite ramos calcâneos, cutâneos, musculares e articulares. Quando atinge a base do quinto metatársico, curva-se medialmente entre a terceira e quarta camadas musculares e termina no ponto onde se une ao ramo plantar profundo da artéria dorsal do pé para formar o arco arterial plantar (Dangelo e Fattini, 1983 ; Moore,1994).

O arco arterial plantar tem seu início na base do quinto metatársico como a continuação da artéria plantar lateral, completa- se pela junção com a artéria plantar profunda, um ramo da artéria dorsal do pé. Ao cruzar o pé, o arco plantar emite quatro artérias metatársicas plantares, três artérias perfurantes e ramos para as articulações do tarso e músculos na região plantar. Estas artérias unem-se aos ramos superficiais das artérias plantares medial e lateral para a formação das artérias digitais plantares (Dangelo e Fattini, 1983.;Moore,1994).

\subsubsection{Sistema Venoso do Pé}

Segundo Moore (1994), as veias digitais dorsais correm ao longo das bordas dorsais de cada dedo e unem-se nas suas membranas interdigitais para a formação das 
veias digitais dorsais comuns. Estas veias unem-se para formar um arco venoso dorsal no dorso do pé e em seguida, convergem medialmente para formar a veia safena parva.

As veias plantares superficiais unem-se para formar um arco venoso plantar a partir do qual os eferentes seguem para as veias marginais medial e lateral que se unem às veias safenas magna e parva (Dangelo e Fattini, 1983.;Moore,1994).

As veias plantares profundas originam-se como veias digitais plantares nas faces plantares dos dedos e se comunicam com as veias digitais dorsais através das veias perfurantes. A maior parte do sangue retorna do pé através das veias profundas, que são conectadas às superficiais por veias perfurantes (Dangelo e Fattini, 1983.; Moore,1994).

\subsection{Avaliação da Função Tegumentar}

\subsubsection{Sistema Tegumentar do Pé}

Sampaio (1989) refere que a pele da face dorsal do pé é fina e móvel, os pêlos são escassos, possui pouca gordura subcutânea e devido a isso os tendões são bem visíveis, principalmente na dorsiflexão. A pele do dorso do pé é suprida pelo nervo fibular superficial.

A pele da face plantar é fina sobre os dedos e no meio do pé mas é espessa no calcanhar e na base do hálux. A pele da região plantar contém muitas glândulas sudoríparas e gordura no tecido subcutâneo principalmente no calcanhar. A região plantar é propícia à sustentação de peso e sustentação dos nervos e vasos sanguíneos aí existentes (Moore, 1994; O’Rahilly, 1985) .

Abaixo da pele, encontra-se a fáscia profunda do pé. Logo abaixo se encontra a aponeurose, que se distribui pelo pé, às vezes espessa e forte em algumas regiões, em outras, fracas e delgadas. A aponeurose da região plantar, que se compõe de faixas de tecido conjuntivo fibroso e denso, tem como objetivo sustentar os arcos longitudinais do pé e manter unidas as suas estruturas. Ela se divide em cinco faixas, que se separam para envolver os tendões digitais (Moore, 1994; O’Rahilly, 1985) .

A pele é o manto de revestimento do organismo, uma estrutura fundamental indispensável para a vida humana. Ela, que isola os componentes orgânicos do meio 
externo, é composta de três camadas: epiderme, derme e tecido subcutâneo (Sampaio, 1989 ; Bates, 1998).

A pele é um órgão complexo que se divide em duas camadas, a epiderme externa e a derme profunda, medindo 0,04 $\mathrm{cm}$ de espessura, a epiderme e a derme 0,5 $\mathrm{cm}$ de espessura (Carpenito, 1993). Esta espessura varia de 0,1 mm na pálpebra até $1 \mathrm{~mm}$ na palma das mãos e sola dos pés (Sampaio, 1989).

A pele tem várias funções: proteger os tecidos internos contra traumatismos, substâncias químicas e outros organismos; receber várias sensações como tato, dor, calor, frio; regular a temperatura do corpo através da radiação; conduzir calor; convergir as moléculas de ar quente para longe do corpo; regular o equilíbrio, prevenindo a perda de água e de eletrólitos e, ainda, receber vitamina D do sol (O’Rahilly, 1985; Bates, 1998).

Sampaio (1989) ressalta que a epiderme é composta de duas camadas : a córnea, que é a mais superficial e acumula uma substância chamada queratina, produzida nas camadas subjacentes, e a camada germinativa ou basal, a mais profunda e responsável pela renovação da epiderme, sendo delimitada pela membrana basal, que separa a derme. Na epiderme encontram-se células especiais chamadas melanócitos, que participam na produção e armazenamento da melanina, o agente de pigmentação da pele (Marinho, 1997).

A epiderme é modificada em diferentes áreas do corpo. Nas palmas das mãos e nas plantas dos pés, é espessada e contém quantidades maiores de queratina, em contraste com a epiderme fina da maior parte do corpo e sua espessura pode aumentar pelo uso ou aumento da pressão na área, podendo resultar na formação de calosidades nas mãos ou nos pés, como se pode observar nos pacientes diabéticos com neuropatia (O’Rahilly, 1985).

Abaixo da epiderme está a derme. Bem vascularizada e composta de tecido epitelial, tecido conectivo, muscular e tecido nervoso, ela é rica em colágeno que proporciona resistência à pele (Carpenito, 1997). Os folículos capilares da derme são ilhas de células que servem para a rápida re-epitelização de ferimentos pequenos. As glândulas sudoríparas controlam a água e a temperatura do corpo. As terminações nervosas são especializadas quanto à sensação de dor, tato, calor, frio e, se forem destruídas, são insubstituíveis (O’Rahilly, 1985). 
O tecido subcutâneo (ou hipoderme) é a camada mais interna da pele onde se localiza a gordura que tem como função a regulagem da temperatura e contém o restante das glândulas sudoríparas e dos folículos capilares (Moore, 1983).

Para compreender melhor a fisiopatologia da ulceração, deve-se compreender primeiro a fisiologia da pele, o processo de cicatrização tecidual e os fatores que podem retardar este processo.

Feistritzer (1995) conceitua a cicatrização como sendo uma resposta altamente organizada que se inicia com a lesão do tecido. Trata-se de uma complexa série de acontecimentos interligados e dependentes uns dos outros, que substitui e restabelece a função normal dos tecidos lesados.

Segundo o autor, há três tipos de cicatrização: primária, secundária e terciária. A cicatrização primária (primeira intenção) ocorre em lesões limpas, com mínimo de destruição e de lesão tecidual, como as incisões cirúrgicas. A cicatrização secundária (segunda intenção) é aquela em que ocorre perda de tecido com a existência de secreção e necrose celular, com remoção posterior, sendo mais demorada do que a primária. A cicatrização terciária (terceira intenção) ocorre quando a cicatrização por aproximação das bordas do ferimento retarda ou as suturas se rompem.

Segundo Sampaio (1989), sempre que o organismo é agredido, desencadeia-se uma reação denominada de processo inflamatório. Quando esse processo está em declínio, o organismo inicia o processo de cicatrização.

No processo inflamatório, as reações da pele aos antígenos são a dilatação capilar (eritema), a dilatação das arteríolas (rubor) e aumento da permeabilidade capilar (vergão) e contribuindo para o edema localizado, os espasmos e o prurido. É através dos fibroblastos, células do tecido conjuntivo, que a pele se renova. Quando a pele é agredida, ocorre uma lesão.As lesões são classificadas de acordo com o grau de prejuízo aos tecidos em lesões sem perda, da pele, como os cortes por materiais perfuro cortante, lesões com perda da epiderme, como nas escoriações, e lesões com perda da epiderme e da derme, como é o caso das queimaduras, das úlceras varicosas e das escaras (Martins,1996; Marinho,1997).

O processo de cicatrização é dividido em três fases: inflamatória, reconstrução (proliferativa) e maturação (Sampaio, 1989; Marinho,1997; Feistritzer, 1995). 
A fase inflamatória é a resposta vascular e inflamatória imediata do tecido à lesão. Qualquer lesão que sangre e traumatize tecidos para além da epiderme desencadeia o processo de coagulação local. A vasoconstricão acontece num curto período e, por uma complexa reação em cadeia-cascata de coagulação, há a formação de tampão na luz dos vasos, na tentativa de controlar a hemorragia. Esse tampão vai desidratando gradualmente e transforma-se numa crosta que veda temporariamente a ferida, protegendo-a da entrada de microorganismos invasores. O tecido severamente lesado é rapidamente aproximado pela rede de fibrina e uma fina camada de sangue coagulado, como se fosse uma cicatriz, reação que dura de cinco a dez minutos e é seguida por uma vasodilatação. Os capilares próximos da ferida tornam-se mais permeáveis e o exsudato inflamatório infiltra-se na ferida. Nessa fase ocorre um aumento de sinais de inflamação (tumor, rubor, calor e dor) (Marinho,1997; Stadelmann, 1998).

A lesão causada no tecido ativa os sistemas complemento e cinina. O sistema complemento é composto por um grupo de proteínas que se encontra inativo no sangue e no fluido intestinal. Quando ativado, desenvolve três atividades principais do sistema: vasodilatação de capilares, quimiotaxia com migração unidirecional de leucócitos fagocíticos dentro da área contaminada e fagocitose efetiva. O aspecto quimiotático do sistema complemento é resultado da produção de C3a e C5a, poderosos e críticos quimioatrativos de neutrófilos e monócitos. As cininas são liberadas pelas plaquetas, após 10 a 30 minutos da lesão e facilitam a saída das células fagocíticas para fora dos vasos. Simultaneamente ocorre um efeito cascata que leva à liberação de histamina dos mastócitos que resulta em vasodilatação e aumento da permeabilidade capilar. Esse efeito é aumentado pelo sistema cinina, que permite que os elementos do sangue anticorpos, proteínas plasmáticas, eletrólitos, complemento e água - atravessem o espaço vascular.O processo ocorre em dois ou três dias. (Bryant,1992; Flanagam, 1997).

À medida que os capilares se dilatam e se tornam permeáveis, há fluxo do fluido que contém proteínas do plasma, anticorpos, eritrócitos, leucócitos e plaquetas para os tecidos lesados, o que é chamado de exsudato inflamatório (Flanagam, 1997).

As plaquetas também liberam fatores de crescimento que atraem monócitos, que são ativados por linfoquinas, secretadas por linfócitos. Uma vez nos tecidos (espaço 
extravascular), essas células, conhecidas como macrófagos, são encontradas na lesão 24 horas após o trauma.Os macrófagos, maiores que os neutrófilos, possuem as mesmas propriedades de quimiotaxia, diapedese e fagocitose (Flanagam, 1997).

Os macrófagos por serem maiores que os neutrófilos, que têm vida curta conseguem fazer a fagocitose de partículas maiores, como detritos necróticos e bactérias, e transportá-las para fora da área lesada.O macrófago é considerado a célula essencial no processo de cicatrização por ter a função de secretar o fator de angiogênese, sendo esta o estímulo para a formação do broto endotelial (Dealey,2001).

Os macrófagos estão presentes em todas as fases de cicatrização do ferimento, visto que também produzem e secretam substâncias biologicamente ativas, tais como prostaglandinas, leucotrienos, fator ativador de fibroblastos e interleucina (Flanagam, 1997; Dealey,2001).

Dentre as prostaglandinas, a mais relevante é a PGE2, pois seus efeitos resultam na regulação, por "feed-back", do sistema monócito/macrófago e inibição da aderência e migração do macrófago. A secreção de interleucina é essencial por aumentar a permeabilidade capilar e estimular o fibroblasto a produzir fator de crescimento derivado de plaquetas (FCDP), que é um agente quimiotático essencial para algumas das etapas do processo de reparação (Bryant,1992; Dealey,2001).

A resposta inflamatória tem uma posição significante na qualidade da cicatrização e pode ser observada clinicamente pela presença local de rubor, calor, tumefação, dor e perda de função. Esses sinais são conseqüência do aumento de fluxo sanguíneo para a área e que, eventualmente, exercem pressão nas terminações nervosas sensoriais, provocando dor. A combinação de dor e edema pode levar à restrição de movimentos no local. A inflamação faz parte da resposta de proteção normal a ferimentos e, embora os sinais sejam semelhantes, não devem ser confundidos com infecção (Dealey,2001; Flanagam, 1997). Essa fase pode durar de quatro a cinco dias, mas em feridas infectadas ou com presença de tecido necrótico o processo é mais prolongado.

A segunda fase é denominada de fase de reconstrução ou fase de proliferação de fibroblastos, que se caracteriza pelo desenvolvimento de tecido de granulação.Trata-se da remoção de tecido morto e bactérias, para dar lugar à cicatrização (reparação). O desenvolvimento de tecido de granulação consiste na formação de uma matriz 
indefinida de fibrina, fibronectina, colágeno, ácido hialurônico e outros, podendo haver macrófagos, fibroblastos e os vasos sanguíneos recém-formados. Há aceleração na produção de tecido neoformado rico em colágeno (Marinho,1997; Stadelmann, 1998; Dealey,2001).

Os macrófagos desempenham um papel importante na fase da cicatrização. Em maior número, assumem a operação e os neutrófilos diminuem. Os macrófagos produzem o fator de crescimento derivado das plaquetas (FCDP) e o fator de crescimento dos fibroblastos (FCF), que são quimiotáticos para fibroblastos, atraindo-os para a ferida e estimulando-os a se dividir e, mais tarde, a produzir as fibras do colágeno.Há um aumento de monócitos fagocíticos e o aparecimento de grande quantidade de fibroblastos. O colágeno tem sido encontrado na ferida já no segundo dia. Há vários tipos de colágeno, caracterizado por diferentes formações de aminoácidos. O tipo III está presente na ferida em cicatrização, em maior quantidade do que normalmente é encontrado na pele. Com o tempo, essa quantidade se reduz devido à elevação do colágeno tipo I. (Marinho,1997; Stadelmann, 1998; Dealey,2001).

A atividade dos fibroblastos depende do suprimento local de oxigênio; se a vascularização for deficiente no local, a ferida não cicatrizará . A superfície da ferida tem uma tensão relativamente baixa ao oxigênio, encorajando os macrófagos a produzirem fator de crescimento transformador beta (FCT $\beta$ ) e fator de crescimento dos fibroblastos (FCF), que estimulam o processo de angiogênese, ou seja, o crescimento de novos vasos sanguíneos. Os capilares abaixo da ferida lançam fibras que crescem rumo à superfície, formando laços. Esses laços formam uma rede dentro da ferida, suprindo-a de oxigênio e nutrientes. Alguns fibroblastos têm função especializada. Conhecidos como miofibroblastos, possuem mecanismo contrátil, igual ao das células musculares lisas, que leva à contração da ferida.Esse processo tem início por volta do quinto ou sexto dias, realizando consideravelmente a contração da área de superfície das feridas abertas. Alguns estudos relatam que a contração é responsável por $40-80 \%$ do fechamento das feridas. À medida que a ferida se enche de novo tecido e uma rede capilar é formada, o número de macrófagos e fibroblastos se reduz gradualmente. Tal processo pode começar mesmo antes de terminar o estágio de inflamação e, se for prolongado, pode ocorrer uma granulação excessiva com hipertrofia. O tempo 
necessário para a reconstrução depende do tipo e do tamanho da ferida; para as feridas simples, pode ser cerca de 24 dias (Dealey,2001).

A terceira fase, denominada de maturação, é a estruturação do novo tecido de cicatrização, a remodelagem. O tecido cicatricial presente remodela-se gradualmente, comparando-se ao tecido normal. O colágeno, distribuído ao acaso, vai ser destruído e substituído por novas fibras colocadas de forma anatômica ao longo do ferimento. A cicatriz gradualmente se achata, tornando-se uma fina linha branca. Isso pode levar até um ano nas feridas fechadas e muito mais tempo nas feridas abertas (Sampaio 1989; Martins, 1996; Marinho, 1997; Dealey,2001).

Alguns fatores que interferem na cicatrização das feridas podem ser locais (presença de necrose, suprimento sanguíneo, infecção local, radiação, tipo de cobertura, comprometimento nervoso, estresse mecânico, entre outros) e sistêmicos (idade, várias patologias, infecção sistêmica e uso de drogas) Destacam-se os relacionados aos pacientes, como idade, sexo, tipo de doença (crônica, aguda), estado nutricional, resistência orgânica, tipo de lesão e tecido lesado e os relacionados aos procedimentos, como técnica de curativo, presença de corpos estranhos (substâncias, bactérias ou resíduos orgânicos ou inorgânicos), hematomas e infecção (Sampaio, 1989; Thomaz, 1997; Marinho, 1997; Dealey,2001).

Outros fatores que retardam a cicatrização são anemia, déficit de oxigênio, temperaturas extremas, desnutrição, desidratação, idade, uso de medicamentos imunossupressores, doenças crônicas como diabetes, oncológicas e vasculares. A obesidade influi negativamente no processo de cicatrização. (Sampaio, 1989; Thomaz, 1997; Marinho, 1997).

De acordo com Bates (1998), com o envelhecimento, a pele torna-se enrugada, frouxa e perde o turgor, também a vascularização da derme diminui. Se ocorrer exposição ao sol, a pele torna-se espessada, amarelada e com sulcos profundos. A pele da região dorsal das mãos, antebraço e pernas torna-se fina, frágil e com manchas esbranquiçadas e despigmentadas. O ressecamento da derme torna a pele descamativa, principalmente nas pernas, onde há o aparecimento de uma rede de fissuras superficiais.

O diabetes é um distúrbio que predispõe os pacientes à dificuldade de cicatrização das feridas, devido à diminuição da síntese de colágeno da angiogênese e da fagocitose. A aterosclerose, especialmente de pequenos vasos, também é comum no 
diabetes pela diminuição do fornecimento de oxigênio tecidual. A neuropatia diabética diminui ainda mais a cicatrização ao interromper o seu controle neurológico (reduzindo a vasodilatação e a sensação protetora da dor) (Marinho, 1997).

As dificuldades em conseguir um controle metabólico adequado, tendo em vista a falta de adesão ao tratamento, e maior predisposição para o agravamento das complicações dos diabéticos em surgimentos de infecções numa população, em aumento de sua longevidade, são constatações que revelam a necessidade de aprofundamento dos conhecimentos sobre os problemas relacionados aos pés de pessoas diabéticas, fazendo análise nas lesões desta população. 


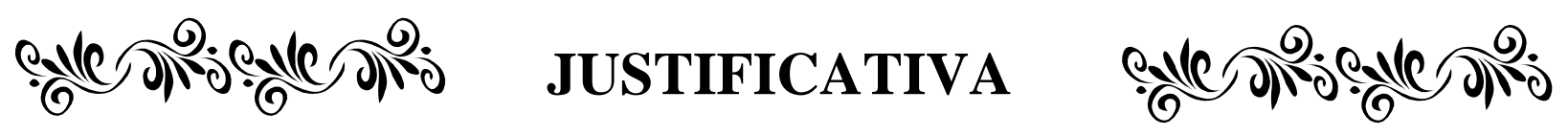


onsiderando que $85 \%$ das amputações em diabéticos são precedidas por
úlceras, essas lesões destacam-se como fatores de risco importantes para as amputações (Reiber, 1998).

Reconhecer os principais fatores que levam à ulceração trará subsídios para o planejamento de intervenções de caráter preventivo, curativo e de reabilitação frente às complicações que ocorrem nos pés das pessoas portadoras de diabetes mellitus.

O entendimento das vias que levam à ulceração capacita o desenvolvimento de estratégias adequadas para permitir a identificação de pacientes de alto risco e prevenir as interações potencialmente perigosas, as quais geralmente resultam em ulcerações. 


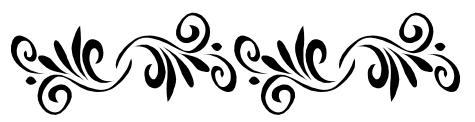

OBJETIVOS

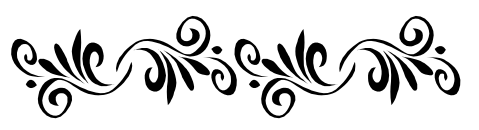




\subsection{Objetivo Geral}

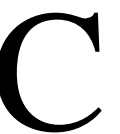

onhecer o perfil dos pacientes com diabetes mellitus que possuem úlcera em pé, atendidos em Unidade Ambulatorial de Marilia-SP.

\subsection{Objetivos Específicos}

1. Caracterizar os pacientes com diabetes mellitus que possuem úlcera em pé, segundo variáveis sócio-demográficas e estilo de vida.

2. Caracterizar os pacientes com diabetes mellitus que possuem úlcera em pé, segundo variáveis relacionadas ao diagnóstico, tratamento, condições clínicas dos pés, controle da doença e complicações.

3. Descrever as características da(s) úlcera(s) em pés das pessoas com diabetes e classificar o grau de comprometimento. 


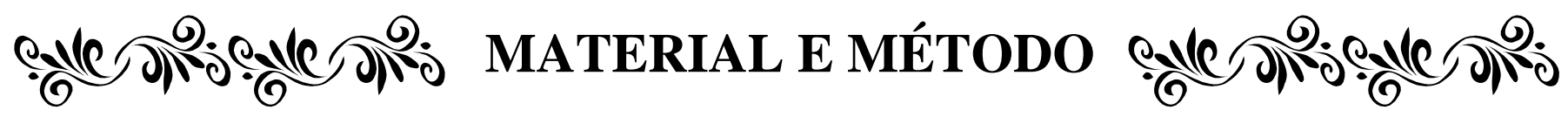




\subsection{DELINEAMENTO DO ESTUDO}

\footnotetext{
7 rata-se de uma pesquisa descritiva com propósito de observar, descrever e

1 explorar aspectos de uma situação (Polit\&Hungler, 1995).
}

\subsection{LOCAL DO ESTUDO}

\subsubsection{O Município de Marília}

Marília é uma cidade de médio porte, situada no interior do Estado de São Paulo, na região da Alta Paulista, distante da capital do Estado por $455 \mathrm{Km}$, através de rodovia asfaltada (Marília, 2001).

O município de Marília, com uma população de 197.342 mil habitantes, sendo 96.502 mil homens e 100.840 mulheres, possui cinco hospitais, com 1085 leitos e apresentou 20.222 internações no ano de 2000, segundo os dados do último senso do IBGE (2000).

Na área da saúde, há no município uma rede de serviços bastante diversificada, gerida pela Gestão Plena do Sistema Municipal, segundo a Norma Operacional Básica do Sistema Único de Saúde (NOB-96) (Marília, 2001).

A rede de atenção à saúde, em Marília, conta com 17 UBs (Unidades Básicas de Saúde) e 08 USFs (Unidades de Saúde da Família), que constituem porta de entrada do sistema de saúde. Os serviços básicos de saúde trabalham com a regionalização dos territórios e clientela de abrangência, com a cobertura de todas as áreas do município. A maioria das unidades está integrada a programas de ensino na área da saúde, contando com a participação de docentes e alunos. Desde 1998, o atendimento aos usuários foi padronizado para toda a rede com o sistema de agendamento de consultas. O sistema de referência e contra-referência está ligado a Central de Agendamentos Eletivos da Secretaria Municipal de Higiene e Saúde (SMHS). 
Método

Material

Há ainda no Município, sob a gerência do Estado, o NGA, CEAMA (Centro de Atendimento Médico), o IAL (instituto Adolfo Lutz), o hemocentro, dois Hospitais Universitários HCI (Hospital das Clínicas I) e HCII (Hospital das Clínicas II), (Faculdade de Medicina de Marília - FAMEMA).

Sob a gerência de entidades filantrópicas, o município conta com a Santa Casa de Misericórdia, o Hospital São Francisco, a Maternidade Gota de Leite e o Hospital Espírita de Marília (HEM).

Marília conta, na área de ensino, com uma Universidade Estadual, com curso de Medicina e Enfermagem.

O HC I de Marilia é um hospital geral nível terciário, uma autarquia de regime especial, cuja estrutura física se divide em três prédios; o HCI, que é destinado à assistência e ensino nas especialidades clínicas e cirúrgicas de pacientes adultos, contendo 100 leitos; o HCII, que realiza o atendimento nas especialidades Pediatria, Neonatologia, Ginecologia e Obstetrícia, contendo 109 leitos e o Hemocentro, que fornece suporte laboratorial, banco de sangue, unidade de quimioterapia e atendimento ambulatorial de onco-hematologia.

O HCI e HCII são referências para uma região de 37 municípios, com uma população de 553.013 mil habitantes pertencentes à DIR. XIV, também com a finalidade de ensino, pesquisa e assistência. (Marília, 1997).

Os programas de saúde que atendem o modelo de atenção vigente são desenvolvidos pela Secretaria Municipal de Higiene e Saúde, e um desses programas é o de combate ao diabetes, ligado ao programa de saúde do adulto.

O SUS Marília conta com a retaguarda de urgência e Emergência do Pronto Socorro do Hospital das Clínicas I e II, que atende diversas especialidades. Os leitos para esta demanda são controlados pela Central de Urgência e Emergência sob o gerenciamento da Secretaria de Estado da Saúde, através da DIR XIV - Marília.

Segundo o IBGE (2000), Marília possui quatro ambulatórios de unidade hospitalar geral:

- Ambulatório do Hospital das Clínicas “Mario Covas”.

- Ambulatório da Santa Casa de Misericórdia de Marília.

- Núcleo de Gestão Assistencial (NGA-29).

- Ambulatório do Hospital São Francisco. 
Método

O ambulatório do Hospital das Clínicas de Marília presta atendimento em diversas especialidades clínicas e cirúrgicas, inclusive o atendimento especial para os pacientes diabéticos.

Este estudo foi desenvolvido no Ambulatório de Especialidades “Mario Covas”, do Hospital das Clinicas I e Faculdade de Medicina e Enfermagem de Marília, um centro de referência de atenção à saúde na especialidade de cirurgia vascular.

Realizam-se no Ambulatório, anualmente, cerca de 22.050 consultas e 11.250 pequenas cirurgias e procedimentos. Conta-se também com serviços para exame e diagnóstico nas diversas especialidades, absorvendo grande parte da demanda do atendimento da população de Marília e região. O funcionamento do Ambulatório “Mario Covas” é realizado das $7 \mathrm{~h}$ às $17 \mathrm{~h}$. Os pacientes são provenientes das Unidades Básicas de Saúde, do município e da região, com agendamento prévio por meio da Secretaria Municipal de Saúde. Também são realizados acompanhamentos médicos após alta hospitalar e após cirurgias.

A especialidade de cirurgia vascular contribui com $11,30 \%$ do atendimento ambulatorial, sendo o ambulatório o local onde os pacientes diabéticos com lesões em pés são atendidos às segundas e às quintas-feiras, no período da manhã, das $7 \mathrm{~h}$ às $11 \mathrm{~h}$.

A equipe que atua no ambulatório de cirurgia vascular é constituída de médicos docentes da área de cirurgia vascular da Faculdade de Medicina de Marília, residentes da mesma especialidade e alunos do quinto e sexto anos de graduação em Medicina.

A enfermagem conta com uma enfermeira docente que gerencia o ambulatório todo e com uma equipe de auxiliares de enfermagem que prestam assistência nos horários de atendimento.

Existem também outros profissionais que realizam atendimento no ambulatório, dando suporte às disciplinas, como nutricionista, assistente social e psicóloga. 
Método

\subsection{POPULAÇÃO BASE DO ESTUDO E AMOSTRA}

A população base do estudo foi composta por pacientes portadores de diabetes mellitus com lesões em pés, atendidos no Ambulatório de Especialidades "Mario Covas” na especialidade de cirurgia vascular, do Hospital das Clínicas da Faculdade de Medicina e Enfermagem de Marília/SP no ano de 2003.

Para se conhecer o número de pacientes portadores de diabetes atendidos no ambulatório do Hospital das Clínicas de Marília, foi solicitada informação ao Núcleo Técnico de Informática (NTI), por meio de uma consulta à listagem com os números de atendimentos médicos realizados em 2002.

Com as informações fornecidas pelo NTI, foi possível identificar que no ano de 2002 foram realizados 23.467 atendimentos médicos. Destes, 565 pessoas possuíam o diagnóstico de diabetes mellitus, sendo, 356 (63,0\%) do sexo feminino e 209 (37,0\%) do sexo masculino, que foram distribuídas segundo a faixa etária, como mostra a Tabela 1.

Tabela 1 - Distribuição da população diabética atendida no Ambulatório de Especialidades do Hospital das Clínicas de Marília, no ano de 2002 segundo faixa etária e sexo. Marília/SP, 2002.

\begin{tabular}{cccc}
\hline $\begin{array}{c}\text { FAIXA ETÁRIA } \\
\text { ANOS }\end{array}$ & $\begin{array}{c}\text { Feminino } \\
\mathbf{N}^{\mathbf{0}}\end{array}$ & $\begin{array}{c}\text { S E X O } \\
\text { Masculino } \\
\mathbf{N}^{\mathbf{0}}\end{array}$ & $\begin{array}{c}\text { Total } \\
\mathbf{N}^{\mathbf{0}}\end{array}$ \\
\hline $00-09$ & 1 & 3 & 4 \\
$10-19$ & 6 & 10 & 16 \\
$20-29$ & 32 & 9 & 41 \\
$30-39$ & 33 & 21 & 54 \\
$40-49$ & 67 & 34 & 101 \\
$50-59$ & 77 & 61 & 138 \\
$60-69$ & 82 & 43 & 125 \\
$70-79$ & 47 & 7 & 54 \\
80 a mais & 11 & 8 & 19 \\
\hline Total & $\mathbf{3 5 6}$ & $\mathbf{2 0 9}$ & $\mathbf{5 6 5}$ \\
\hline
\end{tabular}

Fonte: Base de dados FAMEMA

Ao se identificar qualquer tipo de problemas em pés, os pacientes diabéticos são encaminhados à especialidade de cirurgia vascular. Em 2002, foram atendidos, 115 
Método

pacientes, sendo 58 (50,4\%) do sexo feminino e 57 (49,6\%), do masculino, conforme a tabela 2.

Tabela 2 - Distribuição da população diabética com úlceras no pé, atendida na especialidade de cirurgia vascular do Ambulatório de Especialidades do Hospital das Clínicas de Marília, no ano de 2002 segundo faixa etária e sexo. Marília/SP, 2002.

\begin{tabular}{cccc}
\hline $\begin{array}{c}\text { FAIXA ETÁRIA } \\
\text { ANOS }\end{array}$ & $\begin{array}{c}\text { Feminino } \\
\mathbf{N}^{\mathbf{0}}\end{array}$ & $\begin{array}{c}\text { Masculino } \\
\mathbf{N}^{\mathbf{0}}\end{array}$ & $\begin{array}{c}\text { Total } \\
\mathbf{N}^{\mathbf{0}}\end{array}$ \\
\cline { 2 - 4 } $15-19$ & - & 1 & 1 \\
$20-29$ & 2 & 2 & 4 \\
$30-39$ & 0 & 2 & 2 \\
$40-49$ & 8 & 12 & 20 \\
$50-59$ & 11 & 20 & 31 \\
$60-69$ & 21 & 11 & 32 \\
$70-79$ & 12 & 8 & 20 \\
80 a mais & 4 & 1 & 5 \\
\hline Total & & 57 & $\mathbf{1 1 5}$ \\
\hline
\end{tabular}

Fonte: Base de dados FAMEMA

\subsubsection{Critérios de Inclusão}

Os critérios de inclusão considerados para este estudo foram os seguintes:

- Ser portador de diabetes mellitus e apresentar úlcera em pé.

- Possuir idade superior a 21 anos.

- Aceitação do paciente em participar do estudo.

- Ter condições de responder ao questionário.

\subsubsection{Amostra}

A amostra do estudo foi constituída pelos pacientes que compareceram na unidade, no período de agosto a setembro 2003, às segundas e quintas-feiras das $8 \mathrm{~h}$ às 17h e que atenderam aos critérios de inclusão. 
Método

Foram entrevistados todos os pacientes da referida população e portadores de diabetes mellitus com úlcera no pé que compareceram no ambulatório de especialidades, para serem atendidos na disciplina vascular, no período estabelecido. Foi realizada a abordagem do paciente, antes ou depois da consulta médica, solicitandose o consentimento para participar do estudo e, depois de aceito, foi realizada a entrevista e feito o exame físico do pé em uma sala reservada. O tempo médio de atendimento de cada paciente foi de 50 minutos.

\subsection{DEFINIÇÃO DAS VARIÁVEIS DO ESTUDO}

\subsubsection{Variáveis sócio-demográficas e estilo de vida:}

Sexo, idade, escolaridade, estado civil, ocupação, procedência, tabagismo, etilismo e atividade física .

\subsubsection{Variáveis relacionadas ao diagnóstico:}

Tipo de diabetes, (tipo 1 ou tipo 2), tempo de diagnóstico do diabetes (em anos).

\subsubsection{Variáveis relacionadas ao tratamento}

Foram verificados o tempo do tratamento do diabetes e tipo de tratamento medicamentoso e não medicamentoso, segundo informação fornecida pela pessoa .

\subsubsection{Variáveis relacionadas ao controle do diabetes:}

Foram calculadas as médias dos valores dos exames (glicemia de jejum, colesterol total, triglicérides, HDL, LDL, e IMC), que constavam nos prontuários e realizados durante um ano, e os resultados foram comparados com os índices de normalidade preconizados pelo Ministério da Saúde (2001). A pressão arterial foi aferida no início da entrevista e também comparada com os índices do Ministério da 
Método

Saúde (2001), (tabela 3). Os valores da hemoglobina glicosilada foram verificados da mesma forma, porém os resultados foram comparados com os da Associação Latino Americana de Diabetes (2000), (tabela 4). Os valores dos exames foram coletados na ficha Anexa .

Tabela 3 - Parâmetros bioquímicos e critérios de controle metabólico, segundo Consenso Brasileiro de Condutas para o Diabetes Mellitus - SBD, 2001.

\begin{tabular}{lccc}
\hline \multicolumn{4}{c}{ METAS DO TRATAMENTO DO DM TIPO 2 E HA } \\
GLICOSE PLASMÁTICA (mg/d) & Bom & Aceitável & Mau \\
Jejum & $<110$ & $110-140$ & $>140$ \\
COLESTEROL (mg/dl) & $<200$ & $200-239$ & $>240$ \\
Total & $>45$ & $>45$ & $<45$ \\
HDL & $<100$ & $100-159$ & $>160$ \\
LDL & $<150$ & $150-199$ & $>200$ \\
Triglicerídeos (mg/dl) & & \\
PRESSÃO ARTERIAL (mmHg) & $<135$ & $<140$ & $>140$ \\
Sistólica & $<80$ & $<90$ & $>90$ \\
Diastólica & & \\
ÍNDICE DE MASSA COPORAL(kg/m) & & \\
\multicolumn{2}{c}{$20-25$} & $25-30$ & $>30$ \\
\hline
\end{tabular}

Tabela 4 - Índice de normalidade da hemoglobina glicosilada, segundo a Associação Latino Americana, 2002 .

\begin{tabular}{|c|c|c|c|}
\hline \multicolumn{4}{|c|}{ Hemoglobina glicosilada (mg/dl) } \\
\hline Nível & Bom & Aceitável & Mau \\
\hline $\begin{array}{l}\text { Hemoglobina } \\
\text { glicosilada A1c }\end{array}$ & $<6$ & $7-8$ & $>8$ \\
\hline
\end{tabular}

A hemoglobina glicosilada pode ser definida com o valor médio da população não diabética de referência (Associação Latino Americana de Diabetes, 2000).

\subsubsection{Variáveis relacionadas às complicações do diabetes e doenças associadas:}

Foi verificada, nos prontuários, a presença de complicações do diabetes e doenças associadas. 
Método

\subsubsection{Variáveis relacionadas às condições clínicas dos pés:}

Os dados referentes às condições clínicas dos pés foram obtidos por meio do exame físico composto pela avaliação do estado geral (deambulação/marcha e presença de amputação em membros inferiores), dermatológica (higiene, pele, fâneros e corte de unhas), estrutural (curvatura plantar, dedos em garra e/ou sobrepostos, halux valgus), circulatória (presença de edema, palpação de pulsos pediosos e tibiais posteriores, observação de rubor em pendência, palidez a elevação, temperatura da pele) e neurológica (força muscular, sensibilidade tátil-pressórica com monofilamento de Semnes-Weinsten de $10 \mathrm{~g}$ em nove regiões plantares e um no dorso dos pés, reflexo patelar, aquileu e plantar). Inclui nesta avaliação a observação dos calçados e meias bem como a existência de úlceras e úlceras anteriores.

Circulação Alterada: Foram avaliados, pelo método palpatório, os pulsos poplíteos, pedioso e tibial posterior e classificados em presentes, ausentes e diminuídos (Bevilacqua, 1985; Bates, 1998; Porto, 1996).

A avaliação da sensação tátil pressórica foi verificada por meio do monofilamento Semes-Weinstein de 10g (5.07). Devem ser testados nos nove pontos na região plantar e um no dorso do pé. A incapacidade do paciente de sentir o filamento de $10 \mathrm{~g}$ em quatro ou mais pontos, entre os dez pontos testados, demonstra neuropatia sensitiva, ou seja, a ausência de proteção nos pés. O monofilamento deve ser utilizado cuidadosamente da seguinte maneira: "Mostre o filamento ao paciente e aplique-o em sua mão para que reconheça o tipo de estímulo.Solicite ao paciente para manter os olhos fechados durante o teste. Peça ao paciente para prestar atenção e simplesmente responder "sim" ao sentir o filamento. Ao aplicar o monofilamento, mantenha-o perpendicular à superfície testada, a uma distância de 1-2cm; com um movimento suave, faça-o curvar-se sobre a pele e retire-o. A direção total do procedimento, do contato com a pele e da remoção do monofilamento, não deve exceder a dois segundos. Se o monofilamento escorregar pelo lado, desconsidere a eventual resposta do paciente e teste o mesmo local novamente mais tarde. Use uma seqüência ao acaso nos locais de teste. Havendo áreas ulceradas, necróticas, cicatriciais ou hiperceratótica, teste o perímetro da mesma, se o paciente não responder à aplicação do filamento num determinado local, repetir para confirmar. Conserve o filamento protegido, cuidando 
Método

para não amassá-lo ou quebrá-lo.Se necessário, limpe-o com solução de hipoclorito de sódio a 1:10. Demorará algum tempo para que as pessoas idosas se orientem para que está sendo feito. Evitar perguntar sobre a sensibilidade do monofilamento no local para não reduzir a resposta. Na presença de calos/calosidades, avaliar a região circundante, pois os pacientes provavelmente não sentirão o monofilamento nestas regiões" (Pedrosa,1998; Wunderlich et. al, 1998; Zavala \& Braver, 2000).

\subsubsection{Variáveis relacionadas às características das úlceras:}

Para caracterização das úlceras, foram examinados os seguintes aspectos: as causas, duração, localização, o contorno, as bordas, o exsudato, a dor, o odor, e o tratamento realizado na úlcera.

Neste estudo foi usado o critério de duas dimensões, que são as medidas lineares, realizadas pela medida do lado maior vezes o lado menor da úlcera. Usou-se uma régua de papel descartável para a realização das medidas.

Bryant, (1992) refere que tem aumentado o uso desta técnica , mesmo que, em alguns casos, estas sejam imprecisas porque as medidas lineares fornecem uma base objetiva para avaliar as dimensões completas de uma úlcera. Tais medidas custam pouco, prontamente disponíveis e facilmente são qualificadas pela maioria das clínicas, além de causar pouco desconforto ao paciente. Quando verificada em seqüência fornece informações importante a respeito da direção do processo de cicatrização.

Segundo Krasner (1992) e Flanagan (1994), o cálculo da área é feito pela mensuração do comprimento e da largura da úlcera. Apontam que as medidas de comprimento e largura devem ser em centímetros, observando-se a maior extensão da ferida, que deve ser mensurada de lado a lado.

A coloração do leito da úlcera, segundo Bryant, (1992), direciona a equipe para avaliar a superfície da úlcera aberta e categorizá-la com relação às cores. Se a cor é vermelha e rósea a úlcera é saudável, sendo preta, é preocupante; se a úlcera for amarela, a terapia se faz pela remoção desta superfície e exposição do tecido vermelho. Esta técnica também direciona a equipe para um sistema de tratamento, que tende a simplificar muito a complexidade do processo de cicatrização. O sistema de avaliação através de cores, porém, não deve ser usado sozinho para avaliação da úlcera, devido a 
Método

outras manifestações essenciais do processo de cicatrização, que não contemple neste sistema.

A avaliação do estágio da úlcera, segundo a classificação de Wagner (1981), é a seguinte:

$\begin{array}{cl}\text { Grau } & \text { Características } \\ 0 & \begin{array}{l}\text { Úlceras anteriores, lesões pré ulcerativas. } \\ \text { Presença de deformidades ósseas. }\end{array} \\ 1 & \begin{array}{l}\text { Úlcera superficial com envolvimento do tecido } \\ \text { subcutâneo } \\ \end{array} \\ 2 & \begin{array}{l}\text { Úlcera que penetra no tecido subcutâneo, pode ter } \\ \text { exposição de osso, tendão, ligamento ou cápsula } \\ \text { articular }\end{array} \\ 3 & \begin{array}{l}\text { Osteítes,abscesso ou osteomielites } \\ 4\end{array} \\ 5 & \text { Gangrena de dígitos } \\ \end{array}$

\subsection{PROCEDIMENTOS PARA A COLETA DE DADOS}

\subsubsection{Instrumento de Coleta de Dados}

Os dados foram coletados por meio de um instrumento previamente estruturado e exame físico.

O instrumento utilizado para a coleta de dados da pesquisa foi elaborado, considerando as variáveis de interesse para o desenvolvimento do estudo e a revisão da literatura (Pace et al, 2002; Bersusa, 1998; Porto, 1996).

O instrumento contém cinco partes: identificação, dados sócio-demográficos (questões de números 01 a 06), dados referentes ao estilo de vida (questões de número 07 a 14), dados referentes ao diagnóstico (questões de número 15 a 18), dados referentes ao tratamento (questões de número 19 a 22) dados referentes às complicações (questões de número 23 a 24), dados referentes ao controle do diabetes (questão de 
Método

número 25), dados referentes às características das úlceras (questões de número 26 a 42), dados referentes à avaliação dos membros (questões de número 43 a 73). Também consta, em anexos, uma ficha de coleta dos resultados dos exames, para se avaliar a média anual dos exames.

\subsubsection{Validação do Instrumento de Coleta de Dados}

O instrumento, após a elaboração, foi encaminhado para dois professores da Faculdade de Enfermagem de Marília (FAMEMA) e três professoras da Escola de Enfermagem de Ribeirão Preto (EERP-USP), com conhecimento na área, para apreciação quanto ao conteúdo, clareza, compreensão e forma de apresentação dos itens.

Foi entregue pessoalmente uma carta de solicitação, juntamente com o instrumento a ser avaliado, para cada profissional. Dentro do prazo estabelecido foram devolvidos.

Posteriormente, foram realizadas as devidas correções no instrumento, conforme as sugestões feitas.

A seguir, foi aplicado em três pacientes dando continuidade ao processo de validação de conteúdo e aparência.

\subsubsection{Procedimentos para coleta dos dados}

O paciente foi abordado no momento que comparecia à unidade ambulatorial para consulta médica.O exame físico e a entrevista foram realizados antes ou após as consultas, dependendo da disposição do paciente.

Foram treinadas duas alunas do quarto ano da Faculdade de Enfermagem para auxiliarem na entrevista e exame físico.

\subsection{PROCESSAMENTO DOS DADOS}


Método

Os dados foram codificados e introduzidos num banco de dados com dupla entrada., no programa EPIINFO vs6.02.

Devido à natureza das variáveis em estudo (sócio-demográficas e estilo de vida, relacionadas ao diagnóstico, ao tratamento, ás complicações, ao controle do diabetes, avaliação dos membros inferiores e às características das úlceras) elas estão resumidas por meio de tabelas, gráficos, média e desvio-padrão e sua análise segue as normas preconizadas para um estudo descritivo.

\subsection{CONSIDERAÇÕES ÉTICAS}

O projeto foi encaminhado para apreciação do comitê de ética em pesquisa do hospital em estudo e aprovado de acordo com as Resoluções 196/96 e 251/97 do Conselho Nacional de Saúde.

Ao cliente que participou da pesquisa foi solicitado seu consentimento, por meio de um termo elaborado, com os objetivos do estudo e esclarecimento sobre sua livre participação e garantia de sigilo e anonimato. Após concordarem com a participação, os indivíduos assinaram o referido termo. 


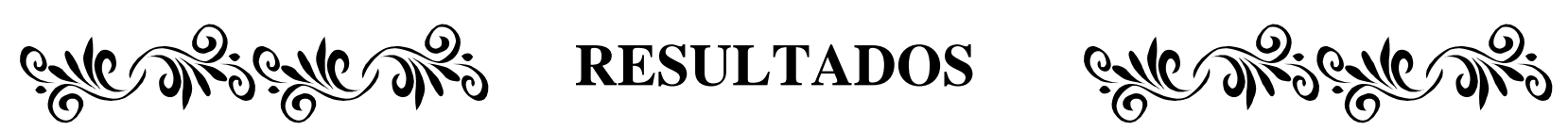


S resultados estão apresentados na seqüência dos objetivos propostos: caracterização dos pacientes com DM e úlcera no pé, segundo as variáveis sócio- demográficas; caracterização dos pacientes com DM e úlcera no pé, segundo as variáveis relacionadas ao diagnóstico, tratamento, condições clínicas dos pés, controle da doença e complicações e caracterização dos pacientes com DM e úlcera no pé, segundo as variáveis relacionadas às características das úlceras.

\subsection{Caracterização dos pacientes com DM e úlcera no pé, segundo as variáveis sócio - demográficas:}

\subsection{1-Sexo, idade, escolaridade, estado civil e procedência.}

A amostra do estudo ficou constituída por 60 pacientes, sendo 31 (51,7\%) do sexo masculino e 29 (48,3\%) do sexo feminino, com idade média de 63 anos (Tabela 5).

Na amostra estudada, observou-se uma maior freqüência de pessoas com DM e úlcera nos pés na faixa etária de 50 a 70 anos (64,4\%) e do sexo masculino (51,6\%) (Tabela 5).

Tabela 5 - Distribuição das pessoas com DM e úlcera no pé, segundo idade (anos) e sexo. Marília-SP, 2003.

\begin{tabular}{ccccccc}
\hline Faixa etária & \multicolumn{2}{c}{ Masculino } & \multicolumn{2}{c}{ Feminino } & \multicolumn{2}{c}{ TOTAL } \\
\hline & $\mathbf{N}^{\mathbf{0}}$ & $\mathbf{\%}$ & $\mathbf{N}^{\mathbf{0}}$ & $\mathbf{\%}$ & $\mathbf{N}^{\mathbf{0}}$ & $\mathbf{\%}$ \\
$30 \vdash 40$ & 4 & 12,9 & - & - & 4 & 6,6 \\
$40 \vdash 50$ & 3 & 9,6 & 1 & 3,4 & 4 & 6,6 \\
$50 \vdash 60$ & 10 & 32,2 & 4 & 13,8 & 14 & 23,3 \\
$60 \vdash 70$ & 10 & 32,2 & 9 & 31 & 19 & 31,6 \\
$70 \vdash 80$ & 4 & 12,9 & 12 & 41,4 & 16 & 26,6 \\
$80 \vdash 90$ & - & - & 3 & 14,4 & 3 & 5 \\
\hline TOTAL & $\mathbf{3 1}$ & $\mathbf{5 1 , 6}$ & $\mathbf{2 9}$ & $\mathbf{4 8 , 3}$ & $\mathbf{6 0}$ & $\mathbf{1 0 0}$ \\
\hline
\end{tabular}


Quanto à escolaridade dos pacientes, 46,6\% não possuíam escolaridade e 36,7\% possuíam o ensino fundamental incompleto (Tabela 6).

Tabela 6 - Distribuição dos pacientes com DM e úlcera no pé, segundo o grau de instrução. Marília-SP, 2003.

\begin{tabular}{ccc}
\hline Escolaridade & $\mathbf{N}$ & $\mathbf{\%}$ \\
\hline Analfabeto & 14 & 23,3 \\
Sem escolaridade/sabe ler escrever & 14 & 23,3 \\
Ensino fundamental incompleto & 22 & 36,7 \\
Ensino fundamental completo & 9 & 15 \\
Ensino médio completo & 1 & 1,7 \\
\hline TOTAL & $\mathbf{6 0}$ & $\mathbf{1 0 0}$ \\
\hline
\end{tabular}

Em relação ao estado civil, 46,7\% informaram viver com o (a) companheiro (a) e 53,3\% sem o (a) companheiro (a) (Tabela 7).

Tabela 7 - Distribuição das pessoas com DM e úlcera no pé, segundo o estado civil. Marília-SP, 2003.

\begin{tabular}{ccc}
\hline Estado Civil & $\mathbf{N}$ & $\mathbf{\%}$ \\
\hline Solteiro & 5 & 8,3 \\
Casado (a)/Amasiado (a) & 28 & 46,7 \\
& & \\
Divorciado (a)/Separado (a) & 6 & 10 \\
Viúvo (a) & 21 & 35 \\
\hline TOTAL & $\mathbf{6 0}$ & $\mathbf{1 0 0}$ \\
\hline
\end{tabular}

A variável ocupação foi classificada em ativa e inativa, sendo a maioria (90\%) de inativos, ou seja, de aposentados e (10\%) de ativos. Dentre estas últimas, foram encontradas as ocupações: carpinteiro, comerciante, pedreiro, lavrador, secretário e empregado doméstico.

No referente à procedência dos pacientes, 28 (46,7\%) são da cidade de Marília, $28(46,7 \%)$ de outros municípios da região de Marília e 4 (6,7\%) de outros municípios do Estado de São Paulo. 
Em relação ao tabagismo, 28 (46,7\%) não fumam e 25 (45\%) são ex - fumantes (Tabela 8).

5.1.2- Tabagismo, etilismo e atividade física.

Tabela 8 - Distribuição das pessoas com DM e úlcera no pé, segundo tabagismo. Marília-SP, 2003.

\begin{tabular}{ccc}
\hline Tabagismo & $\mathbf{N}$ & $\mathbf{\%}$ \\
\hline Sim & 7 & 11,7 \\
Não & 28 & 46,7 \\
Ex-fumante & 25 & 45,0 \\
\hline TOTAL & $\mathbf{6 0}$ & $\mathbf{1 0 0}$ \\
\hline
\end{tabular}

Entre os fumantes e ex - fumantes, o tempo médio de tabagismo foi de 17,8 anos, destacando-se 7 (21,9\%) que fumaram ou fumam por um período de 30 a 40 anos, e $6(18,7 \%)$ por um período de 20 a 30 anos (Tabela 9 ).

Tabela 9 - Distribuição das pessoas com DM e úlcera no pé, segundo o tempo de tabagismo. Marília-SP, 2003.

\begin{tabular}{ccc}
\hline Tempo de Tabagismo & $\mathbf{N}$ & $\mathbf{\%}$ \\
\hline $0 \vdash 10$ & 5 & 15,6 \\
$10 \vdash 20$ & 4 & 12,5 \\
$20 \vdash 30$ & 6 & 18,7 \\
$30 \vdash 40$ & 7 & 21,9 \\
$40 \vdash 50$ & 5 & 15,6 \\
$50 \vdash 60$ & 3 & 9,4 \\
$60 \vdash 70$ & 2 & 6,3 \\
\hline TOTAL & $\mathbf{3 2}$ & $\mathbf{1 0 0}$ \\
\hline
\end{tabular}


O tempo médio de cessação do tabagismo foi de 3,6 anos. A maioria (70,4\%) referiu ter parado de fumar há pelo menos 10 anos (Tabela 10).

Tabela 10 - Distribuição das pessoas com DM e úlcera no pé, segundo o tempo em que pararam de fumar em anos. Marília-SP, 2003.

\begin{tabular}{ccc}
\hline Tempo que pararam de fumar & $\mathbf{n}$ & $\mathbf{\%}$ \\
\hline $0 \vdash 10$ & 19 & 70,4 \\
$10 \vdash 20$ & 7 & 25,9 \\
$20 \vdash 30$ & 1 & 3,7 \\
\hline TOTAL & & \\
\hline
\end{tabular}

O etilismo foi referido por 8 (13,3\%) dos participantes, porém 10 (16,7\%) referiram ser ex - etilistas (Tabela 11).

Tabela 11 - Distribuição das pessoas com DM e úlcera no pé, segundo o etilismo. Marília-SP, 2003.

\begin{tabular}{ccc}
\hline Etilismo & $\mathbf{N}$ & $\mathbf{\%}$ \\
\hline Sim & 8 & 13,3 \\
Não & 42 & 70 \\
Ex - etilista & 10 & 16,7 \\
\hline TOTAL & $\mathbf{6 0}$ & $\mathbf{1 0 0}$ \\
\hline
\end{tabular}

Entre os etilistas e ex-etilistas, o tempo médio de ingestão alcoólica foi de 27,4 anos, destacando que 4 (22,2\%) pacientes ingeriram álcool por um período de 21 a 30 anos (Tabela 12). 
Tabela 12 - Distribuição das pessoas com DM e úlcera no pé, segundo o tempo de etilismo. Marília-SP, 2003.

\begin{tabular}{ccc}
\hline Tempo em que beberam & $\mathbf{N}$ & $\mathbf{\%}$ \\
\hline $5 \vdash 10$ & 5 & 27,8 \\
$11 \vdash 20$ & 3 & 16,7 \\
$21 \vdash 30$ & 4 & 22,2 \\
$31 \vdash 40$ & 2 & 11,1 \\
$41 \vdash 50$ & 2 & 11,1 \\
$51 \vdash 60$ & 2 & 11,1 \\
\hline TOTAL & $\mathbf{1 8}$ & $\mathbf{1 0 0}$ \\
\hline
\end{tabular}

O tipo de bebida referida com maior freqüência foi cerveja 3 (37,5\%), seguida por pinga 2 (25\%) e a associação de pinga com cerveja 2 (25\%) (Tabela 13).

Tabela 13 - Distribuição das pessoas com DM e úlcera no pé, segundo o tipo de bebida ingerida. Marília-SP, 2003.

\begin{tabular}{ccc}
\hline Tipo de bebida & N & \% \\
\hline Pinga & 2 & 25 \\
Cerveja & 3 & 37,5 \\
Pinga/cerveja & 2 & 25 \\
Vinho & 1 & 12,5 \\
\hline TOTAL & $\mathbf{8}$ & $\mathbf{1 0 0}$ \\
\hline
\end{tabular}

Quanto à freqüência de etilismo, com maior destaque a ingestão, foi de até 3 vezes por semana 6 pacientes (75\%) (Tabela 14$)$. 
Tabela 14 - Distribuição das pessoas com DM e úlcera no pé, segundo a freqüência de uso da bebida. Marília-SP, 2003.

\begin{tabular}{ccc}
\hline Freqüência de uso da bebida & $\mathbf{N}$ & $\mathbf{\%}$ \\
\hline Até 3 vezes/semana (final semana) & 6 & 75 \\
4 a 7 vezes/semana (diariamente/quase) & 1 & 12,5 \\
Raramente 1vez/semana & 1 & 12,5 \\
\hline TOTAL & $\mathbf{8}$ & $\mathbf{1 0 0}$ \\
\hline
\end{tabular}

Em relação à freqüência da atividade física, 9 (15\%) informaram que possuem essa prática, sendo a caminhada a modalidade mais referida por 6 (66,9\%) (Tabela 15).

Tabela 15 - Distribuição das pessoas com DM e úlcera no pé, segundo a prática de atividade física. Marília-SP, 2003.

\begin{tabular}{ccc}
\hline Atividade física & $\mathbf{N}$ & $\mathbf{\%}$ \\
\hline Caminhada & 6 & 66,9 \\
Bicicleta & 2 & 22,2 \\
Futebol & 1 & 11,1 \\
\hline TOTAL & $\mathbf{9}$ & $\mathbf{1 0 0}$ \\
\hline
\end{tabular}

Entre as pessoas que referiram praticar atividades, físicas 5 (55,5\%) praticavam diariamente.(Tabela 16). 
Tabela 16 - Distribuição das pessoas com DM e úlcera no pé, segundo a freqüência da atividade física. Marília-SP 2003.

\begin{tabular}{ccc}
\hline Freqüência da Atividade Física & $\mathbf{N}$ & $\mathbf{\%}$ \\
\hline Diariamente ou quase (5 a 7 vezes/semana) & 5 & 55,6 \\
3 a 4 vezes/semana & 1 & 11,1 \\
2 vezes/semana, apenas nos fins de semana & 3 & 33,3 \\
\hline TOTAL & $\mathbf{9}$ & $\mathbf{1 0 0}$ \\
\hline
\end{tabular}

\subsection{Caracterização dos pacientes com DM e úlcera no pé, segundo as variáveis relacionadas ao diagnóstico, tratamento, condições clínicas dos pés, controle da doença e complicações.}

\subsection{1-Diagnóstico e tratamento.}

Para a variável diagnóstico considerou-se o tipo e tempo do diagnóstico do DM.

Quanto ao tipo de DM dos pacientes, verificou-se que 3 (5\%) eram do tipo 1 e 57 (95\%) do tipo 2.

O tempo médio de diagnóstico de DM foi de 12,6 anos, e o intervalo que obteve maior freqüência foi de 5 - 10 (31,6\%), como apresentado na Tabela 17. 
Tabela 17 - Distribuição das pessoas com DM e úlcera no pé, segundo o tempo de diagnóstico. Marília-SP, 2003.

\begin{tabular}{ccc}
\hline Tempo do diagnóstico diabetes & $\mathbf{N}$ & $\mathbf{\%}$ \\
\hline $0 \vdash 5$ & 13 & 21,6 \\
$5 \vdash 10$ & 19 & 31,6 \\
$10 \vdash 15$ & 12 & 20 \\
$15 \vdash 20$ & 6 & 10 \\
$20 \vdash 25$ & 4 & 6,6 \\
$20 \vdash 30$ & 4 & 6,63 \\
$30 \vdash 35$ & 2 & 3,3 \\
\hline TOTAL & $\mathbf{6 0}$ & $\mathbf{1 0 0}$ \\
\hline
\end{tabular}

No que se refere ao tipo de tratamento do DM, $38(63,3 \%)$ das pessoas informaram que faziam dieta, 34 (36,7\%) fazem uso de antidiabéticos orais e 37 (61,7\%) fazem uso de insulina (Tabela 18).

Tabela 18 - Distribuição das pessoas com DM e úlcera no pé, segundo o tratamento medicamentoso e não medicamentoso. Marília-SP, 2003.

\begin{tabular}{ccccccccc}
\hline $\begin{array}{c}\text { Tipo de } \\
\text { tratamento }\end{array}$ & \multicolumn{2}{c}{ Sim } & \multicolumn{2}{c}{ Não } & Ás vezes & \multicolumn{2}{c}{ Total } \\
\hline & $\mathbf{N}$ & $\mathbf{\%}$ & $\mathbf{N}$ & $\mathbf{\%}$ & $\mathbf{N}$ & $\mathbf{\%}$ & $\mathbf{N}$ & $\mathbf{\%}$ \\
\hline Dieta & 38 & 63,3 & 06 & 73,3 & 16 & 26,7 & 60 & 100 \\
Antidiabético oral & 34 & 56,7 & 26 & 43,3 & - & - & 60 & 100 \\
Insulina & 37 & 61,7 & 23 & 38,3 & - & - & 60 & 100 \\
\hline
\end{tabular}

Quanto ao tempo do tratamento do DM, a freqüência maior ocorreu entre 5 a 10 anos (31,6\%), seguido por 0 a 5 anos (21,6\%), (Tabela 19). 
Tabela 19 - Distribuição das pessoas com DM e úlcera no pé, segundo o tempo de tratamento do diabetes. Marília-SP, 2003.

\begin{tabular}{ccc}
\hline Tempo do tratamento do diabetes & $\mathbf{N}$ & $\mathbf{\%}$ \\
\hline $0 \vdash 5$ & 13 & 21,6 \\
$5 \vdash 10$ & 19 & 31,6 \\
$10 \vdash 15$ & 12 & 20 \\
$15 \vdash 20$ & 6 & 10 \\
$20 \vdash 25$ & 4 & 6,6 \\
$20 \vdash 30$ & 4 & 6,63 \\
$30 \vdash 35$ & 2 & 3,3 \\
TOTAL & $\mathbf{6 0}$ & $\mathbf{1 0 0}$ \\
\hline
\end{tabular}

\subsection{2-Controle da doença.}

Para a classificação da pressão arterial utilizaram-se os parâmetros determinados pelo segundo Consenso Brasileiro de Condutas para o Diabetes Mellitus - SBD, 2001.

Em relação à pressão arterial dos pacientes com diabetes mellitus e úlcera no pé, encontrou-se que 37(61,7\%) apresentaram PA sistólica >140 mmhg, 29 (48,3\%) PA diastólica > 90 mmhg, 9(15\%) PA sistólica <140 mmhg, 22 (36,6\%) PA diastólica < 90 mmhg, 14 (23,3\%) PA sistólica < 135 mmhg e 09 (15,0\%) PA diastólica <80 mmhg (Tabela 20).

Tabela 20 - Distribuição das pessoas com DM e úlcera no pé, segundo o Índice de Pressão arterial, Marília-SP, 2003.

\begin{tabular}{c|c|c|c|c|c}
\hline \multicolumn{4}{c|}{ Pressão Arterial } & \multicolumn{2}{c}{ Total } \\
\hline $\begin{array}{c}\text { Sistólica } \\
\text { mmhg }\end{array}$ & $\mathrm{N}^{\mathrm{o}}$ & $\%$ & $\begin{array}{c}\text { Diastólica } \\
\text { mmhg }\end{array}$ & $\mathrm{N}^{\mathrm{o}}$ & $\%$ \\
\hline$<135$ Bom & 14 & 23,3 & $<80 \mathrm{mmhg}$ & 9 & 15 \\
$<140$ Aceitável & 9 & 15 & $<90 \mathrm{mmhg}$ & 22 & 36,7 \\
$>140$ & 37 & 61,7 & $>90 \mathrm{mmhg}$ & 29 & 48,3 \\
\hline TOTAL & $\mathbf{6 0}$ & $\mathbf{1 0 0}$ & & $\mathbf{6 0}$ & $\mathbf{1 0 0}$ \\
\hline
\end{tabular}


O IMC dos pacientes foi classificado em bom, aceitável e mau conforme o Consenso Brasileiro de Condutas para o Diabetes Mellitus- SBD (2001), porém encontraram-se $5(8,4 \%)$ pacientes que não se enquadraram nestas categorias por apresentarem um IMC menor que $20\left(\mathrm{Kg} \mathrm{m}^{2}\right)$. Destacou-se uma maior freqüência (38,4\%) na categoria “mau” em relação a esta variável (Tabela 21).

Tabela 21 - Distribuição das pessoas com DM e úlcera no pé, segundo o Índice de Massa Corpórea (IMC) Marília-SP, 2003.

\begin{tabular}{|c|c|c|c|c|c|c|c|c|c|c|}
\hline \multirow{2}{*}{$\begin{array}{l}\text { Índice de } \\
\text { Massa } \\
\text { Corpórea } \\
\text { (IMC) }\end{array}$} & \multicolumn{2}{|c|}{$<20$} & \multicolumn{2}{|c|}{$\begin{array}{c}\text { Bom } \\
20-25\end{array}$} & \multicolumn{2}{|c|}{$\begin{array}{c}\text { Aceitável } \\
25-30 \\
\end{array}$} & \multicolumn{2}{|c|}{$\begin{array}{r}\text { Mau } \\
>30\end{array}$} & \multicolumn{2}{|c|}{ TOTAL } \\
\hline & $\mathbf{N}^{\mathbf{o}}$ & $\%$ & $\mathbf{N}^{\mathbf{O}}$ & $\%$ & $\mathbf{N}$ & $\%$ & $\mathbf{N}^{\mathbf{0}}$ & $\%$ & $\mathbf{N}$ & $\%$ \\
\hline Homem & 3 & 5,0 & 7 & 11,6 & 8 & 13,3 & 13 & 21,7 & 31 & 51,6 \\
\hline Mulher & 2 & 3,3 & 6 & 10 & 11 & 18,3 & 10 & 16,7 & 29 & 48,4 \\
\hline TOTAL & 5 & 8,4 & 13 & 21,6 & 8 & 31,6 & 34 & 38,4 & 60 & 100 \\
\hline
\end{tabular}

Para avaliar o grau de controle glicêmico, calcularam-se as médias das glicemias realizadas no período de um ano, considerando o número de exames realizados neste período. A média de exames foi de 8,7, sendo que 27 (45\%) pacientes realizaram de um a nove exames (Tabela 22).

Tabela 22 - Distribuição das pessoas com DM e úlcera no pé, segundo o número de exames de glicemia de jejum, Marília-SP, 2003.

\begin{tabular}{ccc}
\hline Número de exames-glicemia & $\mathbf{N}$ & $\mathbf{\%}$ \\
\hline $0 \vdash 10$ & 27 & 45 \\
$10 \vdash 20$ & 11 & 18,3 \\
$20 \vdash 30$ & 10 & 16,7 \\
$30 \vdash 40$ & 1 & 1,7 \\
\hline TOTAL & $\mathbf{4 9}$ & $\mathbf{1 0 0}$ \\
\hline
\end{tabular}

A partir do cálculo das médias glicêmicas, os pacientes foram classificados de acordo com o seu nível glicêmico de jejum, a saber: 8(16,3\%) estavam com bom controle, 2(4,1\%), aceitável e 39(79,6\%)) mau (Tabela 23), segundo o Consenso 
Brasileiro de Condutas para o Diabetes Mellitus (Sociedade Brasileira de Diabetes, 2000).

Tabela 23 - Distribuição das pessoas com DM e úlcera no pé, segundo os níveis glicêmicos, Marília-SP, 2003.

\begin{tabular}{ccc}
\hline Nível glicêmico & N & $\mathbf{\%}$ \\
\hline Bom $<110$ & 8 & 16,3 \\
Aceitável $110-140$ & 2 & 4,1 \\
Mau $>140$ & 39 & 79,6 \\
TOTAL & $\mathbf{4 9}$ & $\mathbf{1 0 0}$ \\
\hline
\end{tabular}

Quanto ao grau de controle de hemoglobina glicosilada, calcularam-se as médias realizadas no período de um ano, considerando o número de exames realizados neste período. A média de exames foi de 1,2 exames (Tabela 24 ).

Tabela 24 - Distribuição das pessoas com DM e úlcera no pé, segundo o número de exames de hemoglobina glicosilada por ano, Marília-SP, 2003.

\begin{tabular}{ccc} 
Número de Exames & $\mathbf{N}$ & $\mathbf{\%}$ \\
\hline $0 \vdash 5$ & - & - \\
$5 \vdash 10$ & 14 & 23,3 \\
$10 \vdash 15$ & 4 & 6,7 \\
\hline TOTAL & $\mathbf{1 8}$ & $\mathbf{1 0 0}$ \\
\hline
\end{tabular}

O exame da hemoglobina glicosilada foi verificada em 18(30\%) pacientes e destes, 5(27,8\%) encontravam-se com os valores considerados adequados; 9(50\%), aceitável e 4(22,2\%), mau (Tabela 25), segundo o Consenso Brasileiro de Condutas para o Diabetes Mellitus (Sociedade Brasileira de Diabetes, 2000). 
Tabela 25 - Distribuição das pessoas com DM e úlcera no pé, segundo os valores de hemoglobina glicosilada, Marília-SP, 2003.

\begin{tabular}{ccc}
\hline Hemoglobina Glicosilada & $\mathbf{N}$ & $\mathbf{\%}$ \\
\hline$<6$ Bom & 5 & 27,8 \\
$<7$ aceitável & 9 & 50 \\
$>8$ mau & 4 & 22,2 \\
TOTAL & $\mathbf{1 8}$ & $\mathbf{1 0 0}$ \\
\hline
\end{tabular}

Quanto ao grau de controle de colesterol, calcularam-se as médias destes exames realizadas no período de um ano, considerando o número de exames realizados neste período. A média de exames foi de 0,4 sendo que 10 (16,7\%) pacientes realizaram de 0 a 5 exames (Tabela 26 ).

Tabela 26 - Distribuição das pessoas com DM e úlcera no pé, segundo o número de exames de colesterol, Marília-SP, 2003.

\begin{tabular}{ccc} 
Número de Exames & $\mathbf{N}$ & $\mathbf{\%}$ \\
\hline $0 \vdash 5$ & 10 & 16,7 \\
$5 \vdash 10$ & 1 & 1,7 \\
TOTAL & $\mathbf{1 1}$ & $\mathbf{1 0 0}$ \\
\hline
\end{tabular}

O nível de colesterol foi verificado em 11(18,3\%) pacientes e destes, 2(18,2\%) encontravam-se com os valores considerados bons, 6(54,5\%), aceitável e3(27,3\%), mau (Tabela 27), segundo o Consenso Brasileiro de Condutas para o Diabetes Mellitus (Sociedade Brasileira de Diabetes, 2000) .

Tabela 27 - Distribuição das pessoas com DM e úlcera no pé, segundo os níveis de colesterol, Marília-SP, 2003.

\begin{tabular}{ccc}
\hline Níveis de Colesterol & N & \% \\
\hline Bom $<200$ & 2 & 18,2 \\
Aceitável $200-239$ & 6 & 54,5 \\
Mau $>240$ & 3 & 27,3 \\
TOTAL & $\mathbf{1 1}$ & $\mathbf{1 0 0}$ \\
\hline
\end{tabular}


Em relação ao grau de controle de triglicérides, calcularam-se as médias destes exames realizadas no período de um ano, considerando o número de exames realizados neste período. A média de exames foi de 0,5, sendo que 12 (20\%) pacientes realizaram de 0 a 5 exames (Tabela 28 ).

Tabela 28 - Distribuição das pessoas com DM e úlcera no pé, segundo número de exames de triglicérides, Marília-SP, 2003.

\begin{tabular}{ccc} 
Número de exames & $\mathbf{N}$ & $\mathbf{\%}$ \\
\hline $0 \vdash 5$ & 12 & 20 \\
$5 \vdash 10$ & 1 & 1,7 \\
TOTAL & $\mathbf{1 3}$ & $\mathbf{1 0 0}$ \\
\hline
\end{tabular}

O nível de triglicérides foi verificado em 13(21,7\%) pacientes e, destes, 7(53,8\%) encontravam-se com os valores considerados bons, 3(23,1\%) aceitáveis e3(23,1\%) mau (Tabela 29), segundo o Consenso Brasileiro de Condutas para o Diabetes Mellitus (Sociedade Brasileira de Diabetes, 2000).

Tabela 29- Distribuição das pessoas com DM e úlcera no pé, segundo os níveis de triglicérides, Marília-SP, 2003.

\begin{tabular}{ccc}
\hline Níveis de triglicérides & N & \% \\
\hline Bom $<150$ & 7 & 53,8 \\
Aceitável 150 - 199 & 3 & 23,1 \\
Mau $>200$ & 3 & 23,1 \\
TOTAL & $\mathbf{1 3}$ & $\mathbf{1 0 0}$ \\
\hline
\end{tabular}

Em relação ao grau de controle do HDL, calcularam-se as médias destes exames realizadas no período de um ano, considerando o número de exames realizados neste período. A média de exames foi de 0,4, sendo que 11 (18,3\%) pacientes realizaram de 0 a 5 exames (Tabela 30 ). 
Tabela 30 - Distribuição das pessoas com DM e úlcera no pé, segundo o número de exames de HDL, Marília-SP, 2003.

\begin{tabular}{ccc}
\hline Número de exames-HDL & $\mathbf{N}$ & $\mathbf{\%}$ \\
\hline $0 \vdash 5$ & 11 & 18,3 \\
$5 \vdash 10$ & 1 & 1,7 \\
\hline TOTAL & $\mathbf{1 2}$ & $\mathbf{1 0 0}$ \\
\hline
\end{tabular}

O exame de HDL foi verificado em 12(20,\%) pacientes e destes, 6(50\%) encontravam-se com os valores considerados bons e aceitáveis e 6(50\%) maus (Tabela 31), segundo o Consenso Brasileiro de Condutas para o Diabetes Mellitus (Sociedade Brasileira de Diabetes, 2000).

Tabela 31 - Distribuição das pessoas com DM e úlcera no pé, segundo os níveis de HDL, Marília-SP, 2003.

\begin{tabular}{ccc}
\hline Nível de HDL & N & $\mathbf{\%}$ \\
\hline Bom e aceitável $>45$ & 6 & 50 \\
Mau $<45$ & 6 & 50 \\
TOTAL & $\mathbf{1 2}$ & $\mathbf{1 0 0}$ \\
\hline
\end{tabular}

Quanto ao grau de controle do LDL, calcularam-se as médias destes exames realizadas no período de um ano, considerando o número de exames realizados neste período. A média de exames foi de 0,37 , sendo que $11(18,3 \%)$ pacientes realizaram de 0 a 5 exames (Tabela 32 ), segundo o Consenso Brasileiro de Condutas para o Diabetes Mellitus (Sociedade Brasileira de Diabetes, 2000).

Tabela 32 - Distribuição das pessoas com DM e úlcera no pé, segundo o número de exames de LDL, Marília-SP, 2003.

\begin{tabular}{ccc} 
Número de exames-LDL & $\mathbf{N}$ & $\mathbf{\%}$ \\
\hline $0 \vdash 5$ & 11 & 18,3 \\
$5 \vdash 10$ & 1 & 1,7 \\
TOTAL & $\mathbf{6 0}$ & $\mathbf{1 0 0}$ \\
\hline
\end{tabular}


O exame de LDL foi verificado em 12(20,\%) pacientes e, os valores considerados bons não foram encontrados em nenhum paciente, 6(50\%) encontravam-se com os valores considerados aceitáveis e 6(50\%),maus(Tabela 33), segundo o Consenso Brasileiro de Condutas para o Diabetes Mellitus (Sociedade Brasileira de Diabetes, 2000).

Tabela 33 - Distribuição das pessoas com DM e úlcera no pé, segundo os níveis de LDL, Marília-SP, 2003.

\begin{tabular}{ccc} 
Nível de LDL & N & \% \\
\hline Bom $<100$ & - & - \\
Aceitável 100 - 159 & 6 & 50 \\
Mau $>160$ & 6 & 50 \\
\hline TOTAL & $\mathbf{1 2}$ & $\mathbf{1 0 0}$ \\
\hline
\end{tabular}

\subsection{3- Complicações.}

As complicações foram relacionadas conforme registros nos prontuários. As condições de risco e as complicações em pés estão presentes em 39 (65\%) pacientes (Tabela 34).

Tabela 34 - Distribuição das pessoas com DM e úlcera no pé, segundo as complicações crônicas do DM, registradas nos prontuários. Marília-SP, 2003.

\begin{tabular}{ccc}
\hline Complicações & $\mathbf{N}$ & $\mathbf{\%}$ \\
\hline Retinopatia & 19 & 31,7 \\
Retinopatia , nefropatia e úlceras & 9 & 15 \\
Doença vascular periférica e pé diabético & 19 & 31,7 \\
Neuropatia e Pé diabético & 11 & 18,3 \\
Nefropatia e retinopatia & 2 & 3,3 \\
\hline TOTAL & $\mathbf{6 0}$ & $\mathbf{1 0 0}$ \\
\hline
\end{tabular}


Ao se verificarem as doenças associadas, destaca-se que $60(100 \%)$ dos pacientes são hipertensos, o que agrava o risco para as complicações em pés, sendo que 16 (26,6\%) apresentaram hipertensão e obstrução arterial crônica (Tabela 35).

Tabela 35 - Distribuição das pessoas com DM e úlcera no pé, segundo as doenças associadas. Marilia-SP, 2003.

\begin{tabular}{|c|c|c|}
\hline Doenças associadas & $\mathbf{N}$ & $\%$ \\
\hline Hipertensão arterial & 12 & 20 \\
\hline $\begin{array}{l}\text { Hipertensão arterial e obstrução arterial } \\
\text { crônica }\end{array}$ & 16 & 26,6 \\
\hline $\begin{array}{l}\text { Hipertensão arterial, Insuficiência } \\
\text { cardíaca, acidente vascular cerebral e } \\
\text { infarto do miocárdio }\end{array}$ & 10 & 16,7 \\
\hline $\begin{array}{l}\text { Hipertensão arterial, Obstrução arterial } \\
\text { crônica, gastrite e pneumonia }\end{array}$ & 10 & 16,7 \\
\hline $\begin{array}{l}\text { Hipertensão arterial, obesidade, } \\
\text { osteomielite e depressão }\end{array}$ & 12 & 20 \\
\hline TOTAL & 60 & 100 \\
\hline
\end{tabular}

\subsection{4- Condições clínicas dos pés.}

As variáveis referentes às condições clinicas dos pés estão apresentadas na seqüência do exame físico realizado: avaliação do estado geral (deambulação/marcha e presença de amputações em membros inferiores); dermatológica (higiene, pele, fâneros e corte de unhas), estrutural (curvatura plantar, dedos em garra e/ou sobrepostos, hallus valgus); circulatória ( presença de edema, consistência do edema, palpação de pulsos pedioso e tibial posterior, rubor em pendência, palidez à elevação, temperatura da pele à palpação) e neurológica (força muscular, sensibilidade tátil pressória com monofilamento de Semmes-Weinsten de $10 \mathrm{~g}$, em nove pontos na região plantar e um na dorsal, reflexos patelar, aquileu e plantar).

Incluiu-se também nesta avaliação, a observação dos calçados e meias que usam habitualmente e que estavam usando no momento da entrevista.

Com referência à mobilidade física, verificou-se que 32 (53,3\%) pacientes deambulam, 10 (16,7\%) não deambulam e 18 (30\%) deambulam com auxílio (Tabela 36) . 
Tabela 36 - Distribuição das pessoas com DM e úlcera no pé, segundo a mobilidade física Marília-SP, 2003.

\begin{tabular}{ccc}
\hline Mobilidade física & $\mathbf{N}$ & $\mathbf{\%}$ \\
\hline Deambula & 32 & 53,3 \\
Não deambula & 10 & 16,7 \\
Deambula com auxílio & 18 & 30 \\
\hline Total & 60 & 100
\end{tabular}

Para classificar os pacientes em relação à presença ou não de alterações na marcha, consideraram-se os que não deambulam e os que deambulam com auxilio como possuidores desta alteração; portanto 33 (55\%) possuíam alteração na marcha e 25 (45\%) não possuíam.

Com referência às amputações, destaca-se que 33 (55\%) pacientes sofreram amputações de membros inferiores (Tabela 37).

Tabela 37 - Distribuição das pessoas com DM e úlcera no pé, segundo as amputações Marília-SP, 2003.

\begin{tabular}{ccc}
\hline Amputações & $\mathbf{N}$ & $\mathbf{\%}$ \\
\hline MID & 14 & 23,3 \\
MIE & 16 & 26,7 \\
Ambos & 3 & 5 \\
Ausente & 27 & 45 \\
\hline Total & $\mathbf{6 0}$ & $\mathbf{1 0 0}$ \\
\hline
\end{tabular}

Ao se investigar sobre história de úlceras anteriores, encontrou-se que 48 (80\%) informaram presença de úlceras anteriores. (Tabela.38)

Tabela 38 - Distribuição das pessoas com DM e úlcera no pé, segundo as úlceras anteriores Marília-SP, 2003.

\begin{tabular}{ccc}
\hline Úlceras anteriores & $\mathrm{N}$ & $\%$ \\
\hline $\mathrm{c}: \mathrm{m}$ & 10 & $0 \mathrm{n}$
\end{tabular}

Elizabeth Pillon Scapim 
Método

Quanto à condição de higiene dos pés, observou-se que 43 (71,7\%) apresentavam-se com boa higienização, 12 (20\%) com regular e 5 (8,3\%) insatisfatória.

Em relação à avaliação da pele e fâneros, bromidrose esteve presente em 50\% dos pacientes, seguido de 49\% de anidrose, 48\% de unhas espessas/aspecto farináceo e 47\% de descamação. Os resultados podem ser visualizados na Tabela 39.

Tabela 39 - Distribuição das pessoas com DM e úlcera no pé, segundo a avaliação da pele e fâneros do pé diabético, Marília-SP, 2003.

\begin{tabular}{|c|c|c|c|c|c|c|}
\hline \multirow[b]{2}{*}{$\begin{array}{l}\text { Avaliação da } \\
\text { pele e fâneros }\end{array}$} & \multicolumn{2}{|c|}{ Presente } & Ausente & \multicolumn{3}{|c|}{ Total } \\
\hline & $\mathbf{N}$ & $\%$ & $\mathbf{N}$ & $\%$ & $\mathbf{N}$ & $\%$ \\
\hline Anidrose & 49 & 81,7 & 11 & 18,3 & 60 & 100 \\
\hline Bromidrose & 50 & 83,3 & 10 & 16,7 & 60 & 100 \\
\hline $\begin{array}{c}\text { Lesões } \\
\text { interdigitais }\end{array}$ & 13 & 21,7 & 47 & 78,3 & 60 & 100 \\
\hline Descamações & 47 & 78,3 & 13 & 21,7 & 60 & 100 \\
\hline $\begin{array}{l}\text { Rachaduras } \\
\text { Fissuras }\end{array}$ & 23 & 38,3 & 37 & 61,7 & 60 & 100 \\
\hline $\begin{array}{l}\text { Unha espessa/ } \\
\text { aspecto } \\
\text { farináceo }\end{array}$ & 48 & 80 & 12 & 20,0 & 60 & 100 \\
\hline $\begin{array}{l}\text { Unha com } \\
\text { coloração } \\
\text { alterada }\end{array}$ & 36 & 60 & 24 & 40,0 & 60 & 100 \\
\hline $\begin{array}{l}\text { Unha com } \\
\text { alteração de } \\
\text { crescimento/ } \\
\text { Encravada }\end{array}$ & 36 & 60 & 24 & 40,0 & 60 & 100 \\
\hline
\end{tabular}

Os calçados e meias, assim como o corte de unhas, foram classificados em adequados e inadequados, sendo apresentados na Tabela 40 . Verificou-se que 45(75\%) usam sapatos inadequados e apenas 15(25\%) usam sapatos adequados; quanto ao corte de unhas, 21 (35\%) dos pacientes apresentavam-se com corte adequado e 39 (65\%) inadequado.

Tabela 40 - Distribuição das pessoas com DM e úlcera no pé, segundo a avaliação do tipo de calçados, meias e corte das unhas. Marília-SP, 2003. 
Método

\begin{tabular}{ccccccc}
\hline Corte de unhas, & \multicolumn{2}{c}{ Adequado } & \multicolumn{2}{c}{ Inadequado } & \multicolumn{2}{c}{ Total } \\
calçados e meias & $\mathbf{N}^{\mathbf{0}}$ & $\mathbf{\%}$ & $\mathbf{N}^{\mathbf{0}}$ & $\mathbf{\%}$ & $\mathbf{N}^{\mathbf{0}}$ & $\mathbf{\%}$ \\
$\begin{array}{c}\text { Corte de unhas } \\
\text { Tipo de calçado que }\end{array}$ & 21 & 35 & 39 & 65 & 60 & 100 \\
$\begin{array}{c}\text { está usando } \\
\text { Tipo de calçado que }\end{array}$ & 15 & 25 & 45 & 75 & 60 & 100 \\
$\begin{array}{c}\text { usa habitualmente } \\
\text { Tipo de meias }\end{array}$ & 25 & 26,7 & 44 & 73,3 & 60 & 100 \\
\hline
\end{tabular}

Quanto a avaliação da estrutura dos pés, destaca-se a alteração dedos em garra com maior freqüência (31,7\%\%), seguido por calos e calosidades (31,7\%), dedos sobrepostos (23,3\%) e proeminência do primeiro metatarso (18,3\%) (Tabela 41).

Tabela 41 - Distribuição das pessoas com DM e úlcera no pé, segundo avaliação estrutural do pé, Marília, 2003.

\begin{tabular}{|c|c|c|c|c|c|c|}
\hline \multirow{3}{*}{ Alterações } & \multicolumn{2}{|c|}{ Presente } & \multicolumn{4}{|c|}{ Ausente } \\
\hline & \multirow[t]{2}{*}{$\mathbf{N}$} & \multirow[t]{2}{*}{$\%$} & \multicolumn{4}{|c|}{ Total } \\
\hline & & & $\mathbf{N}^{\mathbf{o}}$ & $\%$ & $\mathbf{N}^{\circ}$ & $\%$ \\
\hline \multirow{2}{*}{$\begin{array}{l}\text { Pé plano } \\
\text { Arco do pe } \\
\text { acentuado }\end{array}$} & 7 & 11,7 & 53 & 88,3 & 60 & 100 \\
\hline & 10 & 16,7 & 50 & 83,3 & 60 & 100 \\
\hline \multirow{3}{*}{$\begin{array}{l}\text { Dedos em garra } \\
\text { Dedos } \\
\text { sobrepostos } \\
\text { Proeminência } \\
\text { do primeiro } \\
\text { metatarso }\end{array}$} & 19 & 31,7 & 41 & 68,3 & 60 & 100 \\
\hline & 14 & 23,3 & 46 & 76,7 & 60 & 100 \\
\hline & 11 & 18,3 & 49 & 81,7 & 60 & 100 \\
\hline \multirow{2}{*}{$\begin{array}{l}\text { Calos e Calosi } \\
\text { dadades }\end{array}$} & & & & & & \\
\hline & 19 & 31,7 & 41 & 68,3 & 60 & 100 \\
\hline
\end{tabular}

O edema foi observado em 35 (58,3\%) pessoas constituintes da amostra (Tabela 42).

Elizabeth Pillon Scapim

Resultados

Tabela 42 - Distribuição das pessoas com DM e úlcera no pé, segundo a presença de edema dos pés. Marília, 2003.

Edema dos pés $\quad \mathrm{N} \quad \%$


Método

\begin{tabular}{ccc} 
MID & 19 & 31,7 \\
MIE & 14 & 23,3 \\
Ambos & 2 & 3,3 \\
Não & 25 & 41,7 \\
\hline Total & $\mathbf{6 0}$ & $\mathbf{1 0 0}$ \\
\hline
\end{tabular}

Na avaliação do rubor na pendência e empalidecimento à elevação, 27 (45\%) pacientes apresentavam os dois sinais (tabela 43).

Tabela 43. Distribuição das pessoas com DM e úlcera no pé, segundo a avaliação vascular dos pés. Marília, 2003.

\begin{tabular}{ccccc}
\hline Avaliação vascular dos pés & \multicolumn{2}{c}{$\begin{array}{c}\text { Rubor na } \\
\text { pendência }\end{array}$} & \multicolumn{2}{c}{$\begin{array}{c}\text { Empalidecimento à } \\
\text { elevação }\end{array}$} \\
\hline & $\mathbf{N}$ & $\mathbf{\%}$ & $\mathbf{N}$ & $\mathbf{\%}$ \\
\hline Pé D & 6 & 10 & 6 & 10 \\
Pé E & 5 & 8,3 & 5 & 8,3 \\
& & & & \\
Ambos & 16 & 26,7 & 16 & 26,7 \\
Não & 33 & 55 & 33 & 55 \\
\hline TOTAL & $\mathbf{6 0}$ & $\mathbf{1 0 0}$ & $\mathbf{6 0}$ & $\mathbf{1 0 0}$ \\
\hline
\end{tabular}

A temperatura das extremidades de membros inferiores foi avaliada à palpação, comparando-se ambos os lados. A normotermia nos dois pés foi verificada em 37(61,7\%) dos pacientes e em 8(13,3\%) a temperatura estava diminuída nos dois pés (Tabela 44).

Elizabeth Pillon Scapim

Resultados

Tabela 44 - Distribuição das pessoas com DM e úlceras nos pés, segundo a temperatura dos pés à palpação Marília, 2003.

\begin{tabular}{lcc}
\hline Temperatura nos pés & N & $\mathbf{\%}$ \\
\hline Normotérmico em ambos os pés & 37 & 61,7
\end{tabular}


Método

Diminuída em ambos os pés

Assimetria com temperatura diminuída

Assimetria com tempertura aumentada

Normotérmica com amputação

Diminuída com amputação

TOTAL

$8 \quad 13,3$

$5 \quad 8,3$

$6 \quad 10$

$3 \quad 5$

$1 \quad 1,7$

Quanto à avaliação dos pulsos dos pés, verificou-se uma freqüência maior na categoria de pulsos não palpáveis (Tabela 45).

Tabela 45 - Distribuição das pessoas com DM e úlceras nos pés, segundo a avaliação dos pulsos nos pés dos portadores de diabetes Marília, 2003.

\begin{tabular}{|c|c|c|c|c|c|c|c|c|c|c|}
\hline \multirow{2}{*}{$\begin{array}{c}\text { Característica dos } \\
\text { pulsos }\end{array}$} & \multicolumn{2}{|c|}{ Palpáveis } & \multicolumn{2}{|c|}{$\begin{array}{c}\text { Não } \\
\text { palpável }\end{array}$} & \multicolumn{2}{|c|}{ Diminuído } & \multicolumn{2}{|c|}{ Amputados } & \multicolumn{2}{|c|}{ Total } \\
\hline & $\mathbf{N}^{\mathbf{o}}$ & $\%$ & $\mathbf{N}^{\mathbf{O}}$ & $\mathbf{N}^{\mathbf{0}}$ & $\mathbf{N}^{\circ}$ & $\%$ & $\mathbf{N}^{\mathbf{0}}$ & $\%$ & $\mathbf{N}^{\mathbf{o}}$ & $\%$ \\
\hline Tibial Posterior D & 23 & 38,3 & 27 & 45 & 10 & 16,7 & - & - & 60 & 100 \\
\hline Tibial Posterior E & 20 & 33,3 & 23 & 38,3 & 13 & 21,7 & 4 & 6,7 & 60 & 100 \\
\hline Pedioso D & 23 & 38,3 & 26 & 43,3 & 11 & 18,3 & - & - & 60 & 100 \\
\hline Pedioso E & 21 & 35 & 21 & 35 & 14 & 23,3 & 4 & 6,7 & 60 & 100 \\
\hline
\end{tabular}

Tabela 46 - Distribuição das pessoas com DM e úlcera no pé, segundo a avaliação dos pulsos no pé onde se localiza a úlcera dos portadores de diabetes Marília, 2003.

\begin{tabular}{lccccccccc}
\hline \multicolumn{1}{c}{$\begin{array}{c}\text { Característica dos } \\
\text { pulsos no } \\
\text { Pé da Úlcera }\end{array}$} & \multicolumn{2}{c}{ Palpáveis } & \multicolumn{2}{c}{$\begin{array}{c}\text { Não } \\
\text { palpável }\end{array}$} & \multicolumn{2}{c}{ Diminuído } & \multicolumn{2}{c}{ Total } \\
\cline { 2 - 10 } & $\mathbf{N}^{\mathbf{0}}$ & $\mathbf{\%}$ & $\mathbf{N}^{\mathbf{0}}$ & $\mathbf{\%}$ & $\mathbf{N}^{\mathbf{0}}$ & $\mathbf{\%}$ & $\mathbf{N}$ & $\mathbf{\%}$ \\
\hline Pé Direito & 12 & 20 & 17 & 28,3 & 2 & 3,3 & 31 & 51,7 \\
$\begin{array}{l}\text { Pé Esquerdo } \\
\text { Elizabeth Pillon Scapim }\end{array}$ & 9 & 15 & 9 & 15 & 11 & 18,3 & 29 & 48,3 \\
\hline
\end{tabular}

Em relação à avaliação da sensibilidade da região dorsal e plantar nos pés dos portadores de diabetes mellitus com lesões nos pés, pode-se observar que em 49(81,7\%) havia sensibilidade nos pés e em 11(18,3\%) a sensiblidade estava ausente (Tabela 47). 
Método

Tabela 47 - Distribuição dos pacientes portadores de diabetes mellitus com úlcera no pé, segundo a avaliação da sensibilidade da região dorsal e plantar nos pés Marília, 2003.

\begin{tabular}{ccccc}
\hline $\begin{array}{c}\text { Avaliação da sensibilidade dos } \\
\text { pés (N }\end{array}$ & \multicolumn{2}{c}{ Direito } & \multicolumn{2}{c}{ Esquerdo } \\
\cline { 2 - 5 } de pontos) & $\mathbf{N}$ & $\mathbf{\%}$ & $\mathbf{N}$ & $\mathbf{\%}$ \\
\hline $0 \vdash 2$ & 39 & 65 & 44 & 73,3 \\
$2 \vdash 4$ & 10 & 16,7 & 5 & 8,3 \\
$4 \vdash 6$ & 1 & 1,7 & 1 & 1,7 \\
$6 \vdash 8$ & 3 & 5 & 3 & 5 \\
$8 \vdash 10$ & 7 & 11,6 & 7 & 11,7 \\
\hline TOTAL & $\mathbf{6 0}$ & $\mathbf{1 0 0}$ & $\mathbf{6 0}$ & $\mathbf{1 0 0}$ \\
\hline
\end{tabular}

5.6. Caracterização dos pacientes com DM e úlcera no pé, segundo as variáveis relacionadas às características das úlceras.

No presente estudo as úlceras em pés das pessoas com DM serão descritas de acordo com as seguintes variáveis: causa, duração, localização, contorno, borda, características do leito, exsudato, presença de dor, odor, tratamento atual e estágio da úlcera segundo, a classificação de Wagner.

As causas das úlceras relatadas com maior freqüência foram bolha infectada (36,6\%) e trauma mecânico (26,6\%). (Tabela-48) 
Tabela 48 - Distribuição das pessoas com DM e úlcera no pé, segundo as causas das úlceras. Marília, 2003.

\begin{tabular}{lcc}
\hline Causa úlcera & $\mathbf{N}$ & $\mathbf{\%}$ \\
\hline Bolha-infecção & 22 & 36,6 \\
Trauma mecânico & 16 & 26,6 \\
Isquemia/cianose/necrose & 7 & 11,6 \\
Rachadura/infecção & 5 & 8,3 \\
Trauma químico & 2 & 3,3 \\
Fissuras interdigitais/infecção & 2 & 3,3 \\
Calo/infecção & 2 & 3,3 \\
Não sabe & 2 & 3,3 \\
Picada de inseto & 1 & 1,6 \\
Olho de peixe/infecção & 1 & 1,6 \\
\hline Total & $\mathbf{6 0}$ & $\mathbf{1 0 0}$ \\
\hline
\end{tabular}

Quanto à duração das úlceras, o tempo médio em anos foi de 0,9 ano, ocorrendo num intervalos de 0 a 1 ano em 48 pacientes (80\%); de 1a 2 e de 2 a 3, em 5(8,3\%) tempo de maior freqüência (Tabela 49).

Tabela 49 - Distribuição das pessoas com DM e úlcera no pé, segundo o tempo das úlceras, Marília,2003.

\begin{tabular}{ccc}
\hline $\begin{array}{c}\text { Tempo das úlceras } \\
\text { (anos) }\end{array}$ & $\mathbf{N}$ & $\mathbf{\%}$ \\
\hline $0 \vdash 1$ & 48 & 80 \\
$1 \vdash 2$ & 5 & 8,3 \\
$2 \vdash 3$ & 5 & 8,3 \\
$3 \vdash 4$ & - & - \\
$4 \vdash 5$ & 2 & 3,4 \\
\hline Total & 60 & 100 \\
\hline
\end{tabular}

As úlceras foram observadas em diferentes locais do pé, sendo mais freqüentes na região plantar (23,3\%), dedos (21,7\%), hálux (20\%) e calcâneo (13,4\%).(Tabela 50). 
Tabela 50 - Distribuição das pessoas com DM e úlcera no pé, segundo a localização das úlceras, Marília, 2003.

\begin{tabular}{ccc}
\hline Localização & $\mathbf{N}$ & $\mathbf{\%}$ \\
\hline Região plantar & 14 & 23,3 \\
Calcâneo & 8 & 13,4 \\
$2^{\circ}, 3^{\circ}, 4^{\circ}$ e $5^{\circ}$ dedos do pé & 13 & 21,7 \\
Halux & 12 & 20 \\
Maléolo & 5 & 8,3 \\
Dorso do pé & 3 & 5 \\
Região Lateral do pé & 5 & 8,3 \\
\hline Total & $\mathbf{6 0}$ & $\mathbf{1 0 0}$ \\
\hline
\end{tabular}

As dimensões das úlceras variaram de 1 a 130 cm² $^{2}$ com 39 (65\%) entre 1 a 10 $\mathrm{cm}^{2}$ e 12 (20\%) entre 11 a $20 \mathrm{~cm}^{2}$. (Tabela.51)

Tabela 51 - Distribuição das pessoas com DM e úlcera no pé, segundo a dimensão das úlceras, Marília, 2003.

\begin{tabular}{ccc}
\hline Tamanho das úlceras cm & $\mathbf{N}$ & $\mathbf{\%}$ \\
\hline $0 \vdash 10$ & 39 & 65 \\
$10 \vdash 20$ & 12 & 20 \\
$20 \vdash 30$ & 1 & 1,7 \\
$30 \vdash 40$ & 2 & 3,3 \\
$40 \vdash 50$ & - & - \\
$50 \vdash 60$ & 1 & 1,7 \\
$60 \vdash 70$ & 2 & 3,3 \\
$70 \vdash 80$ & 2 & 3,3 \\
$80 \vdash+$ & 1 & 1,7 \\
\hline Total & $\mathbf{6 0}$ & $\mathbf{1 0 0 \%}$ \\
\hline
\end{tabular}

Em relação ao contorno, observou-se que 18 (30\%) eram regulares e 42 (70\%) irregulares e, quanto à borda, 37 (61,7\%) eram planas e 23 (38,3\%) elevadas.

Elizabeth Pillon Scapim Resultados 
Método

Tabela 52 - Distribuição das pessoas com DM e úlcera no pé, segundo a coloração do leito das úlceras, Marília, 2003.

\begin{tabular}{ccc}
\hline Coloração do leito das úlceras & $\mathbf{N}$ & $\mathbf{\%}$ \\
\hline Róseo & 6 & 10, \\
Amarelo & 15 & 25 \\
Vermelho & 25 & 41,7 \\
Preto/Necrose & 14 & 23,3 \\
\hline Total & $\mathbf{6 0}$ & $\mathbf{1 0 0 , 0}$ \\
\hline
\end{tabular}

O exsudato foi analisado quanto às suas características, sendo encontradas 32 (53,3\%) das úlceras com exsudato seroso e 15 (25\%) purulento. (Tabela 53)

Tabela 53 - Distribuição das pessoas com DM e úlcera no pé, segundo o aspecto do exsudato das úlceras, Marília, 2003.

\begin{tabular}{ccc}
\hline Aspecto doExsudato & N & $\mathbf{\%}$ \\
\hline Seroso & 32 & 53,3 \\
Serosanguinolento & 11 & 18,3 \\
Purulento & 15 & 25,0 \\
Ausente & 2 & 3,3 \\
\hline TOTAL & $\mathbf{6 0}$ & $\mathbf{1 0 0}$ \\
\hline
\end{tabular}

Ao ser investigada a presença de dor, 31 (51,7\%) referiram ausência e 23 (38,3\%) presença com intensidade moderada.(Tabela 54) 
Tabela 54 - Distribuição das pessoas com DM e úlcera no pé, segundo dor nas úlceras Marília, 2003.

\begin{tabular}{ccc}
\hline Dor nas úlceras & $\mathbf{N}$ & $\mathbf{\%}$ \\
\hline Ausente & 31 & 51,7 \\
Pouco intensa & 23 & 38,3 \\
Intensa & 6 & 10 \\
\hline TOTAL & & \\
\hline
\end{tabular}

Foi identificada a presença de odor discreto em 35 (58,3\%) das úlceras e forte em 14 (23,3\%).(Tabela.55)

Tabela 55 - Distribuição das pessoas com DM e úlcera no pé, segundo o odor do exsudato das úlceras Marília, 2003.

\begin{tabular}{ccc}
\hline Odor nas úlceras & $\mathbf{N}$ & $\mathbf{\%}$ \\
\hline Discreto & 35 & 58,3 \\
Moderado & 10 & 16,7 \\
& & \\
Forte & 14 & 23,3 \\
Ausente & 1 & 1,7 \\
\hline Total & $\mathbf{6 0}$ & $\mathbf{1 0 0}$ \\
\hline
\end{tabular}

Em relação ao tratamento das úlceras, observa-se que 49 (81,7\%) referiram uso de soro fisiológico+óleo de girassol e 4(6,7\%), uso de soro fisiológico+vaselina (Tabela $56)$. 
Tabela 56 - Distribuição das pessoas com DM e úlcera no pé, segundo o tratamento das úlceras Marília, 2003.

\begin{tabular}{ccc}
\hline Tratamento das úlceras & $\mathbf{N}$ & $\mathbf{\%}$ \\
\hline Soro fisiológico+óleo de girassol & 49 & 81,7 \\
Soro fisiológico+vaselina & 4 & 6,7 \\
Soro fisiológico+papaína & 3 & 5 \\
Soro fisiológico+Iruxol & 2 & 3,3 \\
Soro fisiológico & 2 & 3,3 \\
TOTAL & $\mathbf{6 0}$ & $\mathbf{1 0 0}$ \\
\hline
\end{tabular}

Quanto ao estágio das úlceras, obteve-se, com maior freqüência, o grau 2 (46,7\%) e o grau 1 (23,3\%) (Tabela 57), segundo a classificação de Wagner (1981).

Tabela 57 - Distribuição das pessoas com DM e úlcera no pé, segundo o estágio das úlceras Marília, 2003.

\begin{tabular}{ccc}
\hline Estágio das úlceras & $\mathbf{N}$ & $\mathbf{\%}$ \\
\hline Grau 0 & 14 & 23,3 \\
Grau 1 & 28 & 46,7 \\
Grau 2 & 5 & 8,3 \\
Grau 3 & 4 & 6,7 \\
Grau 4 & 7 & 11,7 \\
Grau 5 & 2 & 3,3 \\
\hline TOTAL & $\mathbf{6 0}$ & $\mathbf{1 0 0}$ \\
\hline
\end{tabular}




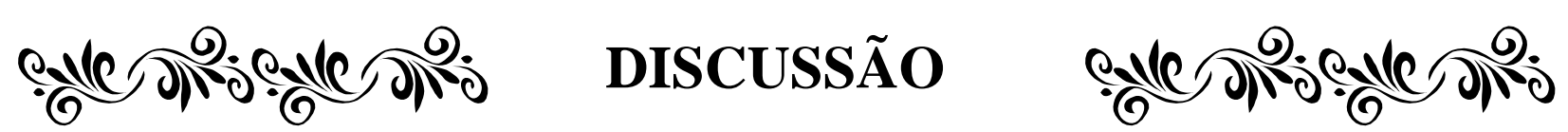




\subsection{Caracterização dos pacientes com DM e úlceras, segundo as variáveis sexo, idade}

$\mathrm{D}$

os 60 pacientes do estudo, 31 (51,7\%) eram do sexo masculino, na faixa etária de 50 a 60 anos seguida de 60 a 70 e 29 (48,3\%) na faixa etária de 70 a 80 anos. A média de idade da população geral foi de 63 anos.

Estudos mostram maior freqüência de úlceras e amputações no sexo masculino (Bernardes et al, 1993; Mayfield et al. 1998; Zavala \& Braver, 2000; Associação Americana de Diabetes, 2001), sem elucidar as causas.

Zavala \& Braver (2000) referem que o sexo masculino se destaca apresentando um risco cerca de 1,6 vezes maior de sofrer amputações. e Mayfield et al. (1998) colocam que o sexo masculino se associa a 1,6\% de aumento de risco para úlceras e de 2,8 a 6,5\% a mais para riscos de de amputações.

Mayfield et al (1998) referem que, em uma pesquisa realizada nos EUA entre 1989 a 1993, a prevalência de amputações foi de 1,6\% para pessoas com diabetes na faixa etária de 18 - 44 anos; 2,4\% na faixa etária de 45 a 64 anos e 3,6\% para pessoas com idade maior ou igual a 65 anos.

Em revisão apresentada pelo Consenso Internacional sobre Pé Diabético (Secretaria de Estado de Saúde-DF, 2001), a prevalência de úlceras nos pés em países desenvolvidos foi estimada em aproximadamente 4 a 10\% dos indivíduos diabéticos e uma incidência correspondente a 2,2 a 5,9\%. No entanto, em estudos nos quais foram analisados pacientes mais jovens, com diabetes tipo 1 ou tipo 2, a prevalência foi estimada entre 1,7 a 3,3\%, comparando-se a 5 a $10 \%$ em que a maioria dos pacientes são mais idosos ou têm diabetes tipo 2.

Mediante os dados acima e considerando que 95\% dos pacientes são do tipo 2, pode-se inferir que o risco para amputações, entre os participantes deste estudo, encontra-se elevado, o que reforça maiores investimentos não só no tratamento e cuidado com as úlceras, como também na prevenção de sua recorrência, pois 48 (80\%) dos pacientes mencionaram úlcera(s) anterior(es). 
Anexos

O Consenso Internacional sobre Pé Diabético (Secretaria de Estado de SaúdeDF, 2001) menciona que o índice de recorrência a longo prazo em relação aos diferentes tipos de úlceras e níveis de amputação ainda é desconhecido , porém em um estudo prospectivo, o índice de recorrência de úlceras no pé diabético é de $44 \%$ no primeiro ano, $61 \%$ no terceiro e $70 \%$ no quinto ano.

Ao se analisar a variável escolaridade, 46,6\% analfabeto e sem escolaridade, $36,7 \%$ ensino fundamental incompleto, verifica-se que a maioria dos pacientes possui baixa escolaridade que somada aos fatores idade e tempo médio do diabetes (12,6 anos), representam características contribuintes com o agravamento do diabetes mellitus, mesmo que não estejam diretamente associados às complicações (Foss et al., 1989; Richard, 1997; Zavala \& Braver, 2000).

Nos estudos de Pace et al., 2002 e Gamba (2001) os autores ressalvam a baixa escolaridade como dificultador ao acesso às informações e menores oportunidades de aprendizagem quanto ao cuidado com a saúde, especialmente ao se considerar que no diabetes mellitus, os próprios pacientes desenvolvem grande parte de seus cuidados diários.

Zavala \& Braver (2000) e Pedrosa et al (1998) referem que o baixo nível social e a falta de acesso à educação aumentam o risco para úlceras e amputações. A baixa escolaridade pode interferir no entendimento das orientações realizadas quanto a doença e os cuidados com as úlceras no pé diabético, levando a complicações mais sérias e a amputações. Portanto as informações devem ser realizadas de maneira bem simples respeitando esta limitação do paciente, e fazendo com que ele se envolva com os seus próprios cuidados.

Quanto ao estado civil, 53,3\% informaram não possuírem companheiro, porém vivem com outros familiares, o que pode influenciar no tratamento do diabetes. Como nora, genro, irmão que não se responsabilizam pelos cuidados, realizam alguns cuidados quando tem tempo não priorizando os cuidados necessários e no tempo certo.

Mayfield et al (1998) verificaram que a falta de relacionamento social (morar sozinho, não receber visitas de amigos, não participar de grupos sociais e religiosos) também contribuiu para elevar o risco de amputações de 2,1 a 3,8\%.

Em relação à ocupação, 90\% estão classificados como inativos, ou seja, aposentados. Em outros estudos relacionados com diabetes mellitus, os autores 
Anexos

encontraram similares freqüências para esta variável (Gamba,2001; Barbui \& Cocco,2002). Esta situação também pode representar outro dificultador em relação ao tratamento do diabetes, uma vez que se relaciona às condições sócio-econômicas das pessoas, dificultando não só a aquisição de medicamentos e materiais básicos para o cuidado, como também acesso à unidade de saúde, uma vez que 53,4 \% dos pacientes procedem de outros municípios.

Quanto a procedência da população, 28 (46,7\%) são da cidade de Marília, 28 (46,7\%) são de outros municípios da região de Marília e 4 (6,7\%) de outros municípios do Estado de São Paulo.

A procedência da população do estudo reforça também a importância da unidade ambulatorial do Hospital onde o presente estudo foi realizado, levando-nos à reflexão sobre sua importância para a cidade e região, como pólo de atendimento à população.

Com destaque às variáveis relacionadas ao tabagismo, etilismo e prática de atividades físicas, consideradas fundamentais para a prevenção e controle das doenças crônicas, identificou-se a presença de tabagismo (ao considerar-se os ex fumantes), e baixa freqüência de etilismo e alta referência de sedentarismo.

Mayfield et al (1998) e Pedrosa et al (1998) referem que o fumo agrava ainda mais as condições crônicas dos pacientes diabéticos, principalmente os portadores de doença vascular periférica onde ocorre o processo aterosclerótico, elevando o risco para amputações ao associar-se às doenças cardiovasculares. Yetzer et al (1992) referem que os pacientes que fumam têm um fator de risco aumentado para úlceras e amputações, porque a nicotina causa vasoconstrição, diminuindo a circulação dos pés.

As recomendações e precauções quanto ao uso da bebida alcoólica para os pacientes diabéticos, determinam que esta pode ser feita moderadamente uma a duas vezes por semanas no limite de dois copos de vinho ou uma lata de cerveja ou uma dose de $40 \mathrm{ml}$ de uísque, desde que acompanhados de algum alimento, pois o excesso de álcool pode produzir hipoglicemia. Deve ser restringida para os pacientes com hipertrigliceridemia, obesos e aqueles com mau controle metabólico (Sociedade Brasileira de Diabetes, 2000).

Outro fator de risco considerado por Zavala \& Braver (2000), é o sedentarismo, que apresentou uma freqüência marcante entre os pacientes do estudo. A ausência da prática regular de atividades físicas prejudicará o fluxo sangüíneo da pele dos pés e 
Anexos

conseqüentemente contribuirá com o desenvolvimento de úlceras e amputações (Coberg et al., 2002).

A atividade física não substitui a insulina, é uma medida de apoio que pode causar piora aguda no controle metabólico nos diabéticos mal compensados, só deve ser praticada quando o estado metabólico estiver compensado. O exercício físico só produzirá efeito benéfico quando praticado de forma regular e gradativa. O tipo de exercício deve ser adequado às possibilidades e limitações de cada pessoa, considerando as complicações crônicas do diabético, retinopatia, neuropatia, nefropatia e outras (Ministério da Saúde,1993).

Além dos benefícios citados, a atividade física poderá contribuir com a redução do peso corporal e obtenção de um adequado controle metabólico.

De acordo com a literatura, 80 a 90\% das úlceras nos pés, são precipitadas por algum tipo de trauma externo, geralmente calçados inadequados ou causadores de lesões (Consenso Internacional sobre Pé Diabético (Secretaria de Estado de Saúde-DF, 2001). Desta forma, salienta-se também que, ao se recomendar atividades físicas, devese avaliar as condições dos pés e os calçados para prevenir lesões ocasionadas pela inadequacão entre estrutura dos pés e calçados (Pace et al, 2002).

\subsection{Caracterização dos pacientes com DM e úlceras, segundo as variáveis relacionadas ao diagnóstico, tratamento, condições clínicas dos pés, controle do DM e complicações associadas.}

Ada (2001) refere que o risco de úlceras ou amputações aumenta em pessoas com tempo de diabetes maior que 10 anos, situação presente neste estudo, em que se encontrou um tempo médio de 12,6 anos.

No que se refere ao tipo de tratamento do DM, $38(63,3 \%)$ das pessoas informaram que fazem dietas, 34 (56,7\%) fazem uso de antidiabéticos orais e 37 (61,7\%) fazem uso de insulina, que pode estar refletindo o comprometimento no grau do controle metabólico, uma vez que complicações nos pés estão presentes. Por outro lado é necessário rever as orientações dietéticas, visto que 34 (56,6\%) dos participantes estão com sobrepeso. 
Anexos

A educação é parte integrante do tratamento, pois o tratamento torna-se irregular se o paciente não for instruído adequadamente. É necessário uma equipe multidisciplinar para a realização desta educação, pois é preciso mostrar ao paciente que o melhor controle reduz nitidamente a incidência e a gravidade das complicações secundárias.

Rodrigues et al (1996) relatam que dentre as várias estratégias para a adesão ao tratamento do diabetes, a equipe de saúde deve investir nas ações educativas do idoso diabético, com temas voltados para o tratamento e prevenção das incapacidades que podem limitar a vida, como as alterações vasculares e as amputações. Portanto as ações educativas devem ser avaliadas quanto ao impacto na adesão ao tratamento, isto é, avaliar, o conhecimento e atitude do paciente em relação ao diabetes, o controle metabólico e a qualidade de vida do mesmo.

Bernardes et al (1993) referem que, na sua amostra, 68,5\% dos pacientes faziam uso de hipoglicemiantes orais e $31,5 \%$ de insulina.

Milman et al (2001), em sua amostra, encontraram 13(56\%) de pacientes que faziam uso de hipoglicemiantes orais e 6(26\%) de insulina.

Quanto ao tempo do tratamento do DM, destaca - se que a maior parte da amostra 31,6\%, fazia o tratamento 5 a 10 anos, seguido por 0 a 5 anos (21,6\%). Tais pacientes, inciaram o tratamento aproximadamente no momento do diagnóstico do DM. Este resultado nos faz refletir sobre o tempo da doença que transcorreu sem que fosse diagnosticada. De acordo com a literatura, o diagnóstico do DM tipo 2 geralmente é feito após um período médio de cinco anos, permitindo a instalação das complicações crônicas, as quais já estão presentes no momento do diagnóstico.

Em relação à medida da pressão arterial dos pacientes com diabetes mellitus e lesões nos pés, no momento da avalição, encontrou-se que 37(61,7\%) apresentaram PA sistólica >140 mmhg, 29 (48,3\%) PA diastólica > 90 mmhg, 9(15\%) PA sistólica <140 mmhg, 22 (36,6\%) PA diastólica < 90 mmhg, 14 (23,3\%) PA sistólica < 135 mmhg e 09 (15,0\%) PA diastólica <80 mmhg.

Segundo o Consenso Brasileiro de Condutas para o Diabetes Mellitus - SBD, (2001), a pressão arterial dos participantes não estão nos níveis desejáveis, favorecendo os riscos de complicações cardiovasculares e ainda dificultando o processo de cicatrização das úlceras. 
Anexos

Quanto aos níveis glicêmicos, 39 (79,6\%) dos pacientes estavam com mau controle, com níveis acima de $140 \mathrm{mg} / \mathrm{dl}$. Salienta-se que não foram encontrados valores deste exame em 11 prontuários, provavelmente por terem sido realizados em outras unidades de saúde ou pela não realização propriamente dita deste exame.

Quanto à freqüência de realização da glicemia, 27 (45\%) dos pacientes possuíam no máximo 10 medidas / ano, apenas 18 (30\%) possuíam valores da hemoglobina glicosilada e, destes, 22\% estavam com valores classificados como “mau controle”, o que pode ser considerada uma freqüência baixa de exames para avaliação do controle glicêmico, principalmente quando os pacientes estão com mau controle. O controle glicêmico é apontando como fator fundamental na etiologia das complicações neuropáticas, as quais predispõem ao desenvolvimento das úlceras e conseqüentemente das amputações ( Reiber et al ,1998; Mayfield et al ,1998; Zavala \& Braver, 2000).

Cabe ainda ressaltar que a prevenção das complicações crônicas microangiopáticas e neuropáticas deve ser realizada por meio do controle persistente de níveis plasmáticos da glicose sanguínea, próximos da normalidade.Tal prevenção deve postergar as graves conseqüências da doença como a amputação. Portanto a necessidade de reconhecer a importância da educação como parte integral do cuidado com a pessoa diabética.

Bernardes et al (1993) encontraram em seu estudo que o grupo de pacientes que evoluiu para amputações foi o daqueles que possuíam valores glicêmicos mais elevados, ou seja, maior ou igual a $200 \mathrm{mg} / \mathrm{dl}$.

A análise dos valores de colesterol, triglicérides, HDL e LDL ficou prejudicada face ao reduzido número de pacientes que apresentavam estes valores registrados nos prontuários.

Em relação às complicações, estas foram listadas conforme registros nos prontuários. Entre as complicações encontradas, destacam-se 19 (31,7\%) retinopatia e a mesma freqüência para doença vascular periférica e pé diabético.

Pacientes diabéticos com doença vascular periférica possuem probabilidade 17 vezes maior para gangrena nas úlceras do que os pacientes que não têm diabetes, elevando o risco de infecção nas úlceras e amputação (Dowdell, 1995).

Ao se verificarem as doenças associadas, destaca-se que os 60 (100\%) dos pacientes são hipertensos, confirmando o risco para as complicações cardiovasculares, 
Anexos

em particular em pés. Destes pacientes hipertensos, 26,6\% possuem também obstrução arterial crônica, o que vem agravar ainda mais o quadro.

Quando há associação de diabetes com outros fatores de risco, como hipertensão, fumo e idade avançada, aumenta a gravidade da doença vascular periférica (Dowdell, 1995).

Considerando as complicações crônicas e doenças associadas como fatores de risco para complicações em pés, pode-se verificar que em $100 \%$ dos pacientes estas estão presentes, levando-nos a destacar o alto risco desta amostra para agravamento das complicações em pés.

Browne \& Sibbald (1999) afirmam que o controle do diabetes é essencial, porque os altos níveis de glicose estão associados ao desenvolvimento de complicações como a neuropatia. A educação do paciente e de sua família são importantes para a adesão do paciente ao tratamento.O conhecimento dos fatores de risco e as mudanças no comportamento são essenciais para que o paciente consiga realizar estas mudanças. Sabe-se que o tratamento da neuropatia é o controle da hiperglicemia e a eliminação dos fatores de risco como tabagismo,hipertensão, hipercolesterolemia, hiperlipidemia, hiperglicemia e obesidade. O controle dos níveis de glicemia e do metabolismo diminui os riscos para o desenvolvimento de úlceras e ajuda na cicatrização das úlceras instaladas.

A avaliação das condições clínicas dos pés dos pacientes identificou a presença de diversos problemas.

Em relação à mobilidade física, verificou-se que 32 (53,3\%) dos pacientes deambulavam, 10 (16,7\%) não deambulam e 18 (30\%) deambulavam com auxílio.

Dealey (2001) menciona que pessoas que não deambulam podem ter problemas com a cicatrização de feridas, devido à estase na circulação periférica, em especial nas pernas. Resulta em edema de estase que causa a demora na remoção de substâncias tóxicas, ocorrendo um retardo na cicatrização.

Em estudos citados por Maffei (1997), em 15\% das autópsias de paciente com uma semana de repouso, havia presença de trombose venosa profunda. Esse índice, pode aumentar para mais de $80 \%$ se o período for maior. 
Anexos

Quanto à alteração na marcha, 32 (53,3\%) pacientes apresentavam algum tipo de alteração que poderiam ser causa ou conseqüência das úlceras nos pés, portanto necessitando de avaliação de especialista.

Referente às amputações, destaca-se que 33 (55\%) dos pacientes sofreram amputações de membros inferiores o que os torna mais susceptíveis a outras.

A mortalidade é quatro vezes maior entre os pacientes previamente amputados, resultado de uma maior freqüência de doença vascular cerebral e nefropatia entre eles (PEDROSA, et al 1998).

Frikberg (2000) refere que as úlceras no pé precedem a maioria das amputações nos membros inferiores entre os pacientes diabéticos.

Ao ser investigado sobre história de úlceras anteriores, encontrou-se que 48 (80\%) informaram presença de úlceras anteriores.

As taxas de recorrência de úlceras ou de amputações a longo prazo, ainda são desconhecidas, mas estima-se que atinjam 44\%, 61\% e 70\% após um, três e cinco anos para úlceras, respectivamente e 50\% nos três primeiros anos pós amputação (Pedrosa et al. 1998).

Quanto à condição de higiene dos pés, observou-se que 43 (71,7\%) apresentavam-se com boa higienização, 12 (20\%) com regular e 5 (8,3\%) insatisfatória. Considera-se que o auto cuidado pode estar prejudicado devido à faixa etária, bem como as dificuldades visuais, presentes na população estudada, porém deve-se estimular o auto cuidado ou envolver a família neste processo, visando à promoção da saúde, melhora da auto-estima e reintegração social.

Em relação à avaliação da pele e fâneros, a bromidrose esteve presente em 50\% dos pacientes, seguido de 49\% de anidrose, 48\% de unhas espessas/aspecto farináceo e 47\% de descamação. A bromidrose pode estar associada á falta de higiene, enquanto que a anidrose pode ser conseqüente a presença de neuropatia autonômica, e poderá evoluir para fissuras caso não seja estabelecida hidratação apropriada. As fissuras representam quebra da barreira natural contra infecções e poderão contribuir para úlceras e amputações.

As unhas espessadas com aspecto farináceo, podem ser resultantes tanto de infecção fúngica como da insuficiência arterial, necessitando avaliação de especialistas, 
Anexos

para o tratamento apropriado. Estas alterações também poderão agir como pontos de pressão para novas úlceras.

Quanto à avaliação da estrutura dos pés, destacam-se o dedos em garra com maior freqüência (31,7\%\%), seguido pelos dedos sobrepostos (23,3\%) e proeminência do primeiro metatarso $(18,3 \%)$.

Levin (1995) relata que as lesões dos nervos motores causados pela neuropatia leva a deformidades como dedos em garra , dedos sobrepostos e outras.

Considerou-se calçado inapropriado, conforme descrito no estudo de Pace et al, (2002), aqueles que eram apertados, de bico fino, abertos e sem cadarço. Entre as mulheres, além das características apontadas, foram consideradas inapropriadas as sandálias que deixavam totalmente expostos os pés, os saltos maiores de três centímetros e aqueles extremamente largos e/ou compridos.

Estudos destacam que os pontos de alta pressão, calosidades, deformidades dos pés, amputação de dedos, inclusive transmetatarsianos, podem ser corrigidos ou supridos com calçados confortáveis ou especiais, coadjuvando com palmilha (Levin, 1996, Mayfield et al., 1998, Frytschi, 2001, Associação Americana de Diabetes, 2002).

Os calçados e meias, assim como o corte de unhas foram classificados em adequados e inadequados. Os sapatos inadequados estavam presentes em 45(75\%) dos pacientes e o corte de unhas inadequado em 39 (65\%) dos pacientes.

Levin (1996), relata que calçados adequados são aqueles que reduzem a pressão nos pés.Os calçados para pacientes diabéticos são baseados na acomodação e acolchoamento do que na correção biomecânica.

Young \& Young (1994) relatam que, para diminuir os riscos e danos causados pelas deformidades, como dedos em garra, é importante que o calçado tenha espaço na parte anterior, dos pododáctilos, o que requer que tenham altura extra. Alguns sapatos especiais podem ser modelado de acordo com a deformidade. Os calçados protetores e adequados são aqueles com palmilhas macias e acolchoadas com amortecedores de pressão, meia palmilha e outras.

Dahmen et al (2001) relatam que um calçado protetor ou uma órtese podem ser requeridos logo após uma amputação mesmo em nível menor. O grau de proteção dos calçados pode ser avaliado em centros especializados, utilizando-se medidas de distribuição da pressão no interior dos sapatos. O uso de meias macias pode reduzir a 
Anexos

pressão, mas deve haver o cuidado de deixar espaço no interior do calçado para acomodar o dorso do pé.

Quanto ao edema, foi observado em 35 (58,3\%) dos pacientes do estudo.

O resultado da evolução de úlcera nos pés está relacionado ao edema, geralmente de origem multifuncional, como nefropatia, trombose venosa e edema neuropático/hidrostático, constituindo estas as causas mais importantes.O tratamento do edema deve ser direcionado à causa básica (Consenso Internacional Sobre Pé Diabético Secretaria de Estado de Saúde-DF,, 2001).

O edema do paciente com problemas vasculares geralmente é discreto e duro, acomete os dedos e região metatarsiana. Com o agravamento da doença, pode avançar para o dorso do pé, tornozelo e, por último, para a perna (Bevilacqua, 1985)

A inflamação é a condição básica do edema na doença arterial. A microcirculação comprometida pela doença arterial, acaba levando à complicação venosa ou capilar (Maffei, 1995).

Pacientes com obstrução do fluxo sanguíneo venoso têm elevação da pressão capilar hidrostática, seguida de extravasamento de líquidos para os tecidos, ocorrendo grande perda de proteínas para o meio, tornando-se repetitivo este ciclo. O edema venoso e a diminuição da reabsorção levam a alterações nos processos metabólicos normais, diminuindo a oxigenação dos tecidos que levam a hipoxemia. Essas alterações fazem com que ocorra liberação de substâncias vasodilatadoras na circulação , causando algias (Maffei, 1995).

Na avaliação do rubor na pendência e empalidecimento à elevação, 27 (45\%) dos pacientes apresentavam os dois sinais.

A temperatura das extremidades de membros inferiores foi verificada à palpação, comparando-se ambos os lados. 37(61,7\%) dos pacientes apresentavam-se normotérmicos em ambos os pés, 8(13,3\%) diminuídos em ambos os pés.

Christensen et al (1991) refere que a temperatura dos pés reflete a eficiência da circulação

Quanto à avaliação dos pulsos, nos pés dos pacientes com DM e lesões nos pés, observam-se freqüências maiores dos pulsos não palpáveis ao compará-los com os palpáveis. 
Anexos

Ao realizar a avaliação dos pulsos, é importante lembrar que 5 a $10 \%$ da população geral podem apresentar ausência destes pulsos, mesmo na ausência de arteriopatia. A pessoa com diabetes poderá ter pulsos não palpáveis pelo comprometimento arterial, porém, clinicamente apresentar boa perfusão, devido à circulação colateral compensatória. Portanto a avaliação do pulso merece atenção por parte do examinador e, quando necessário, deve-se solicitar avaliação do especialista.

Para avaliação da sensibilidade tátil pressórica, foram considerados os parâmetros de Wunderlich et al., (1998) e de Ahroni, (2000). Os quais consideram que a incapacidade do paciente de sentir o filamento de $10 \mathrm{~g}$ em quatro ou mais pontos, entre os dez pontos testados, demonstra neuropatia sensitiva, ou seja, ausência de proteção nos pés.

Em relação à avaliação da sensibilidade da região dorsal e plantar nos pés dos portadores de diabetes mellitus com lesões nos pés, podemos observar que em $37(61,7 \%)$ pacientes tinham sensibilidade nos pés e 23(38,3\%) apresentavam-se com a sensibilidade ausente.

Lavery et al (1998) referem que o exame para avaliar a sensibilidade é um instrumento barato e eficiente, podendo ser usado pelos membros da equipe multidisciplinar e com bons resultados. Acrescenta que na neuropatia ocorre aumento da pressão da área plantar, o que também ocorre na região lateral do pé que é exposta a traumas repetitivos durante o caminhar normal, levando assim á ulcerações. 
Anexos

\subsection{Caracterização dos pacientes com DM e úlcera no pé, segundo as variáveis relacionadas às características das úlceras.}

No presente estudo as úlceras em pés das pessoas com DM foram avaliados de acordo com as seguintes variáveis: causa, duração, localização, contorno, borda, características do leito, exsudato, presença de dor, odor, tratamento atual e estágio da úlcera, segundo a classificação de Wagner.

As causas das úlceras relatadas com maior freqüência foram bolha infectada (36,6\%) e trauma mecânico (26,6\%).

A infecção estava presente em 32\% das úlceras associadas a bolha, rachaduras, fissuras, calos e olho de peixe.

Steed et al (1998) referem que o trauma mecânico, inclui os ocorridos devido ao uso de sapatos inapropriados e são localizados geralmente na ponta dos pés (nos dedos) e nas regiões laterais do pé. Em nosso estudo encontramos uma grande quantidade de pessoas que apresentaram trauma mecânico.Se relacionarmos o uso de sapatos inadequado que também é grande e a localização das úlceras, que se identifica com o relato, entendemos que faltam orientações para estes pacientes quanto à prevenção de úlceras.

Frykberg (1998) refere que as infecções do pé são as maiores causas de hospitalização nos pacientes com DM. Portanto, é a causa direta de uma ùlcera, é certamente uma determinante significativa do resultado. Obviamente, ela é a principal causa de morbidade nas pessoas com diabetes e freqüentemente são acompanhadas de ulceração no pé. Sendo a infecção um fator que predispõe a amputação de membros inferiores, responsabiliza a equipe de enfermagem ou multiprofissional a tomarem condutas rigorosas na prevenção e cuidados. A prevenção deve ser focalizada na educação da pessoa com DM, com especial atenção do ensino do cuidado com o pé, o tratamento das infecções do pé diabético é facilitada por uma prevenção completa dos fatores patogênicos envolvidos, peculiaridades microbiológicas e conceitos atuais no cuidado com o pé diabético.

Segundo o mesmo autor o controle das infecções do pé diabético requer um conhecimento completo da patofisiologia, das características microbiológicas associadas, do diagnóstico atual e regime de tratamento. O cuidado do pé diabético 
Anexos

infectado requer uma combinação de terapias incluindo agentes antimicrobianos, desbridamento cirúrgico, cuidados com a úlcera e evitar o sobrepeso. As complexidades deste problema freqüentemente requer uma equipe multiprofissional especialista que trabalhem coesivamente para cuidar das complicações atuais, bem como das lesões do pé.

Fowler (1998) no seu estudo relata que o diagnóstico de infecção da úlcera é baseado nos sinais e sintomas clínicos e da cultura da úlcera. Culturas são usadas para ajudar na seleção da terapia antibiótica apropriada. O Swabb é a mais importante técnica de cultura e o mais usado, para identificação de carga bacteriana da base do tecido das úlceras abertas. A técnica apropriada para a obtenção do Swabb é essencial para confirmar o diagnóstico da infecção.

Quanto à duração das úlceras, o tempo (dias) médio foi de 322,6 dias, sendo os intervalos de 0 a 100 dias, 28 (46,7\%) e 300 a 400, 10 (16,7\%) com maior freqüência.

Com relação ao tempo das úlceras, Steed et al (1998) referem que se a úlcera está presente há mais de um mês sem cicatrização, pode haver uma infecção ou isquemia ou também a associação dessas.

As úlceras foram observadas em diferentes locais do pé, sendo mais freqüentes na região plantar (23,3\%), dedos (21,7\%), hálux (20\%) e calcâneo (13,4\%).

Yetzer et al (1992) referem que as áreas dos pés com tendência para lesões são o hálux, a superfície plantar na região dos metatarsos, as laterais externas do pé, os calcâneos e os maléolos, confirmando assim algumas áreas em nosso estudo.

Steed et al (1998) referem que as úlceras abaixo da cabeça dos metatarsos podem ocorrer devido a deformidades do pé, principalmente dos dedos em garra, e afirmam que é um local de grande risco para ulceração. Em nosso estudo, a maior porcentagem das úlceras apareceram na região plantar só que em diferentes pontos e a deformidade citada nessa amostra foi pequena.

As dimensões das úlceras variaram de 1 a $130 \mathrm{~cm}^{2}$, com 39 (65\%) entre 1 a 10 $\mathrm{cm}^{2}$ e 12 (20\%) entre 11 a $20 \mathrm{~cm}^{2}$.

Krasner (1992) e Flanagan (1994) referem que a mensuração da ferida deve ser feita sempre pela mesma pessoa com o paciente na mesma posição.

Em relação ao contorno, observou-se que 18 (30\%) eram regulares e 42 (70\%) irregulares e quanto à borda, 37 (61,7\%) são planas e 23 (38,3\%) elevadas. 
Anexos

Mayrovitz et al (1998) afirmam ser bem conhecido o contorno regular das úlceras diabéticas e o das úlceras venosas irregulares.É surpreendente que existam poucas referências para estas características e outras, como a forma.

No referente à coloração do leito da úlcera, 25 (41,7\%) apresentavam-se vermelhas, 15 (25\%) amarelas e 14 (23,3\%) pretas.

Krasner (1995) refere que o sistema de cores fornece uma linguagem fácil de ser entendida, e facilita para o enfermeiro uma melhor escolha na intervenção da úlcera. Este sistema identifica em qual fase do processo de cicatrização a ferida se encontra. As feridas vermelhas são aquelas que estão cicatrizando normalmente. As feridas amarelas são classificadas em dois tipos, as infectadas e as que contêm tecido desvitalizado. As infectadas possuem exsudato purulento. O tecido desvitalizado no leito da ferida é de cor amarela ou branco.As feridas pretas contêm tecido necrosado formado por colágeno desvitalizado e seco.O tratamento para este tipo de ferida é a remoção do tecido necrótico.

O Exsudato foi analisado quanto a suas características, sendo encontradas 32 (53,3\%) das úlceras com exsudato seroso e 15 (25\%) com purulento.

Para Watret (1997) o exsudato é um fluido produzido por feridas agudas e crônicas, e a cor geralmente é amarelo pálido, que se altera com a presença de infecção ou tecido necrótico.O exsudato torna-se mais viscoso e fétido em feridas infectadas. Ele tem função importante na cicatrização, fornece nutrientes para o metabolismo celular, é meio de transporte para as células brancas do sangue e mantém o meio úmido.O autor refere que o exsudato deve ser avaliado também em relação à quantidade, para se poder escolher o melhor curativo que realize a sua absorção.

Ao ser investigada a presença de dor, 31 (51,7\%) referiram ausência e 23 (38,3\%) presença com intensidade moderada.

Veves et al (1998) referem que sintomas dolorosos eram comuns em pacientes com neuropatia com úlceras ou não.A dor estava presente em 33\% dos pacientes no grupo de úlceras no pé. A dor inesperada na úlcera de pé diabético pode indicar processo infeccioso.

Foi identificada a presença de odor discreto em 35 (58,3\%) das úlceras e forte em 14 (23,3\%). 
Anexos

Para Cuzzel \& Stotts (1990) o odor do exsudato fornece informação que pode indicar infecção. Um exsudato purulento e fétido indica a presença de infecção por anaeróbios. Pseudomonas produzem secreção fétida.

Em relação ao tratamento das úlceras nos portadores de diabetes mellitus com lesões nos pés, podemos observar que 49 (81,7\%) fizeram uso de soro fisiológico+óleo de girassol e 4(6,7\%) de soro fisiológico+vaselina .

Pieper \& Caliri (2003) relatam que o ácido graxo essencial , que consiste de ácido linoleico tem sido usado para a prevenção e tratamento de úlcera de pressão no Brasil. Na prevenção ele é usado para massagear a pele íntegra e não vermelha.Para o tratamento, a úlcera é limpa com solução salina, a gaze é embebida no óleo e colocada na úlcera. O óleo é comprado em casas de produtos médicos , em frascos de meio litro, por um preço de 25 reais ou 9 dólares.

Segundo as autoras os ácidos graxos essenciais são necessário para manter a integridade da epiderme e a barreira de água para a pele. Eles são precursores metabólicos do ácido aracdônico e prostaglandinas na epiderme. Prostaglandinas são importante para a regulação da divisão celular e diferenciação epidérmica.A falta de ácido graxo pode levar a um estado hiperproliferativo da pele.

Na nossa realidade podemos observar o uso do óleo de girassol, porém não existem ainda estudos científicos que comprovem a eficácia. O dersani é indicado para a pele íntegra. Devido ao baixo custo do produto e as condições sócio econômica dos pacientes o uso do óleo de girassol foi o tratamento mais usado neste estudo.

Pieper \& Caliri (2003) referem que no Brasil e em muitas outras partes do mundo o fator econômico é a chave na decisão sobre cuidados com úlceras.

Os enfermeiros precisam avaliar o custo dos curativos e do tratamento que se aplica, para poderem defender eficazmente a qualidade dos cuidados.

Young \& Young (1994) referem que nas úlceras com infecções superficiais, é recomendado o curativo diário com cobertura que mantenha a umidade e estimule o desbridamento autolítico. Esse curativo deve ser trocado diariamente para remoção do tecido desvitalizado e da secreção.

No projeto “salvando o pé diabético”, o curativo de escolha foi limpeza com povidine e soro fisiológico. Quando necessário, era realizado o desbridamento O uso de 
Anexos

curativos mais simples mostrava mais eficácia.Também era recomendado o uso de acido graxo líquido (dersani) (Pedrosa, 1998).

Quanto ao estágio das úlceras, obteve-se, com maior freqüência, o grau 2 $(46,7 \%)$ e o grau $1(23,3 \%)$.

Milman et al (2001) referem que, quanto às lesões e distribuição dos pacientes, segundo a classificação de Wagner, a maioria 8 (35\%) apresentava lesões de grau 4, 6 (26\%) de grau 1, 4 (17\%) de grau 2, 3 (13\%) de grau 3 e 2 (9\%) de grau 5 . Ao relacionarmos esses resultados com os do nosso estudo as úlceras de nossa amostra eram menos complexas.

Lavery, et al (1997) referem que a classificação de úlceras auxilia o registro sistemático de características das feridas, o que permite planejar as estratégias de tratamento, acompanhar a efetividade e prever resultados. Um sistema de classificação relevante deve ser fácil de usar e efetivo para comunicar com precisão as condições da úlcera. Os enfermeiros têm um importante papel a desempenhar no tratamento de feridas e precisam estar cientes de suas responsabilidades. Este papel é junto com a equipe multidisciplinar, porque as úlceras não podem ser encaradas como algo isolado do resto do corpo.Portanto diferentes especialidades médicas também estão envolvidas no tratamento das úlceras, de modo que os membros da equipe variam de acordo com as necessidades do paciente.

O sistema de classificação do pé diabético incluem fatores adicionais em conjunção com o nível de envolvimento do tecido. Fatores incluídos são: história de ulceração prévia, presença de deformidade óssea, presença e gravidade da isquemia e presença e gravidade da infecção (Cooper, 2000).

Dealey (2001) refere que um papel importante do enfermeiro no tratamento de feridas é proporcionar educação aos paciente e familiares. A educação do paciente é importante para ampliar seu consentimento e sua compreensão dos diferentes aspectos do tratamento. 


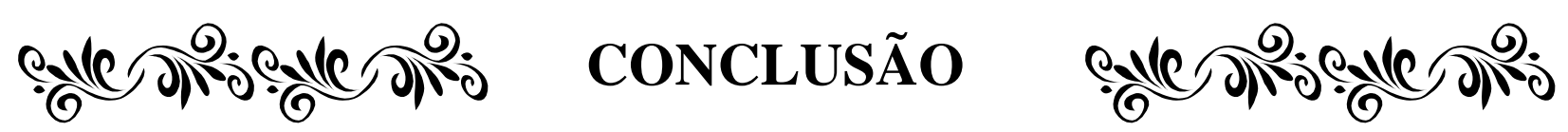




\subsection{Caracterização dos pacientes com DM e úlcera em pé, segundo as variáveis sócio-demograficas e estilo de vida.}

Dos 60 pacientes diabéticos, com úlceras em pés, avaliados na amostra, 51,7\% eram do sexo masculino, com idade média de 63,2 anos.

A maioria dos pacientes, (95\%) possui diabetes tipo 2.

Ao analisar a variável escolaridade , a maioria possui baixa escolaridade e junto com idade e tempo médio do diabetes - 12,6 anos - representam características agravantes do diabetes e das complicações, pois podem interferir no entendimento das orientações, levando a complicações mais sérias como a amputação.

Em relação ao estado civil, 53,3\% possuem companheiro, porém vivem com outros familiares.

90\% dos pacientes avaliados estão classificados como inativos, ou seja, aposentados, condição esta que pode dificultar o tratamento do diabetes, relacionado às condições sócio econômicas deste em nossa sociedade.

Quanto às variáveis relacionadas ao tabagismo, etilismo e atividade física, consideradas fundamentais para a prevenção e controle da doença, identificou-se que 45\% são ex-fumantes com tempo médio de tabagismo de 17,8 anos; 16,7\% são exetilistas e o tempo médio de ingestão alcoólica foi de 27,4 anos; apenas 15\% informaram a prática de atividade física. O sedentarismo é um fator de risco considerável e apresentou freqüência marcante neste estudo. 
Conclusão

\subsection{Caracterização dos pacientes com DM e úlcera em pé, segundo as variáveis relacionadas ao diagnóstico, tratamento, condições clínicas dos pés, controle da doença e complicações.}

O tempo médio de diabetes, é de 12,6 anos, o que aumenta o risco para amputações. 63,3\% das pessoas informaram que fazem dietas; 56,7\% fazem uso de antidiabéticos orais e 61,7\%; o uso de insulina.As orientações dietéticas deverão ser reavaliadas, visto que 56,6\% dos participantes estão com sobrepeso.

Quanto ao tempo do tratamento do DM, 31,6\% confirmam o tempo entre 5 a 10 anos, ou seja, iniciaram o tratamento aproximadamente no momento do diagnóstico do DM.

Em relação à medida da pressão arterial, 61,7\% apresentaram PA sistólica $>140$ mmhg e 48,3\% PA diastólica > 90mmhg. A pressão arterial dos participantes não está nos níveis desejáveis, favorecendo os riscos de complicações cardiovasculares e dificultando o processo de cicatrização das úlceras.

Quanto aos níveis glicêmicos, 79,6\% dos pacientes estavam com mau controle.

Entre as complicações encontradas, destacam-se $31,7 \%$ de retinopatia e a mesma freqüência para doença vascular periférica e pé diabético. Como doenças associadas, destaca-se que $100 \%$ dos pacientes são hipertensos e desses hipertensos, 26,6\% possuem também obstrução arterial crônica, confirmando o risco para as complicações cardiovasculares.

Verificou-se que 53,3\% dos pacientes deambulavam e, com a mesma freqüência, os pacientes possuem algum tipo de alteração na marcha, que poderá ser a causa ou conseqüência das úlceras nos pés.

Destaca-se que 55\% dos pacientes sofreram algum tipo de amputação de membros inferiores, tornando-os susceptíveis a outras amputações. 80\% dos pacientes informaram presença de úlceras anteriores, confirmando a alta recorrência de úlceras.

Quanto à condição de higiene dos pés, 71,7\% apresentavam-se com boa higienizaçã; a bromidrose estava presente em 50\% dos pacientes; a anidrose, em 49\% e unhas espessas/aspecto farináceo, em 48\%. A bromidrose pode estar associada à falta de higiene, enquanto a anidrose pode ser conseqüência da neuropatia autonômica, que pode 
Conclusão

evoluir para fissuras, caso não ocorra a hidratação.As fissuras poderão infeccionar e daí surgirem úlceras, levando a futuras amputações.

$\mathrm{Na}$ avaliação da estrutura dos pés, destacam-se o dedos em garra com 31,7\%; dedos sobrepostos, 23,3\% e proeminência do primeiro metatarso, 18,3\%.

Os sapatos inadequados estavam presentes em $75 \%$ dos pacientes e o corte das unhas inadequado em 65\%.Os calçados adequados são aqueles que reduzem a pressão nos pés e favoreçam boa acomodação desses com o acolchoamento.

Quanto ao edema, esse foi observado em 58,3\% dos pacientes do estudo, na avaliação do rubor na pendência e empalidecimento à elevação, 45\% dos pacientes apresentavam os dois sinais. Quanto à temperatura, 61,7\% apresentavam-se normotérmico em ambos os pés, e 13,3\%, diminuído em ambos os pés.

Na avaliação dos pulsos, observam-se freqüências maiores dos pulsos não palpáveis ao compará-los com os palpáveis.

Em relação à avaliação da sensibilidade da região dorsal e plantar nos pés, em 61,7\% havia sensibilidade nos pés e em 38,3\% a sensibilidade estava ausente.

\subsection{Caracterização dos pacientes com DM e úlcera em pé, segundo as variáveis relacionadas às características das úlceras.}

As causas das úlceras relatadas com maior freqüência foram bolha infectada, $36,6 \%$ e trauma mecânico, 26,6\%, Podem ter ocorrido devido ao uso de sapatos inadequados.

O tempo médio de duração das úlceras foi de 322,6 dias Os locais das úlceras mais freqüentes foram, a região plantar 23,3\%, nos dedos $21,7 \%$ e no hálux $20 \%$.O tempo de duração das úlceras pode estar relacionado com infecção.

Quanto as dimensões das úlceras 65\% apresentavam entre 1 a $10 \mathrm{~cm}$, quanto ao contorno, 30\% eram regulares e em $61,7 \%$ das bordas são planas.

Referente a coloração do leito da úlcera, 41,7\% apresentavam-se vermelhas.O exsudato foi analisado quanto a suas características: 53,3\% tinham exsudato seroso. 
Conclusão

Com relação à dor, 51,7\% referiram ausência da dor. O odor foi discreto em $58,3 \%$ das úlceras. O exsudato fétido pode indicar infecção.Quanto ao tratamento das úlceras, 81,7\% faziam uso de soro fisiológico e óleo de girassol.

O estágio das úlceras que teve maior freqüência foi o grau 2, em 46,7\% dos pacientes.

Os resultados deste estudo refletem a gravidade das complicações relacionadas aos pés dos pacientes com diabetes e reforçam a importância do processo educativo junto aos pacientes, familiares e profissionais para a consolidação de intervenções básicas de cuidados com os pés, uma vez que estas desempenham um papel fundamental na prevenção e diminuição destas complicações que podem conduzir a amputações e comprometimento da qualidade de vida dos pacientes. Apontam também para a necessidade elaboração de um protocolo de atendimento, com ênfase no processo educativo junto a pessoa, familiares e profissionais, visando a uma maior adesão ao tratamento e controle do DM. 


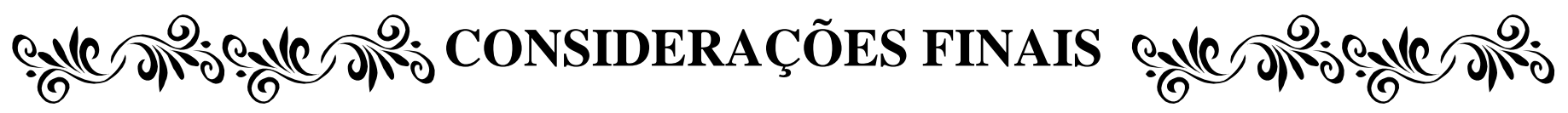


O gerenciamento das úlceras dos membros inferiores requer uma abordagem multidisciplinar, realizada por profissionais que analisem o problema por vários ângulos e, às vezes com diferentes pontos de vista.

Os profissionais de saúde da equipe multidisciplinar, incluindo o enfermeiro devem realizar programas de educação contínuos, nos locais onde os pacientes se encontrem, seja no ambulatório, nas unidades básicas de saúde, no hospital ou na comunidade.

Pelos resultados desse estudo, observou-se a necessidade da educação ao paciente diabético, a partir do nível primário, para não se chegar à complexidade das complicações.

Após o aparecimento da úlcera, a equipe multidisciplinar, deverá realizar estudos sobre o melhor tipo de curativo a ser realizado, levando em consideração os custos, o estado sócio econômico, a idade e outros fatores que poderão influenciar.

Como a a prevenção de amputação em diabéticos é um problema sério e importante, é preciso fazer um esforço considerável para assegurar uma abordagem interdisciplinar dentro da própria equipe de saúde, destacando-se maior e melhor colaboração entre médicos, enfermeiros, psicólogos, fisioterapeutas e outros na busca da melhor maneira de cuidar dos pacientes. Há de se tornar mais eficiente a metodologia de programas de educação para assegurar a participação ativa dos pacientes e seus familiares nos cuidados. Exige-se, também, a participação de pessoas de outros setores, como políticos, administradores e até de fabricantes de calçados, pois uma boa parte das amputações são devidas a lesões provocadas por sapatos mal adaptados. 


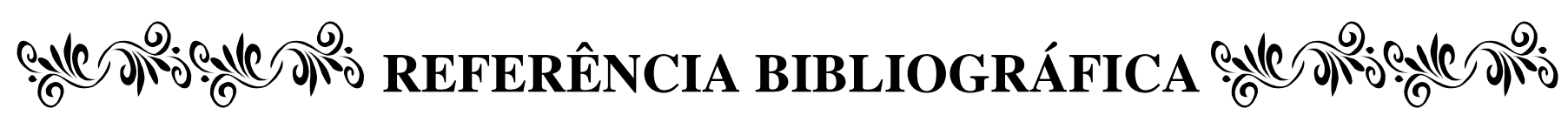


ABBOTT, C. A.; VILEIKYTE, L.; WILlAMSON, S.; CARRINGTON, A. L.; BOUTON, A. J. M. Multicenter study of the incidence of and predictive risk factors for diabetic neuropathic foot ulceration. Diabetes care, v. 21, n. 7, jul. 1998, p. 1071-75.

AHRONI, J. H. Preventing diabetic foot complications. Advances in skin and wound care 2000; 13 (1):38-9.

AMERICAN DIABETES ASSOCIATION. Screening for diabetes. Diabetes Care. v. 24, sup.1, p. s.21-23, jan., 2001.

AMERICAN DIABETES ASSOCIATION. Preventive foot care in people with diabetes. Diabetes Care. v. 24, supl.1, p. 21-23, jan., 2001.

AMERICAN DIABETES ASSOCIATION- Clinical practice recommentations 2002. Diab.Care, v. 25, p. S01-S146, Suplemento 1, 2002.

BATES, B. M. D. Propedêutica médica. 6. ed. Rio de Janeiro: Guanabara Koogan, 1998, p. 692.

BARBUI, E.C.;COCCO, M. I. M.Conhecimento do cliente diabético em relação aos cuidados com os pés. Revista Escola Enfermagem. USP. V. 36, n.1, p. 97-103, 2002.

BERNARDES, C.H.A.; PENTEADO, J. G. ;MARTINS, M. de F. S. ;ROSA, V. A. ;TINÓS, M. S. Pé diabético: Análise de 105 casos. Arq. Bras. de End. e Metab. v. 3, n.3, p. 139-142, 1993.

BERSUSA, A . A . S.Validação do diagnóstico: alteração da perfusão tissular periférica nos pacientes com vasculopatia periférica de membros inferiores. Dissertação de Mestrado, Escola de enfermagem de São Paulo, Universidade de São Paulo, 1998. p. 191.

BEVILACQUA, F. et al. Manual do exame clínico. Rio de Janeiro: Cultura Médica, 1985. 
Bibliográficas

Referências

BILD, D. E. et al. Lower-extremity amputation in people with diabetes. Diabetes care,v. 12 n. 1, p. 24-31, jan.1989.

BRASIL, Ministério da Saúde. Secretaria de Assistência e Promoção à Saúde. Coordenação de Doenças Crônico-Degenerativas. Manual de Diabetes 2. ed. Brasília, 1993. 92 p. (Diabetes Mellitus).

BRASIL, Ministério da Saúde. Diabetes Mellitus. Guia básico para diagnóstico e tratamento. Brasília, 1996.

BRASIL, Ministério da Saúde. Coordenação de Doenças Crônico-Degenerativas. Orientações básicas para o diabético. 2. ed. Brasília, 1993. 105 p. (Diabetes Mellitus).

BRASIL. Ministério da Saúde. Secretaria de Políticas de Saúde. Departamento de Ações Programáticas Estratégicas. Plano de reorganização da atenção à hipertensão arterial e ao diabetes mellitus: Hipertensão arterial e diabetes mellitus.Departamento de ações programáticas estratégicas, Brasília: Ministério da Saúde, 2001.

BROWNE, A. C.; SIBBALD, D. G. The diabetic neuropatic ulcer an overview. J. Ostomy Wound Management. v. 45, p.6s-20s, 1999. Supplement 1 A.

BRYANT,R.A. Acute and chronic wounds : nursing management. 1 ed. St. Louis, Moby, 1992.

CARPENITO, L. J. Diagnóstico de enfermagem: aplicação à prática clínica. 6. ed. Porto Alegre: Artes Médicas,1997.

CHACRA, A . R. RABELO, L. M.; MARTINEZ, T. L. R.; RABELO, M. M. Diabete e coração. Rev. Soc. Cardiol. Estado São Paulo v. 6, n.4, jul/ago, 1996.

CHOR, D, et al. Doenças cardiovasculares : panorama da mortalidade no Brasil. In MINAYO, M. C. S.(org).Os muitos Brasis: saúde e população na década de 80. São Paulo: Hucitec, 1995, p. 57- 86.

COLBERG, S. R. et. al. Chronic exercise is associated with enhanced cutaneous blood flow in tipe 2 diabetes. J.Diab. Compl., v. 16, p. 139-45, 2002. 
Bibliográficas

Referências

CONSENSO INTERNACIONAL SOBRE O PÉ DIABÉTICO. Grupo de Trabalho Internacional sobre pé Diabético. Secretaria de estado de saúde do Distrito Federal. Direção: Pedrosa, H. C., Brasília, p. 20, 2001.

CONSENSO BRASILEIRO DE CONCEITOS E CONDUTAS PARA O DIABETES MELLITUS. Recomendações da Sociedade Brasileira de Diabetes para a Prática Clínica, São Paulo: Sociedade Brasileira de diabetes. p. 53,1997

CONSENSO BRASILEIRO SOBRE DIABETES. Diagnóstico e Classificação do Diabetes Mellitus e Tratamento do Diabetes Mellitus Tipo 2., São Paulo: Sociedade Brasileira de Diabetes, maio, p. 60, 2000.

COOPER, D. Assessment, measurement, and evaluation: their pivotal roles in wound healing. In: Bryant, R. A. Acute and chronic wounds. Nursing management, $2^{\text {nd }}$ edition, Mosby 2000, p.51-83.

CRISTENSEN, M. H.; FUNNELL, M. M. ; EHRLICH, M. R. ;FELlOWS, E. P. ;FLOYD, J. C. How to care for the diabetic foot. American Journal Nursing, Mar, p.50-56. 1991.

CUNHA, E. F.; MARQUES, E. P.; GOMES, M. B. Perfil de pacientes diabéticos internados em hospital universitário do Rio de Janeiro. Arq. Bras. de Endocrin. e Metabol., v. 39, n. 2, p. 111-115, 1995.

CUZZEL, J. Z.; STOTTS, N. A. Trial e error yields to knowledge. American Journal of Nursing. p. 53-60. oct.1990.

DAHMEN, R.;KOOMEN, B.; HASPELS, R. ;HOEKSMA, A. F. Therapeutic footwear for the neuropathic foot. Diabetes Care, v. 24, n. 4, april, p. 705- 09. 2001.

DANGELO, J. G; FATTINI, C. A. Anatomia humana sistêmica e segmentar. 2. ed. São Paulo: Atheneu, 1983. 671 p.

DAVIDSON, M. B.; DIABETES MELLITUS: Diagnóstico e Tratamento. 4 ed. Rio de Janeiro: Revinter, 2001, 389 p. 
Bibliográficas

Referências

DEALEY, C. Cuidando de feridas. um guia para as enfermeiras. 2 ed São Paulo: Atheneu, 2001, 216p.

DOWDELL,H. R. Diabetes and vascular disease:a common association. AACN Clin.Issues, v. 6, n.4, p.526-35, 1995.

FEISTRITZER,N. R. Cicatrização da incisão cirúrgica, curativos e drenos. In MEEKER, M. H.; ROTHROCH, J. C.: cuidados de enfermagem ao paciente cirúrgico. Rio de Janeiro: Guanabara Koogan, 1995. cap. 7, p. 169-178.

FILHO, L. J. Situação dos diabéticos no Brasil. Diabetes \& Metabolism., São Paulo, v. 2, n. 1, p. 4-5, fev. 1998.

FLANAGAN, M. Assesment criteria. Nursing Times. v. 90, n.35, p.76-78. aug. 1994.

FLANAGAN, M. Uma estrutura prática para determinação de ferimentos. Revista Nursing. n. 116, p. 22-26, 1997.

FOSS, M. C. et al. Estudo analítico de uma amostra populacional de diabéticos tipo 2 da região de Ribeirão Preto (SP).Rev. Assoc. Med. Bras.v. .35, n. 2,p.179-83, out/dez. 1989.

FOSS, M. C. Conseqüências do Diabetes Mal Controlado: complicações agudas e crônicas. Temas de Atualização em Diabetes Tipo II, fascículo 2. Ribeirão Preto: Departamento de Clínica Médica. Faculdade de Medicina, USP, 2000.

FOSS, M. C. Diabetes mellitus e suas complicações crônicas. Rev. Bras. Neurol. v. 11 (suplem.1). p. 3 s - 6 s, 1991.

FRANCO, J. J. Estudo sobre a prevalência do diabetes mellitus na população de 30 a 69 anos de idade no município de São Paulo. São Paulo: Escola Paulista de Medicina 1988. 54 p. Tese Livre Docência .

FRANCO, L. J.; et al Diabetes como causa básica ou associada de morte no Estado de São Paulo, Brasil, 1992. Revista de Saúde Pública, v. 32, n. 3, p. 237-245, jun, 1998. 
Bibliográficas

Referências

FRYKBERG, R. G. et al. Diabetic foot disorders. A clinical practice guideline. Supplement Ortho-Mcneil. The journal of foot \& ankle sugery. 2000.

FRISTCHI, C. Preventive care of the diabetic foot. Nurs.Cl. North America, v. 36. n. 2, p. 303-21, 2001.

GAMBA, M. A . Amputação por diabetes mellitus: uma prática prevenível ? um estudo caso-controle. São Paulo: Faculdade de Saúde Pública da USP, 2001. Tese de doutorado.

GROSSI, S. A. A. Prevenção de úlceras nos membros inferiores em pacientes com diabetes mellitus. Rev. Esc. Enf. USP. v. 32, n. 2, p 377-85, dez. 1998

HALL - CRAGGS, E. C. B. Anatomy as a basis for clinical medicine. 3, ed. London: Willians \& Wilkins, Waverly Europe. 1995.

HABERRSHAW, G.; CHZRA, J. Considerações biomecânicas no pé diabético. IN : KOZAK, G. P. CAMPBELL, M. D. ; FRYKBERG, D. P. M. ;HABERSHAW, G. M. Tratamento do pé diabetico. 2 ed. Rio de Janeiro: Interlivros, 1996. Cap.7, P. 59-72.

INTERNATIONAL CONSENSUS ON THE DIABETIC FOOT. International consensus working group on the diabetic foot. 2001.

KHETTRY, U. Patologia do pé diabético. IN : KOZAK, G. P. CAMPBELL, M. D. ; FRYKBERG, D. P. M. ;HABERSHAW, G. M. Tratamento do pé diabetico. 2 ed. Rio de Janeiro: Interlivros, 1996. Cap.5, P41-46.

KING, H.; LEICHTER, S.; KEEN, H. Meetings of directors of world health organization collaborating centers in the field of diabetes. Diabetologia. v. 32. p. 143145, 1989.

KOZAK, G. P. ; GIURINI, J. .M. Neuropatias diabéticas: extremidades inferiores. In:KOZAK, G. P. CAMPBELL, M. D. ; FRYKBERG, D. P. M. ;HABERSHAW, G. M. Tratamento do pé diabético. 2 ed. Rio de Janeiro: Interlivros, 1996. cap. 6, p.4757. 
Bibliográficas

Referências

KRASNER, D. W ound measurements: some tool of the trade. American Journal Nursing, may, p. 89-90, 1992.

KRASNER, D. How to use the red-yellow-black system. American Journal Nursing, v. 95, n. 5, p. 44-47, may 1995.

LAING, P. The development and complications of diabetic foot ulcers. The Am. Journal of Surgery. v.176, n. 2 A supplement. aug.1998. p.11s a 19s.

LAURENTI, R. ;FONSECA, L. A. M. ;Costa JR, M. L. da. Mortalidade por diabetes mellitus no município de São Paulo (Brasil). Rev. Saúde Públ., São Paulo, v.16, p. 7791, 1982.

LAVERY, L. A. ;ARMSTRONG, D. G. ;VELA, S. A.;QUEBEDEAUX, T. L. FLEISCHLI, J. G. Practical criteria for screening patients at high risc for diabetic foot ulceration. Arch. Intern. Med, v. 158, jan, p. 157-62.1998.

LESSA, I.;MENDONÇA,G. A. S. ;TEIXEIRA, M. T. B. Doenças crônicas não transmissíveis no Brasil: dos fatores de risco ao impacto social. Bol. Oficina sanit panam v. 120, n. 5, p.389-413,1996.

LEVIN,N. E. Preventing amputation in the patiet with diabetes. Diabetes Care. v. 18, n.10, p.1383-94, 1995.

LEVIN, N. E. Foot lesions in patients with diabetes mellitus. End. Metab. Clinics North America, v. 25, n. 2, p. 447-62, 1996.

MACEDO, G. Conduta no pé diabético. In: VILLAR, L. (coord.). Endócrinologia clínica. Rio de Janeiro: Medsi, 1999.

MACEDO, G.; PEDROSA, H. C.; RIBEIRO, J. F. Abordagem clínica e terapêutica do pé diabético. In: VILLAR, L. Endocrinologia clínica. Rio de Janeiro: Medsi, 2001.

MAFFEI, F. H. A. Doenças vasculares periféricas. 2. ed. Botucatu: Médica e Científica -Medsi, 1995. p. 1277-301. 
Bibliográficas

Referências

MARÍLIA. Prefeitura Municipal. Marília: Secretaria Municipal de Higiene e Saúde. Plano de Saúde, 1997-2000. p. 8.

. Prefeitura Municipal. Marília: Secretaria Municipal de Higiene e Saúde. Plano de Saúde, 2001-2004. p. 8.

MARINHO, A. de M. Atenção nos cuidados de enfermagem das escaras quanto às associações terapêuticas. Rev. Bras. Enf., Brasília, v. 50, n. 2 p. 257-74, abr/jun.1997.

MARTINS, T. et al. Tratamento de Feridas. Nursing, v. 9,n. 100, p.30-38, maio, 1996.

MAYAlL, R. C. et al. Perna e pé diabético. Anais da Academia Nacional de Medicina, São Paulo, v. 152, n. 3, p. 92-99, 1992.

MAYFIELD, J. A ; REIBER, G. E. ;SANDRERS, L. J. ;JANISSE, D. ;POGACH, L. M. Preventive foot care in people with diabetes. Diabetes care, v. 21, n. 12, p. 21612177, dec., 1998.

MAYROVITZ, H. N.; SMITH,J; INGRAM, C. Comparisons of venous and diabetic plantar ulcer shape and area. Advances in Wound Care. V. 11 n. 4, p. 176-183. dec. 1998.

MCCULLOCH, D. K.; HORDON, L. D. Managemente of diabetic foot lesions. Up to date. v. 8 n.2. 2000.

MILMAN, M. H. S. A.; LEME, C. B. M.; BORELLI, D. T.; KATER, F. R.; BACCILI,E. C. D. C.; ROCHA, R. C. M.; SENGER, M. H. Pé diabético: avaliação da evolução e custo hospitalar de pacientes internados no conjunto hospitalar de pacientes internados no conjunto hospitalar de Sorocaba. Arq. Bras. Endocrinol. Metab. v. 45 n. 5 out. 2001

MOORE, K. L.; DALley, A. F. O membro inferior, a perna, o pé. Anatomia, orientação para a clínica. 3 ed. Rio de Janeiro: Guanabara Koogan, 1994. p. 389-416.

MULDER, G. D.; Evaluating and managing the diabetic foot: an overview. Advances in Skin \& Wound Care. V. 13; n. 1; p. 33-37, 2000 
Bibliográficas

Referências

NALIATO, E. C. O; ZAGURY, L. Diabetes Mellitus e terceira idade. Diabetes \& Metabolism,. Rio de Janeiro, v. 2, n. 2, p. 74-79, abr. 1998.

OLIVEIRA, J. E. A. MILECH, et al. The prevalence of diabetes in Rio de Janeiro, Brazil. The cooperative group of the study of diabetes prevalence in Rio de Janeiro. Diabetes Care. v. 19, n. 6: 663-6, 1996.

OLIVEIRA, J. E. P. Prevalência do Diabetes Mellitus no Rio de Janeiro; Rio de Janeiro FMUF, -1992. 127 p. Tese de Doutorado.

ORGANIZAÇÃO MUNDIAL DE SAÚDE. Prevención de la diabetes mellitus: Informe de um grupo de estúdio de la OMS Ginebra: OMS, 1994. 125 p.

O’RAHILLY, R. Anatomia humana básica: um estudo regional da estrutura humana. Rio de Janeiro: Interamericana, 1985.

PACE, A. E. ; FOSS, M. C. ;VIGO, K. O. ;HAYASHIDA, M. Fatores de risco para complicações em extremidades inferiores de pessoas com diabetes mellitus. Rev Bras. Enferm., Brasília, V. 55, N. 5, P. 514-521, Set./Out. 2002.

PEDROSA, H. C.; NERY, E. da S. ;SENA, F. V.; NOVAES, C.; FELDKIRCHER, T. C.;DIAS, M. S. O.; LEME, L. A. P.;MIZIARA, M.; ASSIS, M. A.; KALUME, C. O desafio do projeto salvando o pé diabético. Terapêutica em diabetes. v. 4, n.19, p. 1$10 \mathrm{mai} / \mathrm{jul}, 1998$.

POLIT \& HUNGLER, Fundamentos de Pesquisa em Enfermagem, 3 ed. Porto Alegre: Artes médicas. 1995 391p.

PORTO, C. C. Exame clínico. Rio de Janeiro: Guanabara Koogan, 1996.

REIBER, G. E.;LIPSKY, B. A. ;GIBBONS, G. W. The burden of diabetic foot ulcers. The Am. Journal of Surgery. v. 176, n. 2, p. 5s a 10s, aug.1998.

RICHARD, J. L. Como rastrear o risco podológico no paciente diabético? Diab.\& Metab. v. 1, n. 4, p. 168-72, 1997. 
Bibliográficas

Referências

ROBBINS. Pathologic basis of Disease 6. ed. Rio de Janeiro: Guanabara Koogan, 2000.

RODRIGUES, A. O., HARA, M. H.; PEREIRA, R. P.;FELTRINI, R. G. Atualidades no Manejo Clínico e Cirúrgico do Paciente com Pé Diabético. RBM - Rev. Bras. Med. v. 55, n. 7, jul. 1998.

RODRIGUES, R. A . P.;MENDES, R. T.;OLIVEIRA, C. C. L.; MARQUES, S.; NETO, J. G. O idoso e o diabetes: a adesão ao tratamento. Arquivos Brasileiros de Medicina. v. 70, n. 5, maio 1996.

SAMPAIO, S. A. P. Dermatologia Básica. 3. ed. São Paulo: Artes Médicas, p. 645, 1989.

SEELEY, R. R. Essentials of anatomy and physiology. St. Louis. 1991. ed. Mosby year book.

SIMONS, D. A Pathogenesis of diabetic neuropathy. In: KAHN, C. R.; WEIR, G. C. Joslin's diabetes mellitus. 13. ed. Philadelphia: Lea \& Febiger, 1994.cap. 39, p. 66590.

SOCIEDADE BRASILEIRA DE DIABETES. Recomendações da Sociedade Brasileira de Diabetes para a prática clínica Consenso brasileiro de conceitos e condutas para o diabetes mellitus; São Paulo: Sociedade Brasileira de Diabetes, 1997.

SOCIEDADE BRASILEIRA DE DIABETES. Consenso brasileiro sobre diabetes. Diagnóstico e classificação do diabetes mellitus e tratamento do diabetes mellitus tipo 2, maio- 2000.

SPICHLER E. R. S.; SPICHLER, D. ;MARTINS, C. S. F. ; FRANCO, L. J. ; LESSA, I. Diabetic lower extremities amputation. Diabetologia 1998;

STADELMANN, W. K. ;DIGENIS, A. G.;TOBIN, G.R. Physiology and healing dynamics of chronic cutaneous wounds. Am. J. Surg., v. 176, Suppl. 2a, p. 26s-38s, aug.1998. 
Bibliográficas

Referências

STEED, D. L. Foundations of good ulcer care. The American Journal of Surgery. v.176, n. 2 A Supl. Aug. 1998.

SUMPIO, B. E. Foot ulcers. Primary care, v. 343, n. 11, p.787-93, 2000.

TORQUATO, M. T. da C.; MONTENEGRO jr,R. M.;VIANA, L.A. L. ;SOUZA,R. A . H. G. de;LANNA, C. M. M. ;LUCAS, J. C. B.; BIDUIM,C.;FOSS, M. C. Prevalence of diabetes melliyus and impaired glucose tolerance in the urban population aged 30-69 years in Ribeirão Preto (São Paulo), Brazil. Med.J., v. 121 n. 6 p. 224-230.

THE EXPERT COMMITTEE ON THE DIAGNOSIS AND CLASSIFICATION OF DIABETES MELLITUS. Diabetes care, v. 24, supl. 1, p.s5-s17, jan., 2001.

THOMAZ, J. B. Fundamentos de cirurgia vascular e angiologia. São Paulo: Fundo editorial BYK, 1997. 646 p.

VEVES, A et al. Endothelial dysfunction and the expression of endothelial nitric oxide synthetase in diabetic neuropathy vascular disease and foot ulceration. Diabetes. v.3; p. 457-463, 1998.

WAGNER, F. W. The dçs vascular foot a system of diagnosis and treatment. Foot Ankle. v. 2, p. 64-122, 1981.

WATRET,T. L. Know How : management of wound exsudate. Nursing Times. v. 93, n.23, p. 45-46, jul. 1997.

WUNDERLICH, R. P.; ARMSTRONG D. G.; HUSAIN, S.K.; LAVERY, L. A. Defining loss of protective sensation in the diabetic foot. The journal for prevention and healing. A.D.V. Wound Care. v. 11, p. 123-128, 1998.

YETZER, E. A; SULLIVAN, R. L. Rehabilitation Nursing v.17, n.5, p.247-251, 1992. YOUNG, M.; YOUNG, C. Foot work. Nursing Times. v. 90, n.7, p. 60-73, fev. 1994.

ZAVALA, A.V.; BRAVER, D. Semiologia do pé. Prevenção primária e secundária do pé diabético. Diabetes clínica, v. 4, p. 137-144,2000. 


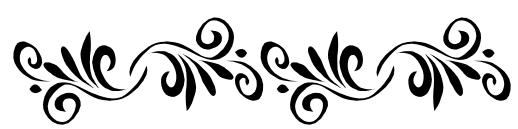

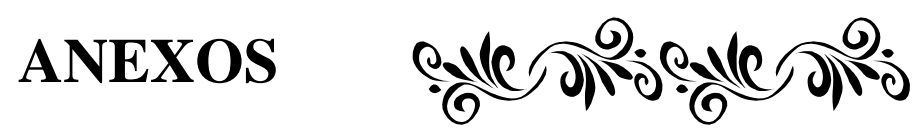




\section{ANEXO I}

Instrumento de Coleta de Dados

Perfil dos pacientes com diabetes mellitus que possuem ulcera em extremidade de membro inferior de uma unidade ambulatorial da cidade de Marilia-SP.

\section{I - IDENTIFICAÇÃO}

Data:

Nome:

Registro:

Endereço:

Cidade:

$$
\text { II - VARIÁVEIS SÓCIO-DEMOGRÁFICAS }
$$

1. Sexo

1-Masculino 2-Feminino

2. Idade: anos DN:

3. Escolaridade

1 - Analfabeto

2 - Sem escol/sabe ler ou escrever

3 - Ensino fundamental incompleto

4 - Ensino fundamental completo

\section{Estado Civil}

1 - Solteiro (a)

2 - Casado (a)/amasiado

5. Ocupação:

6. Procedência

1 - Marília

2 - Região de Marília

5 - Ensino médio incompleto

6 - Ensino médio completo

7 - Universitário incompleto

8 - Universitário completo

3 - Divorciado (a)/Separado (a)

4 - Viúvo (a)

3 - Outros municípios do Estado de São

4 - Outros Estados

III - DADOS SOBRE O ESTILO DE VIDA:

7. Tabagismo: Fuma?

$1-$ Sim

2 - Não

3 - Ex-fumante

OBS:

8. Por quanto tempo fumou? (anos)

9. Etilismo

$1-\operatorname{Sim}$

2 - Não

3 - Ex-etilista

10. Por quanto tempo bebeu? (anos)

11. Que tipo de bebida costuma beber?

12. E com que freqüência?

13. Quais atividades físicas costuma praticar?

14. Com que freqüência?

IV - VARIÁVEIS RELACIONADAS AO DIAGNÓSTICO:

15. Quanto tempo tem diabetes?

16. Tipo de diabetes:

1 - Tipo 1

17. ÍMC

Peso:

3 - Outros Altura:

18. PA:

V - VARIÁVEIS RELACIONADAS AO TRATAMENTO:

19. Tempo do tratamento dos diabetes (anos):

Para as questões 19, 20 e 21

20. Antidiabético oral:

2 - Não 3 - às vezes

21. Insulina:

22. Dieta 
Anexos

VI - VARIÁVEIS RELACIONADAS ÀS COMPLICAÇÕES:
23. Complicações relacionadas ao diabetes:
24. Amputação:
1 - MID
$2-\mathrm{MIE}$
3 - Ambos
4 - Ausente
5-outros:

OBS:

VII - VARIÁVEIS RELACIONADAS AO CONTROLE DO DIABETE:

25 - Verificar no prontuário do paciente, os exames do último ano e anotar no anexo.

(glicemia, hemoglobina glicosilada, colesterol total, triglicérides, HDL, LDL).

VIII - VARIÁVEIS RELACIONADAS ÀS CARACTERÍSTICAS DAS ULCERAS:

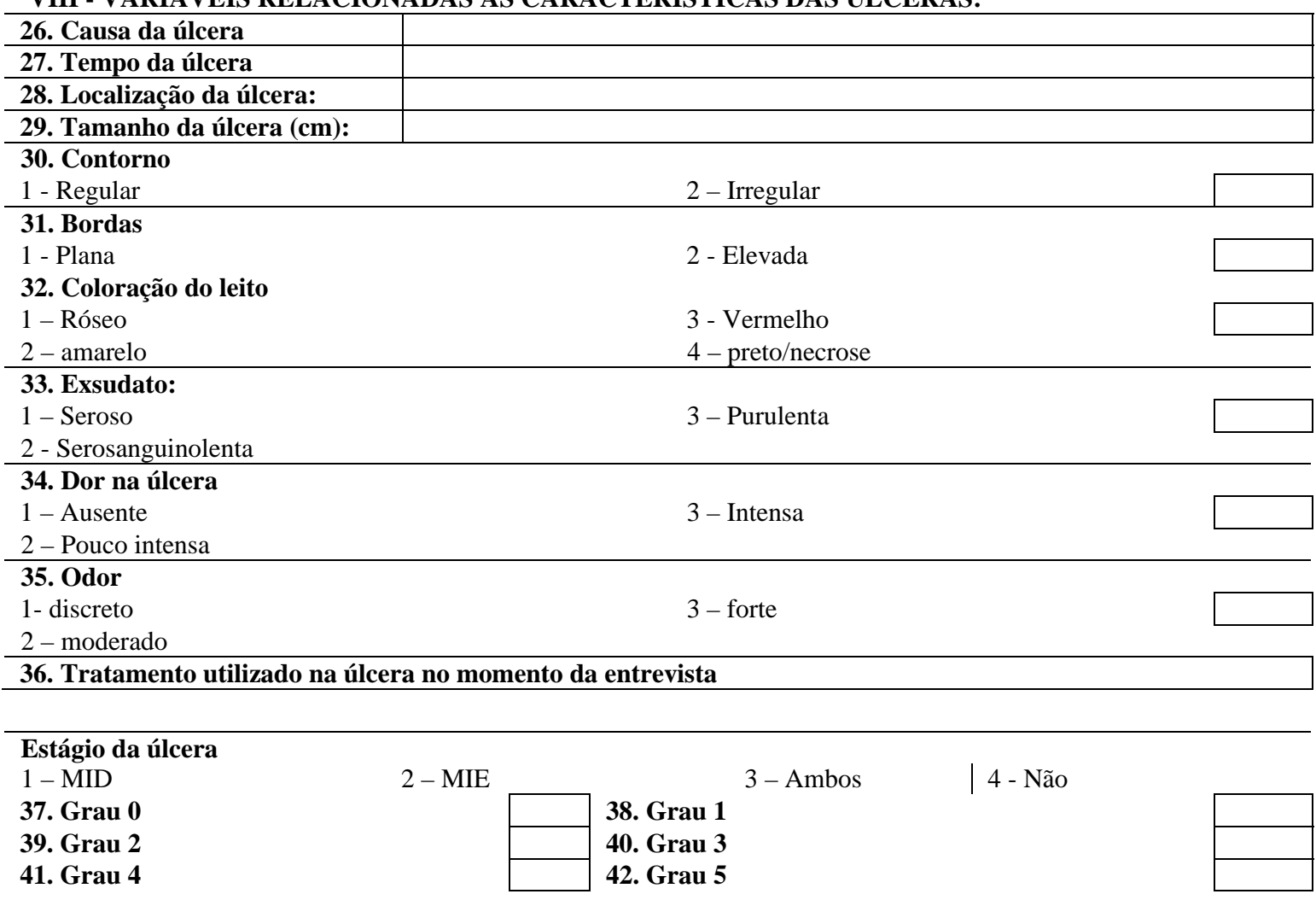

IX - VARIÁVEIS RELACIONADAS À AVALIAÇÃO DOS MEMBROS INFERIORES:

43. Alteração na marcha/modo de pisar:

1-Sim 2-Não Obs:

44. Mobilidade

1 - Deambula

2 - Não deambula

3 - Deambula com auxílio

45. Úlceras anteriores

1-Sim

2 - Não Obs:

46. Higienização dos pés:

1 - Boa 2-Regular

47. Edema

1- MID

2 - MIE

48. Consistência

1- mole (inelástico)

Para questões 51 e 52

1 - Normal

$2-\mathrm{MIE}$

49. Temperatura pé $D$

50. Temperatura pé $\mathrm{E}$

Para questões 53 a 65

1 - MID

51. Anidrose

$2-$ MIE

$2-$ Frio

2- duro (elástico)

3 - insatisfatória

3 - Ambos

4 - Não

51. Anidrose

52. Bromidrose

3 - Quente

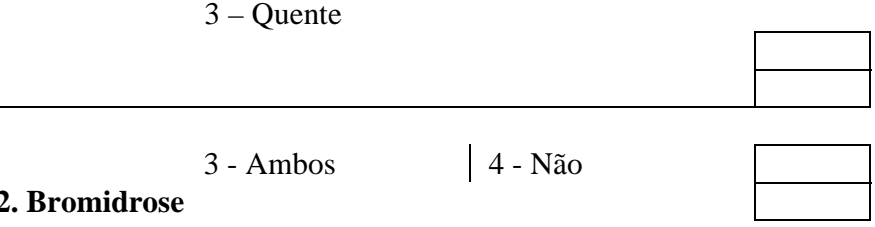


Anexos

53. Lesões interdigitais

55. Rachaduras/fissuras

57. Unha com coloração alterada

59. Pé plano

61. Dedos em garra

63.Proeminência primeiro metatarso
54. Descamações

56. Unha Espessa/aspecto farináceo

58. Unha com alteração de crescimento/encravada

60 - Arco do pé acentuado

62 - Dedos sobrepostos

64- Calos/Calosidades

Para questões 65 a 67

1 - adequado

65. Corte unhas:

67. Tipo de calçado que usa habitualmente OBS:

2 - inadequado

66. Tipo de Calçado que está usando

68. Tipo de meias

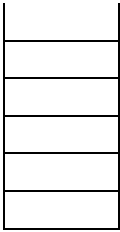

\begin{tabular}{l|l|l|l|}
\hline Para questões 69 e 70 \\
$\begin{array}{l}\text { 1 - Pé direito } \\
\text { 69. Rubor com pendência }\end{array}$
\end{tabular}

73. Sensibilidade tátil pressórica: 
Anexos

ANEXO II

DIAGNÓSTICOS / RESULTADOS DE EXAMES LABORATORIAIS

Diagnósticos:
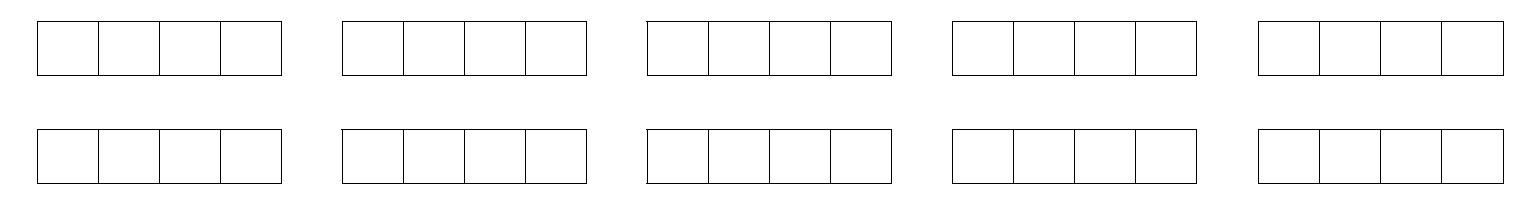

\begin{tabular}{|c|c|c|c|c|c|c|c|c|c|c|c|}
\hline \multirow[t]{2}{*}{ Data } & \multirow[t]{2}{*}{ Glicemia } & \multirow[t]{2}{*}{ Henoglobina } & \multicolumn{4}{|c|}{ Glicosúria fracionada } & \multirow[t]{2}{*}{ Cetonuria } & \multirow[t]{2}{*}{ Colesterol Total } & \multirow[t]{2}{*}{ Triglicérides } & \multirow[t]{2}{*}{ HDL } & \multirow[t]{2}{*}{ LDL } \\
\hline & & & 1 & 2 & 3 & 4 & & & & & \\
\hline & & & & & & & & & & & \\
\hline & & & & & & & & & & & \\
\hline & & & & & & & & & & & \\
\hline & & & & & & & & & & & \\
\hline & & & & & & & & & & & \\
\hline & & & & & & & & & & & \\
\hline & & & & & & & & & & & \\
\hline & & & & & & & & & & & \\
\hline & & & & & & & & & & & \\
\hline & & & & & & & & & & & \\
\hline & & & & & & & & & & & \\
\hline & & & & & & & & & & & \\
\hline & & & & & & & & & & & \\
\hline & & & & & & & & & & & \\
\hline & & & & & & & & & & & \\
\hline & & & & & & & & & & & \\
\hline & & & & & & & & & & & \\
\hline & & & & & & & & & & & \\
\hline & & & & & & & & & & & \\
\hline & & & & & & & & & & & \\
\hline & & & & & & & & & & & \\
\hline & & & & & & & & & & & \\
\hline
\end{tabular}

Fonte: Pace et al (2002) 
Anexos

\section{ANEXO III \\ Escala de Classificação de Wagner}

Grau 0 - Úlceras anteriores, lesões pré ulcerativas. Presença de deformidades ósseas.

Grau 1 - Úlcera superficial com envolvimento do tecido subcutâneo.

Grau 2 - Úlcera que penetra no tecido subcutâneo, pode ter exposição de osso, tendão, ligamento ou cápsula articular.

Grau 3 - Osteítes,abscesso ou osteomielites.

Grau 4 - Gangrena de dígitos.

Grau 5 - Gangrena do pé que requer desarticulação. 
Anexos

\section{ANEXO IV}

Marília, 20 de março de 2003.

$\operatorname{Ilmo~(a)~Sr~(a)~}$

Como aluna do Programa de Pós - Graduação da Escola de Enfermagem de Ribeirão Preto-USP, estamos desenvolvendo uma pesquisa com objetivo geral de Conhecer o perfil dos pacientes com diabetes mellitus que possuem úlcera em pé, atendidos em uma unidade ambulatorial de Marília-SP.

Objetivos específicos:

1. Caracterizar os pacientes com diabetes mellitus que possuem úlcera em pés, segundo variáveis sócio demográficas e estilo de vida.

1. Caracterizar os pacientes com diabetes mellitus que possuem úlcera em pé, segundo variáveis relacionadas ao diagnóstico, tratamento, condições clínicas dos pés, controle da doença e complicações.

2. Descrever as características da (s) úlcera (s) em pés das pessoas com diabetes e definir o grau de comprometimento.

Trata-se de um estudo descritivo e o tratamento para análise estatística devido à natureza das variáveis, será agrupado por meio de tabelas, gráficos, média e desvio padrão.

Vimos através deste solicitar a vossa colaboração profissional para a validação deste instrumento.

Solicitamos que faça seu julgamento quanto à clareza e adequação sobre o conteúdo deste instrumento, sugerindo inclusões ou exclusões das questões, caso julgue necessário.

Desde já agradecemos sua disponibilidade em dispor seu tempo com nossa pesquisa, certo de que sua contribuição será de grande valia na ampliação de possibilidades deste estudo. Colocamo-nos a disposição para esclarecimentos que se façam necessário.

Atenciosamente

Elizabeth Pilon Scapim 
Anexos

\section{ANEXO V \\ TERMO DE CONSENTIMENTO LIVRE E ESCLARECIDO}

Pelo presente consentimento ${ }^{*}$, declaro que fui informado (a), de forma clara e detalhada do presente projeto de pesquisa "Perfil dos pacientes com diabetes mellitus que possuem úlcera no pé, atendidos em unidade ambulatorial da cidade de Marília- SP” a ser realizada pela Pesquisadora Responsável, Enfermeira Elizabeth Pilon Scapim.

Este estudo tem como objetivo, caracterizar a população diabética com lesões em pés, com isso queremos conhecer melhor os fatores que levaram à formação das úlceras. Também contribuirá para a programação da prevenção, e para a assistência de enfermagem das úlceras já instaladas.

Neste sentido, gostaríamos de solicitar a vossa colaboração para participar da pesquisa respondendo o questionário e a realização do exame físico nos pés. As respostas serão marcadas e após o término da entrevista você poderá ler as informações fornecidas se assim o quiser. A sua identificação será mantida de forma sigilosa.

O pesquisador compromete-se a respeitar as condições de saúde de cada informante e a não causar desconforto.

Agradecemos desde já a sua colaboração e participação no nosso estudo.

Nome e assinatura do participante:

Assinatura da pesquisadora:

Data:

O presente documento baseado nos artigos 10 a 16 das Normas de Pesquisa em Saúde do Conselho Nacional de Saúde, será assinado em duas vias de igual teor, ficando uma via em poder do participante da pesquisa e a outra com a pesquisadora. 